\title{
Bias in the mirror
}

Citation for published version (APA):

Sukhera, J. I. (2018). Bias in the mirror: exploring implicit bias in health professions education. [Doctoral Thesis, Maastricht University]. Datawyse / Universitaire Pers Maastricht. https://doi.org/10.26481/dis.20181129js

Document status and date:

Published: 01/01/2018

DOI:

10.26481/dis.20181129js

Document Version:

Publisher's PDF, also known as Version of record

\section{Please check the document version of this publication:}

- A submitted manuscript is the version of the article upon submission and before peer-review. There can be important differences between the submitted version and the official published version of record.

People interested in the research are advised to contact the author for the final version of the publication, or visit the DOI to the publisher's website.

- The final author version and the galley proof are versions of the publication after peer review.

- The final published version features the final layout of the paper including the volume, issue and page numbers.

Link to publication

\footnotetext{
General rights Owners
rights.

- You may freely distribute the URL identifying the publication in the public portal. please follow below link for the End User Agreement:

www.umlib.nl/taverne-license

Take down policy

If you believe that this document breaches copyright please contact us at:

repository@maastrichtuniversity.nl

providing details and we will investigate your claim.
}

Copyright and moral rights for the publications made accessible in the public portal are retained by the authors and/or other copyright owners and it is a condition of accessing publications that users recognise and abide by the legal requirements associated with these

- Users may download and print one copy of any publication from the public portal for the purpose of private study or research.

- You may not further distribute the material or use it for any profit-making activity or commercial gain

If the publication is distributed under the terms of Article $25 \mathrm{fa}$ of the Dutch Copyright Act, indicated by the "Taverne" license above, 


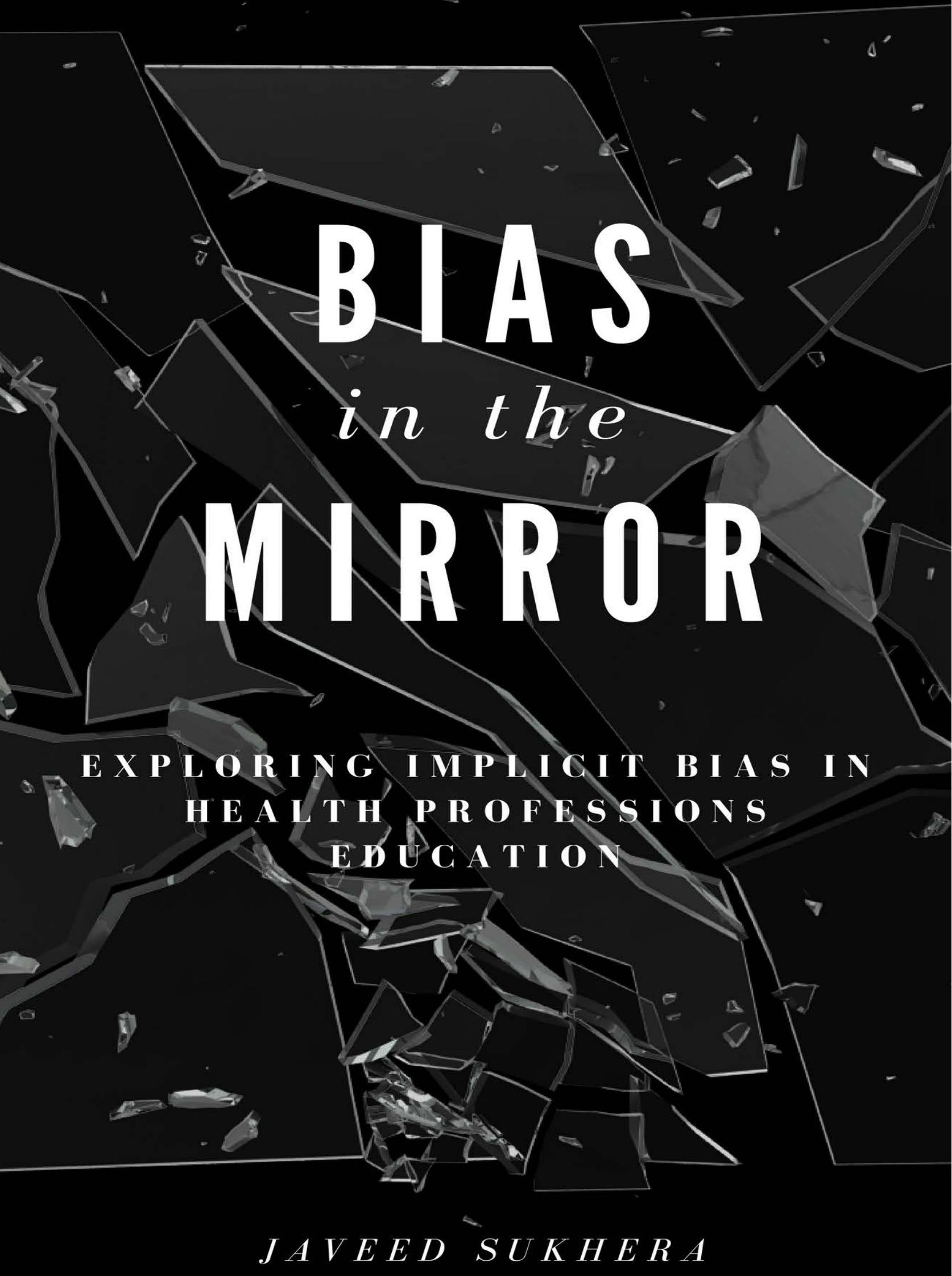


The research reported here has been carried out at

D. Maastricht University in Learning!

In the School of Health Professions Education

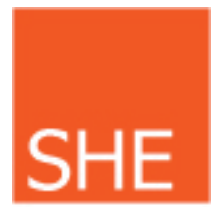

(C) copyright J.I Sukhera, Maastricht 2018

Printing: Datawyse | Universitaire Pers Maastricht

ISBN: 978-94-6380-053-2 


\section{Bias in the Mirror:}

\section{Exploring Implicit Bias in Health Professions Education}

ter verkrijging van de graad van doctor aan de Universiteit Maastricht, op gezag van de Rector Magnificus, Prof. dr. Rianne M. Letschert, volgens het besluit van het College van Decanen,

in het openbaar te verdedigen,

op Donderdag 29 november 2018, om 1345 uur

door

Javeed Iqbal Sukhera

geboren op October 9, 1980 


\section{Supervisors}

Prof.dr. P.W. Teunissen, Maastricht University

Prof.dr. L. Lingard, Maastricht University/Schulich School of Medicine and Dentistry, The University of Western Ontario

Prof.dr. C.J. Watling, Schulich School of Medicine and Dentistry, The University of Western Ontario

\section{Assessment Committee}

Prof.dr. Erik Driessen (Chair), Maastricht University

Dr. Janneke Frambach, Maastricht University

Prof.dr. Gerrit Glas, Vrije Universiteit

Dr. Conny Seeleman, UMC Utrecht

Prof.dr. Cees van der Vleuten, Maastricht University 


\section{Table of Contents}

$\begin{array}{lll}\text { Chapter } 1 \text { Introduction } & 7\end{array}$

Chapter 2 A Framework for Integrating Implicit Bias into Medical Education 21 Published as: Sukhera J, Watling C. A framework for integrating implicit bias recognition into health professions education. Academic Medicine. 2018 Jan 1;93(1):35-40.

Chapter 3 Labeling of Mental Illness Stigma in a Paediatric Emergency

Department and its Implications for Stigma Reduction Education

Published as: Sukhera J, Miller K, Milne A, Scerbo C, Lim R, Cooper A, Watling C. Labelling of mental illness in a paediatric emergency department and its implications for stigma reduction education. Perspectives on medical education. 2017 Jun 1;6(3):165-72.

Chapter 4 The Idealized versus Actual Self: Exploring Responses to

Feedback about Implicit Bias in Health Professionals

Published as: Sukhera, J., Milne, A., Teunissen, P.W., Lingard, L., Watling, C. The Actual Versus Idealized Self: Exploring Responses to Feedback About Implicit Bias in Health Professionals. Acad Med. 93(4) April 2018, p 623-629

Chapter 5 Exploring the Influence of Feedback about Implicit Bias in Mental Health Professionals

Submitted for publication, July 2018

Chapter 6 Striving While Accepting: Exploring the Relationship Between Identity and Implicit Bias Recognition and Management Accepted for Publication as: Sukhera, J., Wodzinski, M., Teunissen, P.W., Lingard, L., Watling, C., Striving while Accepting: Exploring the Relationship Between Identity and Implicit Bias Recognition and Management. Acad Med Supl.

Chapter 7 Adaptive Reinventing: Implicit Bias and the Co-Construction of Social Change

Published as: Sukhera, J., Milne, A., Teunissen, P.W., Lingard, L., Watling, C. Adv in Health Sci Educ (2018). https://doiorg.proxy1.lib.uwo.ca/10.1007/s10459-018-9816-3

Chapter 8 Discussion 
Samenvatting

Valorisation

163

Acknowledgements

Curriculum Vitae 
CHAPTER 1

\section{Introduction}




\section{Introduction}

\section{Bias is everywhere.}

Over time, the residue of experience builds associations between concepts, ideas and social categories. Bias can therefore be defined as an inclination towards or against something or someone. Biases may influence attitudes and behaviours. Some biases are explicit, and can be obvious. Others are subtler yet remain conscious, intentional and deliberate.

In contrast, implicit biases are stereotypes that form through experiences and work outside our awareness. These biases are a part of life. They help us categorize our experiences and organize our world. Implicit biases can be positive or negative. They can be useful, but also harmful. Health professionals often develop expertise through heuristics and biases that facilitate clinical decision making. In other circumstances, implicit biases may protect against workplace violence and promote safety. For some of our most vulnerable patients, however, the effects of implicit bias may lead to discriminatory behaviours that have widespread implications.

Research on implicit bias in health care has demonstrated how implicit bias perpetuates disparities and erodes equity. A study by Green et al in 2007 found that despite explicitly denying a preference for white versus Black patients, doctors implicitly perceived Black patients as less co-operative regarding medical procedures. Those doctors who demonstrated increased levels of implicit biases were more likely to treat their white patients over treating Black patients for their heart attacks ${ }^{1}$. Similar research has found that implicit biases contribute to racial disparities in pain treatment and adversely influence several patient populations ${ }^{2-9}$. Underserved groups often experience bias in healthcare settings that results in inequitable treatment ${ }^{10}$. Such disparities can also exist at the organizational or systemic level, leading to poor outcomes ${ }^{11}$.

We also know that implicit biases lead to behaviour that undermines trust. Groups that experience discrimination experience a profound negative effect which leads to self-reinforcing cycles of distancing and disconnection between patients and professionals. Individuals who encounter implicit biases can gradually begin to apply these negative biases towards themselves. Eventually, members of certain marginalized groups might begin to conform to such biases through their behaviour and interactions ${ }^{4}$, paradoxically reinforcing existing biases.

The problem of implicit biases is that by definition, implicit biases influence health professionals without their knowledge. Implicit biases may perpetuate discrimination by health professionals even when they are well educated and consciously 
attempt to suppress stereotypes ${ }^{12}$. Social psychology researchers have suggested that implicit biases represent a unique type of racism that is inherently complex and includes ambivalent and nuanced attitudes that are more challenging to address than traditional racism ${ }^{13}$. Given their unique and complex nature, broad and multi-layered strategies are required to mitigate the negative impact of bias.

One such strategy involves education. Several authors have described a process of bias education that involves promoting awareness and fostering behavioural change ${ }^{14-17}$. Educational efforts are constrained, however, by research that suggests that clinical learning environments may not only perpetuate existing biases, but increase them. For example, the CHANGES study conducted over 4 years across 49 medical schools in the United States found that factors such as hearing negative comments from faculty about Black patients may predict increases in negative implicit biases ${ }^{18}$.

Despite growing interest, however, implicit bias recognition and management is an underdeveloped area of research in health professions education. Until we develop sound educational strategies to facilitate implicit bias recognition and management, the promise of equitable and just health care for all remains unfulfilled. This thesis sets out to explore the process of teaching and learning about implicit bias within both individuals and clinical learning environments. The work reported in this thesis was conducted in the setting of Canadian healthcare, which affords an opportunity to explore how health professions curricula may address the problem of health disparities.

\section{From Cultural Competence Training to Critical Consciousness}

In the Canadian context, both the health sector ${ }^{19}$ and health professions education community have been tasked with reducing health disparities and educating health professionals about bias ${ }^{20}$. To address the role of health professionals in perpetuating disparities through cultural or gender related biases, accreditors for undergraduate medical programs in both the United States and Canada include standards related to cultural competence and bias. The Liaison Committee for Medical Education states, "Medical students must learn to recognize and appropriately address gender and cultural biases in themselves and others, and in the process of health care delivery. ${ }^{21 "}$ In Canada, the 2019 standards state that faculty must ensure the curriculum prepares medical students to "recognize and appropriately address personal biases (cultural, gender, racial, belief) and how these biases influence clinical decision-making and the care provided to patients. ${ }^{22 "}$

The concept of cultural competence has been adopted as a strategy to address health disparities and advance equity. While definitions of cultural competence often vary, mental health researchers originally described the notion of cultural 
competence as, "a set of congruent behaviors, attitudes, and policies that come together in a system, agency or amongst professionals and enables that system, agency or those professionals to work effectively in cross-cultural situations. ${ }^{23 "}$ Cultural competence interventions may range from increasing minority recruitment to language-appropriate health education and provider education on cross-cultural issues $^{24,25}$. Cultural competence training programs seek to improve awareness, knowledge and skills, leading to changes in behaviour, practice and patientprofessional interactions.

While cultural competence education has gained momentum, academics have expressed concern regarding stereotypic teaching strategies, such as treating minority ethnic groups homogeneously ${ }^{26}$. Other criticisms include lack of attention to socioeconomic issues and system level structures ${ }^{27,28}$. In a seminal critique of cultural competence, Kumagai and Lypson critically analyze cultural competency, proposing that fostering critical consciousness of the self, others and the world within safe learning environments may facilitate moving beyond cultural competence. They write, "The development of critical consciousness involves a reflective awareness of the differences in power and privilege and the inequities that are embedded in social relationships - an act that Freire calls 'reading the world' - and a reorientation of perspective towards a commitment to social justice. ${ }^{29}$

\section{Fostering Critical Consciousness through Implicit Bias Awareness}

Existing educational literature on implicit and explicit biases is primarily related to clinical decision making and diagnostic errors. ${ }^{30-34}$ Educational activities related to implicit biases seek systematic educational strategies to addressing biases in healthcare, including both promoting awareness of one's own implicit biases and enhancing conscious efforts to overcome these biases. Some suggest that conscious deliberation on complex problems can help overcome initial biases, ${ }^{35}$ while other authors have proposed checklists in an effort to eliminate implicit bias from clinical decisions ${ }^{36}$. Educational interventions related to implicit bias may include delivering the Implicit Association Test (IAT) as a measure of bias ${ }^{37}$ and then utilizing the IAT as a trigger for self-reflection ${ }^{17}$. Additional techniques include enhancing perspective taking and empathy, ${ }^{38}$, identifying common identities, and emphasizing counter-stereotypes ${ }^{12}$. Several authors have also suggested that any education relating to implicit bias should normalize bias and emphasize that the removal of all bias is impossible ${ }^{38}$. Therefore, rather than pursuing the goal of eliminating bias, literature suggests that interventions that address implicit bias should emphasize the responsibility for learners to acknowledge the potential negative impact of bias on patient outcomes and take responsibility to overcome these negative effects.

Much of the research related to implicit bias has been in the field of social psychology, and most of that work assumes a positivist or post-positivist epistemological 
position. My decision to explore how implicit bias recognition can be leveraged to promote critical consciousness represents a social constructivist approach. My perspective aligns with arguments from Sharma and Kuper who state, "highlighting the social construction of race is an essential starting point for educators and trainees to tackle racialized health disparities in our clinics and challenge racism in our classrooms, educational and research institutions, and communities ${ }^{39 . "}$ The work within this thesis is part of a growing movement within health professions education research to challenge existing paradigms related to health disparities education. Advancing critical consciousness involves appreciation of the hidden acts of discrimination and prejudice that accumulate over time ${ }^{40}$.

\section{Implicit Bias and Mental Illness Stigma}

I have chosen to specifically examine implicit bias in the context of mental illness stigma reduction. Mental illness stigma is defined as negative biases and associated behaviours towards individuals with mental illness and will also be referred to only using the word stigma in this thesis. Research in this area has the potential to inform educational interventions to reduce stigma towards other types of patient populations. Sociology research suggests that any group that deviates from social norms is prone to labeling and stigmatization, leading to devaluation, mistrust, further discrimination, and poorer outcomes ${ }^{41}$. Interrupting the process and addressing implicit beliefs that influence stigma can therefore improve outcomes.

Implicit bias recognition and management curricula have the potential to be especially effective against mental illness stigma. Evidence shows that uncertainty is often a trigger for implicit bias ${ }^{42}$ and that those who wish to be unbiased may be more anxious in situations where they are afraid of becoming biased ${ }^{38}$. Mental illness is an area where a tremendous amount of uncertainty and complexity exist. In addition, implicit bias training is designed to move beyond direct confrontation of bias. This aligns with stigma reduction research, which suggests that mere protest stigma (shaming those who demonstrate stigma) can have adverse effects such as rebound behaviours that result in increased bias ${ }^{43-45}$. For educational interventions that incorporate conscious awareness of implicit bias as an effective strategy, they must be designed to address a potential "kick-back" effect where individuals over-compensate and develop counter-biases in response to bias-eradication efforts ${ }^{46}$.

Research suggests that despite advances, mental Illness stigma can have disastrous consequences for patients, families and healthcare organizations ${ }^{47,48}$. Fortunately, stigma reduction research is an emerging field in the literature, with several approaches showing benefit in specifically reducing health worker stigmatization. Examples include education, and contact with individuals with mental illness. Workshops and healthcare worker education in stigma reduction has been success- 
ful in several jurisdictions $44,47,48$. The literature describes several limits to traditional stigma reduction strategies, however. For example, individuals with greater prejudice are less likely to benefit from education alone ${ }^{43}$ and contact-based intervention is better when conducted face-to-face and when the two individuals share a common goal, are of equal power and engage in rewarding activities ${ }^{49}$. Through understanding how educational efforts to reduce stigma can achieve their potential without becoming derailed by their limitations, research on implicit bias and stigma therefore has the potential to generate knowledge to advance equity and reduce disparities.

\section{Research Questions and Approach}

The research I present in this thesis seeks to explore the process of implicit bias recognition and management in health professions education. Specific research questions include:

1) How do patients and health professionals perceive implicit bias to influence the healthcare experience?

2) How do healthcare practitioners perceive the influence of an intervention that promotes awareness of implicit bias?

3) Once implicit biases are brought into conscious awareness, how do individuals and learning environments influence each other over time in dealing with this awareness?

As described in each individual chapter, all studies utilize qualitative research methods and are informed by constructivist epistemological stance and include core aspects of constructivist grounded theory methodology. Grounded theory provides a useful approach to explore the critical questioning of a social process and how it relates both to individuals and a clinical learning environment. Despite several schools of grounded theory research, constructivist grounded theory is particularly useful for the research questions posed above. For Charmaz, "early grounded theory works stress discovering and analyzing a basic social process."(50). Her approach emphasizes action as researchers delve into authentic representation of the marginalized voices of research participants ${ }^{51}$.

\section{Eliciting Reflection: the Implicit Association Test}

Participant interviews in several studies involved completion of an online version of the implicit association test (IAT), which serves as a prompt for discussion and deeper reflection. The IAT is an important aspect of implicit bias-related research and education. Developed by researchers in the 1990's, the test is an online metric of response time that measures implicit associations between certain concepts ${ }^{37}$. 
The IAT has been researched extensively and found to be insensitive to procedural variation 37,52 and less susceptible to faking ${ }^{53}$. The IAT has also demonstrated solid internal consistency ${ }^{54-57}$, and high test-retest reliability ${ }^{58}$.

The experience of taking the IAT involves logging into a web-based platform and clicking keys in response to visual representation of specific categories. For example, concepts such as "black" and "white" would be associated with "good" and "bad." Individual response latency is then calculated and used as a proxy for the strength of implicit associations between categories. There are multiple versions of the IAT designed to uncover a range of different implicit biases, however, all operate on the same principles.

Several studies utilized the mental illness version of the IAT which measures associations between the concepts of physical illness and dangerousness versus mental illness and dangerousness. At the end of the test, participants receive a result that indicates they either hold no dangerousness bias related to mental or physical illness, or that they hold mild, moderate or strong dangerousness bias. The mental illness IAT is available online to the public at project implicit (http://implicit.harvard.edu). To our knowledge these studies are the first to utilize IAT as a prompt for qualitative research.

Despite its strengths, the IAT is not without criticism. Critics suggest that instead of reflecting authentic negative attitudes, IAT scores may stem from other associations such as victimization, maltreatment and oppression ${ }^{59-62}$. In a paper, Mitchell and Tetlock suggest, "data fails to support the rhetoric... IAT research has not led to new practical solutions to discrimination. The implicit prejudice construct should be subjected to greater theoretical and empirical scrutiny ${ }^{63 . "}$

Despite these critiques, we chose to use the IAT because it served as an elicitation prompt for our qualitative research methods. We were less interested in the IAT's power to change bias, and more fascinated with the potential of the IAT to trigger reflection and conversation. This perspective is consistent with a social constructivist approach to understanding and exploring how implicit bias awareness influences individuals and clinical learning environments.

\section{Reflexivity}

A social constructivist epistemological stance encourages constant reflection on how knowledge is generated ${ }^{64}$. Some authors have argued that practicing reflexivity can foster the deconstruction of stereotypes only when researchers become more reflexive themselves 65 . 
As a practicing child and adolescent psychiatrist, and someone with an interest in global and cross-cultural medicine, I have always been fascinated by the issue of health disparities and how to address equity through education. I came into an early career faculty position with a desire to explore and expand beyond traditional approaches to cultural competency education. While working in an administrative role to develop and integrate curricula regarding global and public health for undergraduate medical students, I faced relentless clinical demands and found myself frequently on-call within the context of a specialized paediatric emergency department. I began to witness discriminatory behaviour towards my patients who were suffering from mental illness that I found disconcerting. I was also struck by how my colleagues who do not work in mental health, and are all well-intentioned professionals, would perpetuate biases despite their best intentions to provide equitable and professional health care to their patients. I further realized that I too may unknowingly demonstrate bias towards certain patients and their families, thus humbling myself to the vulnerability of all health professionals when it comes to implicit biases.

As my daily clinical experiences began to intersect with my research interests, I gradually became fascinated with how health professionals may unwittingly perpetuate health disparities. Thus, I chose to explore how implicit bias recognition and management can be understood and applied through empirical research. I embarked on the initial project described in chapter three, and it became clear that the process of becoming consciously aware of one's biases comprised a unique form of feedback that merited further exploration.

The chapters that follow were conducted within a large academic health sciences centre in London, Ontario, Canada. All studies included semi-structured interviews with practicing physicians and nurses, with some postgraduate residents as well. Chapter three begins within the context of a paediatric emergency department. The initial study explored the social process of implicit bias within the specific context of biases towards patients with mental illness. Each interview began with the mental illness version of the IAT. During the course of this research, I was struck by the emotional reactions from participants to the process of taking the IAT and receiving their results. Chapter four shifted towards exploring how paediatric physicians process and integrate feedback about their implicit biases. In this study we discovered the tensions related to personal and professional identity that are evoked through bias-related feedback information. Chapters five and six, therefore explore the intersection between identity and implicit bias recognition. Chapter seven returns to the paediatric emergency context where the research began, to explore how individuals and learning environments influence one another once hidden biases have been revealed. 
Since the topic of implicit bias is by its very nature related to questioning, analyzing and reflecting on assumptions that are outside of one's conscious awareness, critical questioning was an intrinsic part of the research process from the inception of this work. As a physician and a psychiatrist, I was positioned as an insider within the local and international context. My initial inquiry was conducted within a clinical environment that I was also an outsider to, pediatric medicine. Throughout the early phases of my research I reflected frequently on how vacillating between being an insider and outsider provided a unique perspective to conduct research and analyze data. I found I could relate to my participants' responses but was also fascinated by their perspectives, given they saw a variety of patients and not just those with mental illness. The topic of identity serendipitously became central to several of the chapters in this thesis. Exploration then shifted to a group of psychiatrists that were colleagues and often former students. Throughout each study, my coinvestigators remained removed from the research context which facilitated analysis from multiple stances and perspectives. I also intentionally sought input from a nurse collaborator who could provide an insider perspective related to nursing.

\section{Thesis Outline}

Chapter 2 describes a framework for integrating implicit bias recognition and management into health professions education. The framework is derived from current research and experience, and aims to provide practical tools for curriculum developers.

Chapter 3 explores how patients and health professionals perceive bias to influence their healthcare experience. This study explored bias towards individuals with mental illness in an acute care environment through use of the IAT as a discussion prompt.

Chapters 4 through 6 focus on the issue of feedback related to implicit bias once participants complete the IAT. Chapter 4 explored how health professionals process and integrate feedback about their implicit biases. Findings from this work led to a deeper exploration regarding the potentially threatening nature of IAT feedback to health professionals' identity in chapter 5. This study investigated how mental health professionals perceive the influence of feedback that is potentially threatening to their identity. Chapter 6 reached beyond how individuals process feedback by exploring reciprocal influences between identity and implicit bias recognition and management. 
Chapter 7 broadens from feedback at an individual level by researching how individuals and workplace learning environment influence one another once awareness of implicit biases are triggered. 


\section{References}

(1) Green AR, Carney DR, Pallin DJ, Ngo LH, Raymond KL, Iezzoni LI, et al. Implicit bias among physicians and its prediction of thrombolysis decisions for black and white patients. Journal of general internal medicine. 2007;22(9):1231-8.

(2) Chapman EN, Kaatz A, Carnes M. Physicians and implicit bias: how doctors may unwittingly perpetuate health care disparities. J Gen Intern Med. 2013;28(11):1504-10.

(3) Cooper LA, Roter DL, Carson KA, Beach MC, Sabin JA, Greenwald AG, et al. The associations of clinicians' implicit attitudes about race with medical visit communication and patient ratings of interpersonal care. Am J Public Health. 2012;102(5):979-87.

(4) Dovidio JF, Penner LA, Albrecht TL, Norton WE, Gaertner SL, Shelton JN. Disparities and distrust: the implications of psychological processes for understanding racial disparities in health and health care. Social science \& medicine (1982). 2008;67(3):478-86.

(5) Fallin-Bennett K. Implicit bias against sexual minorities in medicine: cycles of professional influence and the role of the hidden curriculum. Academic Medicine. 2015;90(5):549-52.

(6) Haider AH, Schneider EB, Sriram N, Scott VK, Swoboda SM, Zogg CK, et al. Unconscious Race and Class Biases among Registered Nurses: Vignette-Based Study Using Implicit Association Testing. Journal of the American College of Surgeons. 2015;220(6):1077-86.e3.

(7) Hall WJ, Chapman MV, Lee KM, Merino YM, Thomas TW, Payne BK, et al. Implicit Racial/Ethnic Bias Among Health Care Professionals and Its Influence on Health Care Outcomes: A Systematic Review. Am J Public Health. 2015;105(12):e60-76.

(8) Sabin JA, Greenwald AG. The influence of implicit bias on treatment recommendations for 4 common pediatric conditions: pain, urinary tract infection, attention deficit hyperactivity disorder, and asthma. American Journal of Public Health. 2012;102(5):988-95.

(9) Sabin JA, Marini M, Nosek BA. Implicit and explicit anti-fat bias among a large sample of medical doctors by BMI, race/ethnicity and gender. PloS one. 2012;7(11):e48448.

(10) Fuller K. Eradicating essentialism from cultural competency education. Acad Med. 2002;77(3):198-201.

(11) Nelson AR, Smedley BD, Stith AY. Unequal Treatment:: Confronting Racial and Ethnic Disparities in Health Care (full printed version): National Academies Press; 2002.

(12) Stone J, Moskowitz GB. Non-conscious bias in medical decision making: what can be done to reduce it? Med Educ. 2011;45(8):768-76.

(13) Gaertner SL, Dovidio JF. The aversive form of racism: San Diego, CA, US: Academic Press; 1986.

(14) Byrne A, Tanesini A. Instilling new habits: addressing implicit bias in healthcare professionals. Advances in Health Sciences Education. 2015;20(5):1255-62. 
(15) Carnes M, Devine PG, Baier Manwell L, Byars-Winston A, Fine E, Ford CE, et al. The effect of an intervention to break the gender bias habit for faculty at one institution: a cluster randomized, controlled trial. Acad Med. 2015;90(2):22130.

(16) Gonzalez CM, Kim MY, Marantz PR. Implicit bias and its relation to health disparities: a teaching program and survey of medical students. Teach Learn Med. 2014;26(1):64-71.

(17) Teal CR, Shada RE, Gill AC, Thompson BM, Frugé E, Villarreal GB, et al. When best intentions aren't enough: helping medical students develop strategies for managing bias about patients. Journal of general internal medicine. 2010;25(2):115-8.

(18) van Ryn M, Hardeman R, Phelan SM, Ph DD, Dovidio JF, Herrin J, et al. Medical School Experiences Associated with Change in Implicit Racial Bias Among 3547 Students: A Medical Student CHANGES Study Report. J Gen Intern Med. 2015;30(12):1748-56.

(19) Security HDTGotACoPHaH. Reducing Health Disparities - Role of the Health Sector: A Discussion Paper. Canada: Public Health Agency of Canada; 2004.

(20) Canada AFMC. The future of medical education in Canada (FMEC): a collective vision for MD education: Association of Faculties of Medicine of Canada (AFMC); 2010.

(21) Education LCoM. Functions and structure of a medical school: Standards for accreditation of medical education programs leading to the MD degree: Liaison Committee on Medical Education; 2007.

(22) Schools CotAoCM. Standards and Elements. Canada; 2018.

(23) Cross TL. Towards a Culturally Competent System of Care: A Monograph on Effective Services for Minority Children Who Are Severely Emotionally Disturbed. 1989.

(24) Betancourt JR. Cross-cultural medical education: conceptual approaches and frameworks for evaluation. Acad Med. 2003;78(6):560-9.

(25) Betancourt JR, Cervantes MC. Cross-cultural medical education in the United States: key principles and experiences. Kaohsiung J Med Sci. 2009;25(9):471-8.

(26) Betancourt JR, Green AR, Carrillo JE, Park ER. Cultural competence and health care disparities: key perspectives and trends. Health affairs. 2005;24(2):499505.

(27) Bourgois P, Holmes SM, Sue K, Quesada J. Structural Vulnerability: Operationalizing the Concept to Address Health Disparities in Clinical Care. Academic Medicine. 2017;92(3):299-307.

(28) Metzl JM, Hansen H. Structural competency: theorizing a new medical engagement with stigma and inequality. Social Science \& Medicine. 2014;103:126-33.

(29) Kumagai AK, Lypson ML. Beyond cultural competence: critical consciousness, social justice, and multicultural education. Academic Medicine. 2009;84(6):782-7.

(30) Mamede S, van Gog T, Moura AS, de Faria RM, Peixoto JM, Rikers RM, et al. Reflection as a strategy to foster medical students' acquisition of diagnostic competence. Med Educ. 2012;46(5):464-72. 
(31) Norman G. Dual processing and diagnostic errors. Advances in Health Sciences Education. 2009;14(1):37-49.

(32) Norman G, Sherbino J, Dore K, Wood T, Young M, Gaissmaier W, et al. The etiology of diagnostic errors: a controlled trial of system 1 versus system 2 reasoning. Acad Med. 2014;89(2):277-84.

(33) Norman GR, Eva KW. Diagnostic error and clinical reasoning. Medical education. 2010;44(1):94-100.

(34) Sibbald M, de Bruin AB. Feasibility of self-reflection as a tool to balance clinical reasoning strategies. Adv Health Sci Educ Theory Pract. 2012;17(3):419-29.

(35) Mamede S, Schmidt HG, Rikers RM, Custers EJ, Splinter TA, van Saase JL. Conscious thought beats deliberation without attention in diagnostic decisionmaking: at least when you are an expert. Psychological research. 2010;74(6):586-92.

(36) Ely JW, Graber ML, Croskerry P. Checklists to reduce diagnostic errors. Academic Medicine. 2011;86(3):307-13.

(37) Greenwald AG, McGhee DE, Schwartz JL. Measuring individual differences in implicit cognition: the implicit association test. Journal of personality and social psychology. 1998;74(6):1464.

(38) Burgess D, van Ryn M, Dovidio J, Saha S. Reducing racial bias among health care providers: lessons from social-cognitive psychology. J Gen Intern Med. 2007;22(6):882-7.

(39) Sharma M, Kuper A. The elephant in the room: talking race in medical education. Advances in Health Sciences Education. 2017;22(3):761-4.

(40) Monrouxe LV. When I say... intersectionality in medical education research. Medical education. 2015;49(1):21-2.

(41) Link BG, Cullen FT, Struening E, Shrout PE, Dohrenwend BP. A modified labeling theory approach to mental disorders: An empirical assessment. American Sociological Review. 1989:400-23.

(42) Hall KH. Reviewing intuitive decision-making and uncertainty: the implications for medical education. Med Educ. 2002;36(3):216-24.

(43) Corrigan PW. On the stigma of mental illness: Practical strategies for research and social change: American Psychological Association; 2005.

(44) Corrigan PW. Research and the elimination of the stigma of mental illness. British Journal of Psychiatry. 2012;201(1):7-8.

(45) Corrigan PW, Rafacz JD, Hautamaki J, Walton J, Rusch N, Rao D, et al. Changing stigmatizing perceptions and recollections about mental illness: the effects of NAMI's in Our Own Voice. Community Ment Health J. 2010;46(5):517-22.

(46) Ross HJ. Everyday bias: Identifying and navigating unconscious judgments in our daily lives: Rowman \& Littlefield; 2014.

(47) Yamaguchi S, Wu SI, Biswas M, Yate M, Aoki Y, Barley EA, et al. Effects of shortterm interventions to reduce mental health-related stigma in university or college students: a systematic review. J Nerv Ment Dis. 2013;201(6):490-503.

(48) Mittal D, Sullivan G, Chekuri L, Allee E, Corrigan PW. Empirical studies of selfstigma reduction strategies: a critical review of the literature. Psychiatric Services. 2012.

(49) Corrigan PW, Shapiro JR. Measuring the impact of programs that challenge the public stigma of mental illness. Clin Psychol Rev. 2010;30(8):907-22. 
(50) Charmaz K. Constructing grounded theory: A practical guide through qualitative research. SagePublications Ltd, London. 2006.

(51) Charmaz K. Developing grounded theory: The second generation: Left Coast; 2008.

(52) Nosek BA, Greenwald AG, Banaji MR. Understanding and using the Implicit Association Test: II. Method variables and construct validity. Personality and Social Psychology Bulletin. 2005;31(2):166-80.

(53) Steffens MC. Is the implicit association test immune to faking?. Experimental psychology. 2004 Jun;51(3):165-79.

(54) Greenwald AG, Nosek BA. Health of the Implicit Association Test at age 3. Zeitschrift für experimentelle psychologie. 2001;48(2):85-93.

(55) Greenwald AG, Farnham SD. Using the implicit association test to measure selfesteem and self-concept. Journal of personality and social psychology. 2000;79(6):1022.

(56) Dasgupta N, McGhee DE, Greenwald AG, Banaji MR. Automatic preference for White Americans: Eliminating the familiarity explanation. Journal of Experimental Social Psychology. 2000;36(3):316-28.

(57) Bosson JK, Swann WB, Pennebaker JW. Stalking the perfect measure of implicit self-esteem: The blind men and the elephant revisited? Journal of personality and social psychology. 2000;79(4):631-43.

(58) Nosek BA, Greenwald AG, Banaji MR. The Implicit Association Test at age 7: A methodological and conceptual review. Automatic processes in social thinking and behavior. 2007:265-92.

(59) Uhlmann EL, Brescoll VL, Paluck EL. Are members of low status groups perceived as bad, or badly off? Egalitarian negative associations and automatic prejudice. Journal of Experimental Social Psychology. 2006;42(4):491-9.

(60) Blanton H, Jaccard J, Christie C, Gonzales PM. Plausible assumptions, questionable assumptions and post hoc rationalizations: Will the real IAT, please stand up? Journal of Experimental Social Psychology. 2007;43(3):399409.

(61) Banaji MR, Nosek BA, Greenwald AG. No place for nostalgia in science: A response to Arkes and Tetlock. Psychological Inquiry. 2004;15(4):279-89.

(62) Andreychik MR, Gill MJ. Do negative implicit associations indicate negative attitudes? Social explanations moderate whether ostensible "negative" associations are prejudice-based or empathy-based. Journal of Experimental Social Psychology. 2012;48(5):1082-93.

(63) Mitchell G, Tetlock PE. Popularity as a Poor Proxy for Utility. Psychological science under scrutiny: Recent challenges and proposed solutions. 2017:164.

(64) Ramani S, Konings KD, Mann K, van der Vleuten CPM. A Guide to Reflexivity for Qualitative Researchers in Education. Acad Med. 2018.

(65) Verdonk P, Abma T. Intersectionality and reflexivity in medical education research. Med Educ. 2013;47(8):754-6. 


\section{CHAPTER 2}

\section{A Framework for Integrating Implicit Bias into Medical Education}

Published as:

Sukhera J, Watling C. A framework for integrating implicit bias recognition into health professions education. Academic Medicine. 2018 Jan 1;93(1):35-40.

(C) 2018 the Association of American Medical Colleges 


\begin{abstract}
Existing literature on implicit bias is fragmented and comes from a variety of fields like cognitive psychology, business ethics, and higher education, but implicit-biasinformed educational approaches have been underexplored in health professions education and are difficult to evaluate using existing tools. Despite increasing attention to implicit bias recognition and management in health professions education, many programs struggle to meaningfully integrate these topics into curricula. The authors propose a six-point actionable framework for integrating implicit bias recognition and management into health professions education that draws on the work of previous researchers and includes practical tools to guide curriculum developers. The six key features of this framework are creating a safe and nonthreatening learning context, increasing knowledge about the science of implicit bias, emphasizing how implicit bias influences behaviors and patient outcomes, increasing self-awareness of existing implicit biases, improving conscious efforts to overcome implicit bias, and enhancing awareness of how implicit bias influences others. Important considerations for designing implicit-bias-informed curricula-such as individual and contextual variables, as well as formal and informal cultural influences-are discussed. The authors also outline assessment and evaluation approaches that consider outcomes at individual, organizational, community, and societal levels. The proposed framework may facilitate future research and exploration regarding the use of implicit bias in health professions education.
\end{abstract}




\section{Introduction}

Biases, stereotypes, and associations that exist outside conscious awareness may adversely influence the health of minority, underserved, and stigmatized populations. Unconsciously held biases, also known as implicit biases, may lead to inaccurate or compromised clinical decisions ${ }^{1-3}$ and an erosion of trust between health professionals and patients due to poor interpersonal interactions and biased behaviors. ${ }^{4,5}$ Implicit bias in health care has been demonstrated in several studies. For example, among 202 first-year medical students at Johns Hopkins School of Medicine, 66\% showed an implicit preference toward Caucasians, and 86\% demonstrated a preference toward upper-class individuals.6 Among practicing physicians, another study found that, despite consciously expressing explicit egalitarian goals, physicians were less likely to recommend thrombolysis to African American patients, as compared with Caucasians with similar symptoms ${ }^{1}$. Other work has highlighted that bias adversely impacts women, ${ }^{7}$ obese individuals, ${ }^{2}$ fathers, ${ }^{8}$ patients with chronic pain, ${ }^{2,9}$ and patients with chronic fatigue syndrome. ${ }^{10}$

Not all implicit bias is negative or destructive. In many settings, cognitive heuristics (including unconscious associations) are encouraged as a form of pattern recognition that is necessary for clinical decision making. ${ }^{11}$ In other situations, negative implicit associations may protect against workplace violence and promote safety. ${ }^{12}$ Further, positive implicit bias may lead to counterproductive outcomes related to conflicts of interest and professional misconduct. ${ }^{13}$ Rather than pursuing the goal of eliminating bias, any intervention that incorporates implicit bias into health professions education should emphasize how health professionals can mitigate the negative influence of bias on patient outcomes. Implicit-bias-informed curricula can, therefore, offer systematic educational strategies for addressing biases in health care by both promoting awareness of one's own implicit biases and enhancing conscious efforts to overcome these biases.

The existing literature on implicit bias is fragmented and comes from a variety of fields like cognitive psychology, business ethics, and higher education. Implicitbias-informed educational interventions have been underexplored in health professions education and are difficult to evaluate using existing tools. Despite increasing attention to implicit bias recognition and management in health professions education, many programs struggle to meaningfully integrate these topics into curricula because of difficulty recruiting faculty champions, perceived lack of relevance, and pressure to concentrate on medically focused curricular content. ${ }^{14,15}$ Despite some promising approaches, implicit bias recognition and management is often included in the form of brief interventions that are poorly integrated into curricula and lack cohesive assessment and evaluation strategies. ${ }^{16}$ Integrating existing research on educating health professions students on the impact of implicit bias and its rela- 
tionship to patient-centered care into curricula, therefore, requires a cohesive and unifying framework.

While some authors have proposed such conceptual frameworks in the past, ${ }^{17-20} \mathrm{a}$ recent surge in interest in implicit-bias-informed education ${ }^{21}$ has prompted a renewed call for a practical framework to integrate implicit bias recognition and management into health professions curricula. Further, attention to evaluation and assessment strategies that consider outcomes at individual, organizational, community, and societal levels is needed. In this Perspective, we propose a six-point actionable framework for integrating implicit bias recognition and management into health professions education that draws on the work of previous researchers and includes practical tools to guide curriculum developers. We then outline assessment and evaluation approaches to consider outcomes at the level of the individual, organization, community, and society. 


\section{A Six-Point Framework}

Our framework includes six key features: creating a safe and nonthreatening learning context, increasing knowledge about the science of implicit bias, emphasizing how implicit bias influences behaviors and patient outcomes, increasing selfawareness of existing implicit biases, improving conscious efforts to overcome implicit bias, and enhancing awareness of how implicit bias influences others

\section{Figure 1}

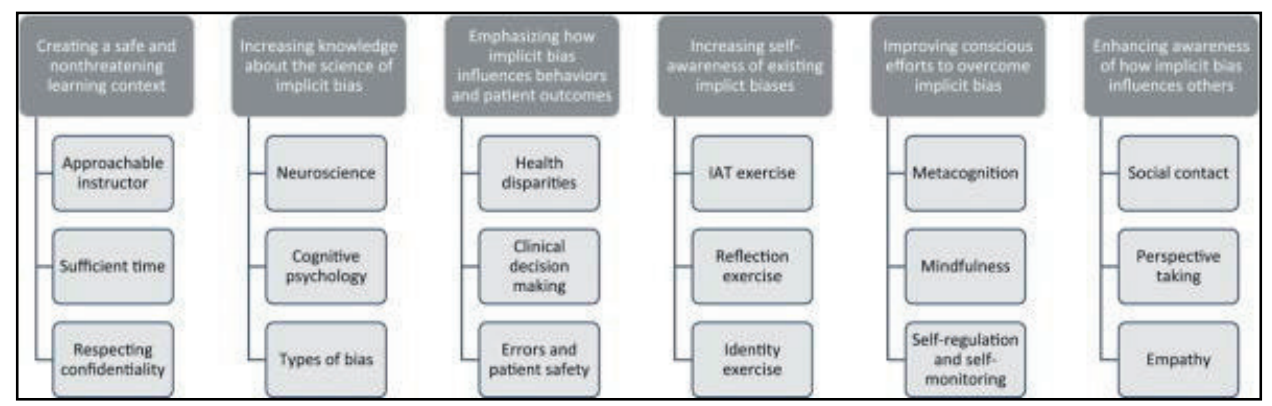

Framework to integrate implicit bias recognition and management into health professions curricula, as proposed by the authors. The framework includes six key features: creating a safe and nonthreatening learning context, increasing knowledge about the science of implicit bias, emphasizing how implicit bias influences behaviors and patient outcomes, increasing self-awareness of existing implicit biases, improving conscious efforts to overcome implicit bias, and enhancing awareness of how implicit bias influences others. Under each key feature are a few examples of elements or strategies that should be incorporated into each category; for example, another strategy for increasing self-awareness of existing implicit biases is the use of facilitated discussions on how bias impacts care. Abbreviation: IAT indicates implicit association test. 


\section{Creating a safe and nonthreatening learning context}

Teaching about bias, stereotyping, and privilege can be risky; both learners and faculty may be challenged to confront attitudes that they may not feel necessary to address or willing to disclose. Directly challenging both negative and positive biases can also produce a negative "kick-back" that reinforces counterproductive biases. ${ }^{22}$ By emphasizing the pervasive qualities of implicit bias, instructors can reinforce that bias is everywhere and, therefore, guilt regarding individually held biases is a common human experience. Thus, a key distinction between traditional education about diversity or cultural competence and implicit-bias-informed curricula is a proactive shift away from guilt and toward responsibility. ${ }^{22}$ Several authors emphasize that, when teaching about bias, there should be explicit recognition that the removal of all bias is impossible. ${ }^{23-25}$

When designing interventions, educators should also recognize instructor and learner characteristics that support a climate of safety. Choosing instructors that are approachable, inclusive, nonthreatening, inspiring, open-minded, encouraging, and knowledgeable can best facilitate safe and nonjudgmental learning environments. ${ }^{21,26}$ Since students from a nondominant group are likely to approach discussions about privilege and bias with different personal experiences than students who belong to traditionally privileged groups, learning environments should proactively avoid reinforcing feelings of resentment or anxiety for learners. Instructors can promote a nonthreatening learning environment by openly addressing the discomfort that accompanies discussions about bias and privilege. Most organizations have existing codes of conduct that can be introduced into the intervention to emphasize the importance of core values, including respect, integrity, and confidentiality. Educators must ensure sufficient time so that learners do not feel rushed and power balances between teacher and learners, as well as between various health professions, are acknowledged.

\section{Increasing knowledge about the science of implicit bias}

Any intervention that incorporates implicit bias recognition into health professions education should include content regarding the psychological and neurobiological components of bias and provide an evidence-based framework for understanding the cognitive science that underlies implicit biases. Incorporating cognitive psychology and neuroscience into the intervention has the potential to increase relevance for learners, while illustrating that implicit bias is impossible to eradicate and common to patients, caregivers, and providers. Emphasizing that bias is a result of neurobiological mechanisms that can restrict an individual's ability to be open to multiple perspectives ${ }^{14}$ helps activate prior knowledge about learners' 
own biases and experiences with others' biases. Teaching learners about psychological processes that are outside their conscious awareness is also important because health care providers may underestimate the extent to which biases influence their behaviors. ${ }^{27}$

Increasing knowledge about the nature of implicit bias should include a demonstration of different types of bias, including both positive and negative biases. Educators should ensure that there is a discussion about the constructive aspects of bias, clarifying that bias can be adaptive in some circumstances and destructive in others. Illustrating that bias may be a useful tool to promote safety and belonging, while providing clinically relevant examples of how bias influences patient outcomes, is important and highlights how implicit bias recognition and management is distinct from traditional approaches to diversity, cultural competence, and stigma reduction.

\section{Emphasizing how implicit bias influences behaviors and patient outcomes}

The influence of implicit bias on patient outcomes is a key component of our framework. By aligning interventions with existing curricula on health disparities, instructors can connect discussions about bias with the role of history and both visible and invisible sociocultural forces that impact health. Citing statistics and existing research on implicit bias in medical education, as well as discussing the impact of internalized bias on stereotypes, helps motivate learners to learn how to address and mitigate their biases. For certain health professions, specific reference to literature on clinical decision making and cognitive psychology, including certain types of bias, such as anchoring (relying too heavily on the first piece of information about a patient) or confirmation bias (the tendency to favor information in a manner that confirms preexisting beliefs), may lay the groundwork for learners to engage with ideas about how biases may adversely affect care.

\section{Increasing self-awareness of existing implicit biases}

The implicit association test (IAT) may provide a useful trigger for self-reflection, discussion, and awareness of one's own existing biases. 28,29 The IAT is a computerbased exercise that asks participants to associate words and pictures to assess automatic associations between concepts by measuring the time and latency of individuals' responses. For example, the IAT can demonstrate an association between groups of people (blacks and whites) and stereotypes (good and bad). ${ }^{28}$ The IAT has typically demonstrated good internal consistency, ${ }^{30-33}$ insensitivity to procedural variation, ${ }^{28,34}$ high test-retest reliability, ${ }^{35}$ and less susceptibility to faking 
than explicit measures of bias, such as surveys. ${ }^{36}$ Criticism of the IAT suggests that, instead of reflecting negative attitudes, IAT scores may stem from associations such as victimization, maltreatment, and oppression. ${ }^{37-42}$ Given these critiques, we recommend using the IAT as a prompt for reflection and not as a metric for measuring implicit bias or evaluating curricula.

Other techniques that may help elicit awareness of existing implicit biases include facilitated discussions on how bias impacts care and reflection and identity exercises. Techniques that enhance reflective capacity may be useful, and curriculum designers are encouraged to make explicit connections between bias-related curricula and other curricular content that foster reflective practice. One simple potential identity exercise could pair up participants to discuss the dominant and nondominant cultures to which they belong. Individual reflection on identity and times that individual learners felt different or treated inequitably can also increase awareness of existing biases. There are examples in the health professions literature of potentially useful tools to facilitate reflection, such as the privilege and responsibility curricular exercise. ${ }^{43}$

\section{Improving conscious efforts to overcome implicit bias}

When learners become aware of their implicit biases, they often ask, "What should I do about it?"19 Since forming conscious egalitarian goals is simply not enough to reduce the impact of implicit bias on patient care, ${ }^{44}$ and research emphasizes the importance of conscious effort to avoid applying stereotypes, ${ }^{45,46}$ particular attention to training and tools that help learners understand their thinking, reasoning, and the influence of bias on their behaviors and decisions is an essential ingredient for implicit-bias-informed curricula.

Specific techniques for improving conscious efforts to overcome bias come from social psychology and include metacognitive strategies that facilitate the ability of learners to think about their thinking. ${ }^{22,47}$ Some authors have also advocated for improving self-regulation and self-monitoring. 48,49 To this end, encouraging learners to set discrete goals and to reevaluate their success at longitudinal checkpoints over time facilitates increased monitoring and reflection on biases and attitudes. ${ }^{50}$ Another technique that holds promise is the role of mindfulness training, which can improve attention to biased judgments and behaviors. ${ }^{51}$

\section{Enhancing awareness of how implicit bias influences others}


In contrast to self-awareness, enhancing social perspective taking and empathy for others is another important component of implicit bias recognition and management. ${ }^{17,44}$ Explicit attention to the cognitive and affective components of empathy that unite patients and providers within a shared emotional context protects against stereotyping and discrimination that is rooted in implicit bias. ${ }^{52,53}$ More specifically, reframing patient-provider contact as an interaction between collaborating equals can shift one's thinking of diverse individuals as outsiders to perceiving them as part of one's own social groups by emphasizing a shared human identity. ${ }^{54-56}$

Cultivating empathy through implicit-bias-informed curricula can be achieved through strategies that enhance social perspective taking and facilitate positive emotions. Research demonstrates that when nurses were shown pictures of either white or black patients with expressions of pain and asked how much pain medication they recommended, those who were instructed to imagine how the patient felt recommended equal analgesic treatment, as compared with those who were told to use their best judgment, who recommended more pain medication for white patients. ${ }^{57}$ Techniques for enhancing perspective taking may include role-play, participatory theater, and social contact with matched patients or families with lived experience. For example, social-contact-based interventions may involve inviting patients who belong to marginalized groups that have experienced bias in clinical settings to speak to providers, share their story, and engage in discussion. Social contact has produced favorable outcomes in reducing implicit bias toward sexual minorities,58 patients with mental illness, ${ }^{59-61}$ and females. ${ }^{62}$

Social-contact-based interventions, however, may have unintended consequences. Research on mental illness stigma demonstrates that social contact will reduce stigmatizing attitudes and behaviors only when it is conducted in person and between individuals of equal power. ${ }^{59-61}$ Creating an authentic learning environment with an equalized power differential is challenging. Additionally, contact with patients with mental illness can lead to both positive and negative experiences for health care providers 19,63 and should only be used with careful planning and caution because of the possibility that it may reinforce destructive stereotypes.

\section{Designing Interventions}

The first step in implicit-bias-related educational interventions is to determine whether educators will focus on a specific type of bias, such as gender, race, culture, etc., or bias in general. Once the focus of the intervention is determined, instructors should clarify whether they are teaching about bias related to specific or broad contexts. For example, will the curricula teach about gender bias in relation to car- 
diovascular health, to clinical outcomes in general, or to how it influences organizational issues and health policy? The broader the intervention, the more time and integration with curricula it will require. Attention to the influence and outcomes of bias at individual, organizational, community, and societal levels also requires deliberate attention from the early stages of instructional design and throughout the implementation process.

Educators should consider learners' stage in their professional trajectory and clinical experience, as well as how oriented they are to implicit bias and its role in health care, when designing interventions. Considering clinical experience and context is crucial because expecting learners without clinical experience to engage with complex clinical scenarios may lead to feedback that the educational intervention lacks relevance. Dynamics related to interprofessional teams should also be considered because of their potential influence on discussions of privilege and power. For example, will the intervention target undergraduate preclinical students, clinical clerks, or postgraduate trainees? Are learners undifferentiated, or have they developed the identity of a specific specialty or subspecialty? Are learners from diverse health disciplines or members of one particular group? Using established methodologies to design curricula and write relevant and measurable learning objectives will help facilitate these decisions and develop the appropriate assessment and evaluation strategies.

Previous research emphasizes that the recognition of bias cannot be taught in a single session. ${ }^{16}$ Curriculum designers should also consider how they will sustain implicit bias recognition and management interventions within a learning environment or organization. Cultural and hidden curricular influences that may work against the intervention must be considered. Learners may internalize and perpetuate patterns of behavior that they are exposed to over time. In the landmark Medical Student Cognitive Habits and Growth Evaluation Study (CHANGES), van Ryn and colleagues 63 found that, despite their efforts to reduce implicit race bias, hearing negative comments about black patients from physicians and residents worsened implicit racial biases over the course of undergraduate medical education.

\section{Evaluation and Assessment Strategies}

While traditional program evaluation and learner assessment strategies using a knowledge, skills, and attitudes framework are a good start, ${ }^{64}$ a purely outcomesdriven approach to program evaluation may be too narrow to capture the complexity related to implicit-bias-informed curricula. ${ }^{65}$ Evaluation of these curricula requires the broadening of existing frameworks to consider the influence of biasrelated strategies on the individual, their organization, the community, and society 
at large. We recommend an evaluation approach that generates useful information to guide the adaptation of implicit-bias-informed curricula to rapidly evolving social and cultural contexts. ${ }^{66}$

We encourage curriculum designers to start with a logic model and establish their desired outcomes at organizational and societal levels. Is your curriculum designed to improve learner attitudes while promoting cultural change, diversity, and inclusion? Do you aim to improve health care quality and patient experience? Is there an overall equity-related goal in mind? Addressing these questions is of paramount importance when determining evaluation metrics. Organizational tools pertaining to achieving accreditation benchmarks related to diversity, inclusion, and cultural competence, such as those published by the Association of American Medical Colleges, ${ }^{13,67}$ may be useful in some circumstances, while population-based data might be useful in others. Patient-related outcomes, such as satisfaction surveys, may provide meaningful data to gauge the impact of curricula on real-world outcomes.18 Evaluation strategies must also consider that desired outcomes may take time. Therefore, longitudinal approaches and both quantitative and qualitative methods should be considered.

Learner-related outcomes are an essential component of any program evaluation. For these kinds of outcomes, we propose mapping assessment strategies to the points on our framework (Figure 2). For example, increasing knowledge about the science of implicit bias and emphasizing how implicit bias influences behaviors and patient outcomes can be assessed through pre and post knowledge tests. ${ }^{68}$ Improving conscious efforts to overcome implicit bias can be assessed through modified observed clinical evaluation methods, such as mini-clinical evaluation exercises and objective structured clinical examinations. ${ }^{69,70}$ Increasing self-awareness of existing implicit biases and enhancing awareness of how implicit bias influences others can be assessed through portfolios and multisource feedback, respectively. Portfolios are learner-compiled dossiers that include content such as work completed, reflec-

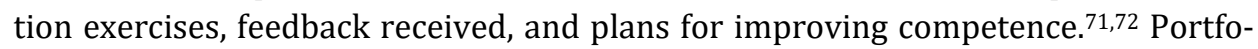
lios may facilitate the assessment of reflective skills if there is adequate structure, coaching, and direction. ${ }^{73}$

There seems to be an emerging consensus that no single method of assessment or evaluation will be sufficient. ${ }^{74}$ Nonetheless, considering how evaluating and assessing implicit-bias-informed curricula relates to emerging models for assessing professional competence of learners merits further reflection, research, and exploration. 


\section{Figure 2}

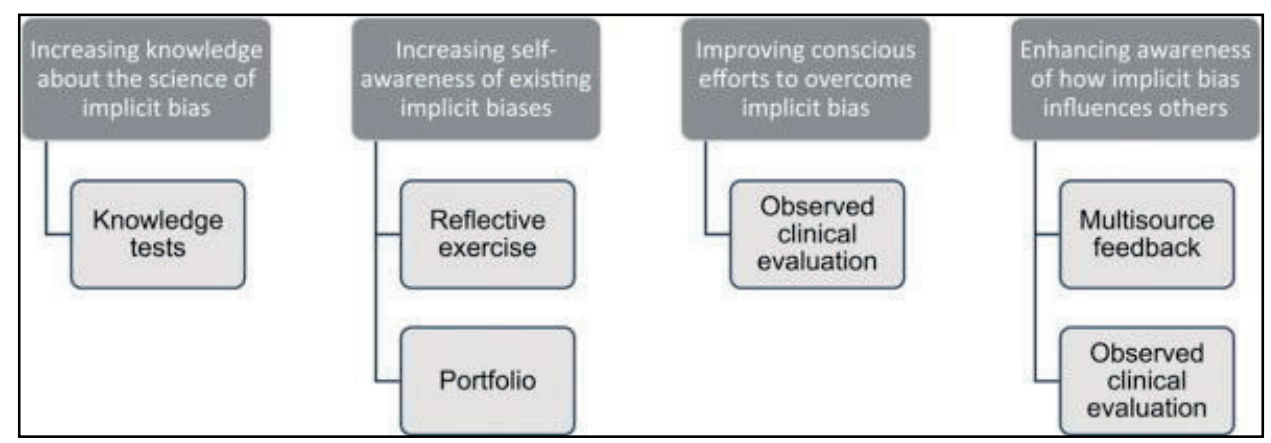

Figure 2. Example strategies to assess learner-related outcomes, mapped onto features of the authors' proposed framework. The use of these assessment strategies is potentially useful for evaluating implicit-bias-informed curricula for learners.

\section{Conclusion}

We believe that implicit bias recognition and management can be effectively integrated into health professions education by considering our six-point actionable framework. We suggest that educational interventions that are delivered in safe and nonthreatening environments and foster perspective taking and empathy through social contact are important. Interventions should also teach learners what implicit bias is, demonstrate how it influences clinical decisions and patient outcomes, increase awareness of existing implicit biases in learners, and enhance conscious efforts to overcome the adverse impact of implicit bias. Interventions should consider power dynamics between teachers, learners, and patients and consider the sociocultural context in which such dynamics are played out. Lastly, evaluation and assessment strategies should consider outcomes at the levels of the individual, organization, community, and society. Our proposed framework may facilitate future research and exploration regarding the use of implicit bias in health professions education. 


\section{References}

(1) Green AR, Carney DR, Pallin DJ, et al. Implicit bias among physicians and its prediction of thrombolysis decisions for black and white patients. J Gen Intern Med. 2007;22:1231-1238.

(2) Sabin JA, Greenwald AG. The influence of implicit bias on treatment recommendations for 4 common pediatric conditions: Pain, urinary tract infection, attention deficit hyperactivity disorder, and asthma. Am J Public Health. 2012;102:988-995.

(3) Chapman EN, Kaatz A, Carnes M. Physicians and implicit bias: How doctors may unwittingly perpetuate health care disparities. J Gen Intern Med. 2013;28:1504-1510.

(4) Dovidio JF, Kawakami K, Gaertner SL. Implicit and explicit prejudice and interracial interaction. J Pers Soc Psychol. 2002;82:62-68.

(5) Fazio RH, Jackson JR, Dunton BC, Williams CJ. Variability in automatic activation as an unobtrusive measure of racial attitudes: A bona fide pipeline? J Pers Soc Psychol. 1995;69:1013-1027.

(6) Haider AH, Sexton J, Sriram N, et al. Association of unconscious race and social class bias with vignette-based clinical assessments by medical students. JAMA. 2011;306:942-951.

(7) Verdonk P, Benschop YW, de Haes HC, Lagro-Janssen TL. From gender bias to gender awareness in medical education. Adv Health Sci Educ Theory Pract. 2009;14:135-152.

(8) Stivers T, Majid A. Questioning children: Interactional evidence of implicit bias in medical interviews. Soc Psychol Q. 2007;70:424-441.

(9) Weinstein SM, Laux LF, Thornby JI, et al. Physicians' attitudes toward pain and the use of opioid analgesics: Results of a survey from the Texas Cancer Pain Initiative. South Med J. 2000;93:479-487.

(10) Friedberg F, Sohl SJ, Halperin PJ. Teaching medical students about medically unexplained illnesses: A preliminary study. Med Teach. 2008;30:618-621.

(11) Eva KW, Norman GR. Heuristics and biases-A biased perspective on clinical reasoning. Med Educ. 2005;39:870-872.

(12) Sukhera J, Chahine S. Reducing mental illness stigma through unconscious bias-informed education.

https://www.mededpublish.org/manuscripts/449/v1. Accessed April 27, 2017.

(13) Association of American Medical Colleges. The Diversity Research Forum:

"Tools for assessing and measuring diversity in medical education." https://members.aamc.org/eweb/upload/The\%20Diversity\%20Research\%2 0Forum\%20Tools\%20for\%20Assessing.pdf. Published 2006 Accessed April 27, 2017. 
(14) Johnson I, Donovan D, Parboosingh J. Steps to improve the teaching of public health to undergraduate medical students in Canada. Acad Med. 2008;83:414418.

(15) Tyler IV, Hau M, Buxton JA, et al. Canadian medical students' perceptions of public health education in the undergraduate medical curriculum. Acad Med. 2009;84:1307-1312.

(16) Gonzalez CM, Kim MY, Marantz PR. Implicit bias and its relation to health disparities: A teaching program and survey of medical students. Teach Learn Med. 2014;26:64-71.

(17) Burgess D, van Ryn M, Dovidio J, Saha S. Reducing racial bias among health care providers: Lessons from social-cognitive psychology. J Gen Intern Med. 2007;22:882-887.

(18) Blair IV, Steiner JF, Havranek EP. Unconscious (implicit) bias and health disparities: Where do we go from here? Perm J. 2011;15:71-78.

(19) Teal CR, Gill AC, Green AR, Crandall S. Helping medical learners recognise and manage unconscious bias toward certain patient groups. Med Educ. 2012;46:80-88.

(20) Moss-Racusin CA, Dovidio JF, Brescoll VL, Graham MJ, Handelsman J. Science faculty's subtle gender biases favor male students. Proc Natl Acad Sci U S A. 2012;109:16474-16479.

(21) Boscardin CK. Reducing implicit bias through curricular interventions. J Gen Intern Med. 2015;30:1726-1728.

(22) Ross HJ. Everyday Bias: Identifying and Navigating Unconscious Judgments in Our Daily Lives. 2014.Lanham, MD: Rowman \& Littlefield.

(23) Burgess DJ, Fu SS, van Ryn M. Why do providers contribute to disparities and what can be done about it? Gen Intern Med. 2004;19:1154-1159.

(24) Czopp AM, Monteith MJ, Mark AY. Standing up for a change: Reducing bias through interpersonal confrontation. J Pers Soc Psychol. 2006;90:784-803.

(25) Vorauer JD, Sasaki SJ. Helpful only in the abstract? Ironic effects of empathy in intergroup interaction. Psychol Sci. 2009;20:191-197.

(26) Young M. What is learning and why does it matter? Eur J Educ. 2015;50:17-20.

(27) van Ryn M, Fu SS. Paved with good intentions: Do public health and human service providers contribute to racial/ethnic disparities in health? Am J Public Health. 2003;93:248-255.

(28) Greenwald AG, McGhee DE, Schwartz JLK. Measuring individual differences in implicit cognition: The implicit association test. J Pers Soc Psychol. 1998;74:1464-1480.

(29) Teal CR, Shada RE, Gill AC, et al. When best intentions aren't enough: Helping medical students develop strategies for managing bias about patients. J Gen Intern Med. 2010;25(suppl 2):115-118. 
(30) Bosson JK, Swann WB Jr, Pennebaker JW. Stalking the perfect measure of implicit self-esteem: The blind men and the elephant revisited? J Pers Soc Psychol. 2000;79:631-643.

(31) Dasgupta N, Greenwald AG. On the malleability of automatic attitudes: Combating automatic prejudice with images of admired and disliked individuals. J Pers Soc Psychol. 2001;81:800-814.

(32) Greenwald AG, Farnham SD. Using the implicit association test to measure selfesteem and self-concept. J Pers Soc Psychol. 2000;79:1022-1038.

(33) Greenwald AG, Nosek BA. Health of the Implicit Association Test at age 3. Z Exp Psychol. 2001;48:85-93.

(34) Nosek BA, Greenwald AG, Banaji MR. Understanding and using the Implicit Association Test: II. Method variables and construct validity. Pers Soc Psychol Bull. 2005;31:166-180.

(35) Nosek BA, Greenwald AG, Banaji MR. Bargh JA. The implicit association test at age 7: A methodological and conceptual review. In: Automatic Processes in Social Thinking and Behavior. 2007:New York, NY: Pyschology Press; 265-292.

(36) Steffens MC, Schulze König S. Predicting spontaneous big five behavior with implicit association tests. Eur J Psychol Assess. 2006;22:13-20.

(37) Blanton H, Jaccard J, Christie C, Gonzales PM. Plausible assumptions, questionable assumptions and post hoc rationalizations: Will the real IAT, please stand up? J Exp Soc Psychol. 2007;43:399-409.

(38) Gill MJ, Andreychik MR, Getty PD. More than a lack of control: External explanations can evoke compassion for outgroups by increasing perceptions of suffering (independent of perceived control). Pers Soc Psychol Bull. 2013;39:7387.

(39) Uhlmann EL, Brescoll VL, Paluck EL. Are members of low status groups perceived as bad, or badly off? Egalitarian negative associations and automatic prejudice. J Exp Soc Psychol. 2006;42:491-499.

(40) Banaji MR, Nosek BA, Greenwald AG. No place for nostalgia in science: A response to Arkes and Tetlock. Psychol Inq. 2004;15:279-289.

(41) Greenwald AG, Nosek BA, Sriram N. Consequential validity of the implicit association test: Comment on Blanton and Jaccard (2006). Am Psychol. 2006;61:56-61.

(42) Greenwald AG, Poehlman TA, Uhlmann EL, Banaji MR. Understanding and using the Implicit Association Test: III. Meta-analysis of predictive validity. J Pers Soc Psychol. 2009;97:17-41.

(43) Holm AL, Rowe Gorosh M, Brady M, White-Perkins D. Recognizing privilege and bias: An interactive exercise to expand health care providers' personal awareness. Acad Med. 2017;92:360-364.

(44) Stone J, Moskowitz GB. Non-conscious bias in medical decision making: What can be done to reduce it? Med Educ. 2011;45:768-776. 
(45) Shelton D, Smith J, Purnell-Greene M. Design of a mental health promotion program for vulnerable African American youth. J Forensic Nurs. 2005;1:158165.

(46) Shelton JN. Interpersonal concerns in social encounters between majority and minority group members. Group Process Intergr Relat. 2003;6:171-185.

(47) Schraw G, Crippen KJ, Hartley K. Promoting self-regulation in science education: Metacognition as part of a broader perspective on learning. Res Sci Educ. 2006;36:111-139.

(48) Devine PG. Stereotypes and prejudice: Their automatic and controlled components. J Pers Soc Psychol. 1989;56:5-18.

(49) Devine P, Monteith M. Mackie DM, Hamilton DL. The role of discrepancyassociated affect in prejudice reduction. In: Affect, Cognition, and Stereotyping: Interactive Processes in Group Perception. 1993:San Diego, CA: Academic Press; 317-344.

(50) Sandars J, Cleary TJ. Self-regulation theory: Applications to medical education: AMEE guide no. 58. Med Teach. 2011;33:875-886.

(51) Lueke A, Gibson B. Mindfulness meditation reduces implicit age and race bias: The role of reduced automaticity of responding. J Pers Soc Psychol. 2015;6:284-291.

(52) Halpern J. What is clinical empathy? J Gen Intern Med. 2003;18:670-674.

(53) Decety J, Cowell JM. Friends or foes: Is empathy necessary for moral behavior? Perspect Psychol Sci. 2014;9:525-537.

(54) Dovidio JF, Gaertner SL. Aversive racism and selection decisions: 1989 and 1999. Psychol Sci. 2000;11:315-319.

(55) Nier JA, Gaertner SL, Dovidio JF, Banker BS, Ward CM, Rust MC. Changing interracial evaluations and behavior: The effects of a common group identity. Group Process Intergr Relat. 2001;4:299-316.

(56) Dovidio JF, Gaertner SL. Zanna MP. Aversive racism. In: Advances in Experimental Social Psychology. 2004:Amsterdam, Netherlands: Elsevier; 1-51.

(57) Drwecki BB, Moore CF, Ward SE, Prkachin KM. Reducing racial disparities in pain treatment: The role of empathy and perspective-taking. Pain. 2011;152:1001-1006.

(58) Burke SE, Dovidio JF, Przedworski JM, et al. Do contact and empathy mitigate bias against gay and lesbian people among heterosexual first-year medical students? A report from the Medical Student CHANGE study. Acad Med. 2015;90:645-651.

(59) Corrigan P. Changing stigma through contact. Adv Schizophr Clin Psych. 2005;1:54-58.

(60) Corrigan PW, Shapiro JR. Measuring the impact of programs that challenge the public stigma of mental illness. Clin Psychol Rev. 2010;30:907-922. 
(61) Corrigan PW. How clinical diagnosis might exacerbate the stigma of mental ilness. Soc Work. 2007;52:31-39.

(62) Carnes M, Devine PG, Baier Manwell L, et al. The effect of an intervention to break the gender bias habit for faculty at one institution: A cluster randomized, controlled trial. Acad Med. 2015;90:221-230.

(63) van Ryn M, Hardeman R, Phelan SM, et al. Medical school experiences associated with change in implicit racial bias among 3547 students: A Medical Student CHANGES study report. J Gen Intern Med. 2015;30:1748-1756.

(64) Kirkpatrick DL. Evaluating Training Programs: The Four Levels. 1998.San Francisco, CA: Berrett-Koehler Publishers.

(65) Haji F, Morin MP, Parker K. Rethinking programme evaluation in health professions education: Beyond “did it work?” Med Educ. 2013;47:342-351.

(66) Ginsburg S, McIlroy J, Oulanova O, Eva K, Regehr G. Toward authentic clinical evaluation: Pitfalls in the pursuit of competency. Acad Med. 2010;85:780-786.

(67) Lie D, Boker J, Cleveland E. Using the tool for assessing cultural competence training (TACCT) to measure faculty and medical student perceptions of cultural competence instruction in the first three years of the curriculum. Acad Med. 2006;81:557-564.

(68) Epstein RM, Hundert EM. Defining and assessing professional competence. JAMA. 2002;287:226-235.

(69) Norcini JJ. Peer assessment of competence. Med Educ. 2003;37:539-543.

(70) Norcini JJ, Blank LL, Arnold GK, Kimball HR. The mini-CEX (clinical evaluation exercise): A preliminary investigation. Ann Intern Med. 1995;123:795-799.

(71) Van Tartwijk J, Driessen EW. Portfolios for assessment and learning: AMEE guide no. 45. Med Teach. 2009;31:790-801.

(72) Driessen E, van Tartwijk J, van der Vleuten C, Wass V. Portfolios in medical education: Why do they meet with mixed success? A systematic review. Med Educ. 2007;41:1224-1233.

(73) Driessen EW, van Tartwijk J, Overeem K, Vermunt JD, van der Vleuten CP. Conditions for successful reflective use of portfolios in undergraduate medical education. Med Educ. 2005;39:1230-1235.

(74) van der Vleuten CP, Schuwirth LW, Scheele F, Driessen EW, Hodges B. The assessment of professional competence: Building blocks for theory development. Best Pract Res Clin Obstet Gynaecol. 2010;24:703-719. 



\section{CHAPTER 3}

\section{Labeling of Mental Illness Stigma in a}

Paediatric Emergency Department and its Implications for Stigma Reduction Education

Published as:

Sukhera J, Miller K, Milne A, Scerbo C, Lim R, Cooper A, Watling C. Labelling of mental illness in a paediatric emergency department and its implications for stigma reduction education. Perspectives on medical education. 2017 Jun 1;6(3):165-72.

(C) 2017 Springer 


\begin{abstract}
Introduction: Stigmatizing attitudes and behaviours towards patients with mental illness have negative consequences on their health. Despite research regarding educational and social contact-based interventions to reduce stigma, there are limitations to the success of these interventions for individuals with deeply held stigmatizing beliefs. Our study sought to better understand the process of implicit mental illness stigma in the setting of a paediatric emergency department to inform the design of future educational interventions.
\end{abstract}

Methods: We conducted a qualitative exploration of mental illness stigma with interviews including physician, nurse, service user, caregiver and administrative staff participants $(n=24)$. We utilized the implicit association test as a discussion prompt to explore stigma outside of conscious awareness. We conducted our study utilizing constructivist grounded theory methodology, including purposeful theoretical sampling and constant comparative analysis.

Results: Our study found that the confluence of socio-cultural, cognitive and emotional forces results in labelling of patients with mental illness as time-consuming, unpredictable and/or unfixable. These labels lead to unintentional avoidance behaviours from staff which are perceived as prejudicial and discriminatory by patients and caregivers. Participants emphasized education as the most useful intervention to reduce stigma, suggesting that educational interventions should focus on patient-provider relationships to foster humanizing labels for individuals with mental illness and by promoting provider empathy and engagement.

Discussion: Our results suggest that educational interventions that target negative attributions, consider socio-cultural contexts and facilitate positive emotions in healthcare providers may be useful. Our findings may inform further research and interventions to reduce stereotypes towards marginalized groups in healthcare settings.

What this paper adds: In a healthcare setting, mental illness stigma results from labelling patients with mental illness as time-consuming, unpredictable or unfixable. Perceived lack of self-efficacy in healthcare providers further perpetuates stigmatizing attributions. Educational interventions to reduce stigma may be more effective if they focus on patient-provider relationships and foster humanizing labels while increasing empathy skills. Work with individual providers is not enough to reduce stigma without considering socio-cultural influences. 


\section{Introduction}

Despite increasing attention and levels of public acceptance about the underlying cause of mental illness, mental illness stigma (negative attitudes and behaviours towards individuals with mental illness) continue to adversely impact patients and families ${ }^{1-4}$. A recent review found that stigma decreases help-seeking behaviours among individuals with mental illness(es) ${ }^{5}$. Stigma has been associated with a low quality of life and well-being ${ }^{6,7}$, persistent stress ${ }^{8}$, interference with recovery ${ }^{9}$, lower treatment adherence ${ }^{10}$, shortened life span ${ }^{11}$ and suicide ${ }^{12}$. Stigma also adversely impacts family relationships and contributes to caregiver fatigue ${ }^{13}$.

Explanatory frameworks for stigma vary, ranging from individual cognitive models to motivational and structural models. ${ }^{14,15}$. In particular, the work of Scheff and Goffman in the 1960s proposed modified labelling theory, emphasizing that stigma is an individual process enacted through social interactions ${ }^{16-20}$. Further scholars have refined Goffman and Scheff's original work, describing stigma as resulting from converging forces including labelling of difference, linking of labels to undesirable characteristics, placement of labelled persons in distinct categories to accomplish separation and, lastly, the experience of discrimination that leads to unequal outcomes 17,18 .

Global efforts to reduce mental health stigma have been implemented by governments in most Western countries including the European Union, Australia, the USA and Canada ${ }^{16}$. Current models for stigma reduction include education and social contact. Education plays a role in reducing stigma by increasing knowledge about mental health and fostering counter-stereotypes about individuals with mental illness ${ }^{21}$. The success of stigma reduction interventions is typically measured by psychometrically validated scales at the individual level and through conceptual domains such as behaviour, penetration, psychological perspective, and knowledge at organizational and population levels 21 . While the public believes that stigmareduction efforts have produced decreased stigma, research suggests that stigmatization of mental illness has shown a corresponding increase, which is perpetuated by associations between mental illness and dangerousness ${ }^{22}$.

Existing research on stigma reduction education reveals several constraints on the power of current approaches to effect meaningful change. Educational interventions that provide information to dispel stereotypes regarding mental illness are considerably less effective for individuals who exhibit greater prejudice ${ }^{14}$. In contrast, social contact-based interventions that promote interpersonal contact with patients with mental illness are more effective than education alone 23,24 . Social contact-based interventions have limited effect unless the contact is in person ${ }^{25}$, the interactions are rewarding and enriching ${ }^{16}$, and the individuals encountering each other are of equal power 26,27 , and pursue rewarding activities 28 
towards a common goal ${ }^{29}$. Creating authentic learning environments that equalize the power differential between patients and healthcare providers is challenging. In most healthcare settings, patients and providers are rarely matched to each other, and when patients suffering from mental illness present in emergency or acute-care settings, there can be conflicting agendas and goals.

The success and sustainability of educational and contact-based interventions in healthcare organizations are therefore limited. Contact with patients with mental illness can lead to both positive and negative experiences for healthcare providers. If their experience reinforces their negative stereotype that patients with mental illness are dangerous, they may potentially further stereotype all patients with mental illness. Additionally, many interventions fail because they occur in organizational or sociocultural contexts that do not adequately address sociocultural or societal influences ${ }^{21}$. A recent review of stigma reduction interventions in healthcare students and professionals found that education and contact-based interventions are often difficult to sustain, which raises questions as to whether cost of implementation may outweigh benefits ${ }^{30}$.

We sought to address these limitations by considering deeper levels of stigma that may exist outside of conscious awareness. Implicit attitudes towards mental illness are gaining increasing recognition in the literature ${ }^{31-35}$. Since explicit attitudes and behaviour are often poorly assessed 36,37, implicit measures such as the implicit association test (IAT) may play a role in future stigma reduction efforts. The IAT is an online tool that serves to bring an individual's implicit attitudes regarding mental illness into their conscious awareness. The test pairs concepts with groups utilizing reaction time as primary outcome. Shorter latencies indicate stronger implicit associations. For example, the IAT measures associations between 'dangerousness' and either 'mental illness' or 'physical illness' 38.

Given the constraints of existing educational and contact-based interventions, our study sought to explore the social process of stigma including how stigmatizing attitudes and behaviours influence the healthcare experience. By exploring implicit stigma in a specific and targeted setting (paediatric emergency department) with diverse participant groups, we endeavoured to develop a deeper understanding of mental illness stigma to inform future educational interventions and reduce the adverse impact of stigma on patient outcomes.

\section{Methods}

We utilized a constructivist grounded theory approach to explore the process of stigmatizing attitudes and behaviours in an emergency setting. Constructivist grounded theory is well suited to explore a social process that is not currently explained by a well-established theoretical construct ${ }^{39}$. 
Patients and families who utilize emergency department mental health services often report that stigma adversely impacts their experience ${ }^{40,41}$. We chose the paediatric emergency department of an accredited Canadian academic health science centre to understand the process of stigma in a discrete environment that was representative of the gateway to acute-level healthcare. The principal investigator (JS) also maintains insider status as a child and adolescent psychiatrist and the research question emanated from observations during clinical activity regarding differential treatment of patients with mental illness and physical illness in this specific environment. A paediatric setting provided an opportunity to study the complex interplay between patients, caregivers and providers and was an ideal setting due to insider status, size, and scope of the clinical environment. Approval was obtained from the Western University Research Ethics Board (105881) to conduct the study.

Consistent with grounded theory principles, we used a purposeful, theoretical sampling approach. Our initial recruitment and interviews focused on patients and caregiver participants, addressing critiques of stigma research being uninformed by the lived experiences of patients and caregivers 42,43 . We then invited multiple stakeholders including administrative staff, nurses and physicians through recruitment notices posted internally and through electronic means. Participants were asked to participate in 60-minute semi-structured interviews to explore stigma in a hospital setting. Analysis of our early interviews with patients and caregivers revealed the importance of clerical registration staff as part of the experience of stigma in a hospital setting. Therefore, we expanded our sample to include emergency department registration clerks.

Since our study was designed to move beyond existing stigma reduction paradigms and consider implicit attitudes about mental illness, we utilized a novel qualitative methodology that incorporated the mental illness IAT as an interview prompt. The use of specific triggers is a commonly used technique in grounded theory methodology to facilitate deeper discussion. Each interview began by reviewing a letter of information describing the nature of the IAT and that participation was voluntary. To promote safe disclosure, participants were advised that their IAT results would remain confidential and interviewers were prepared to debrief any potential emotional reactions regarding IAT results. In all interviews, participants were asked about the experience of taking the IAT and whether they felt that implicit associations played a role in mental illness stigma. In this study, the IAT was used as a prompt to trigger a richer interview about the process and experience of stigma and IAT results were not a part of the analysis. A separate study focused on participant responses to the IAT.

The team was composed of the principal investigator (JS), a child and adolescent psychiatrist, faculty member and $\mathrm{PhD}$ candidate in health professions education, as well as a paediatric emergency clinical leader (RL), research staff (KM), a clinical social worker (AC), and two registered nurse educators (AM and CS). Coinvestigators also included CW who has expertise in health professions education 
research and qualitative research methods. Team members JS, KM, AM and CS conducted 24 individual semi-structured interviews from June to December 2015. To minimize power differential, a physician (JS) conducted the physician interviews, research staff (KM) conducted patient/caregiver interviews and nursing staff (AM and CS) conducted nursing and administrative staff interviews. Interviews followed a discussion guide developed from the initial literature review which included broad and open-ended questions exploring definitions of stigma, effects and possible interventions. The discussion guide was adapted iteratively as the study proceeded in accordance with a constructivist grounded theory approach ${ }^{39}$.

Initial analysis was conducted by a team consisting of JS, KM, AM, and CS, beginning with line-by-line coding and utilizing constant comparative analysis to develop focused codes and working towards major themes. Key themes were shared with the entire team as analysis shifted to axial coding and the development of an explanatory theory that accounted for possible relationships between themes. Data collection continued until authors felt that sufficient data had been collected to enable a coherent and logical conceptual understanding of the process under study 44. Findings were shared with a representative sample of participants via email to achieve triangulation. Participants from each group described general agreement with the synthesis of the results.

A total of 24 interviews were conducted across the various stakeholder groups. Four interviews were with service users (SU), 6 with caregivers (CG), 2 with clerical staff (CS), 2 with administrative staff (AS), 5 with physicians (MD) and 5 with nursing staff $(\mathrm{RN})$. Participants were assigned a number based on the stakeholder group to which they belonged.

\section{Results}

Broadly, most participants defined stigma as negative attitudes towards patients with mental illness and the behaviours that result from those attitudes. When asked to describe a situation that included stigma, participants described situations that fit with general definitions without contextual nuances specific to the emergency department. We found that key sociocultural and organizational influences on stigma - including media, history and a lack of mental health resources - contributed to fear and helplessness in providers. Patients with mental illness were labelled as time-consuming, dangerous, unpredictable and unfixable which led to avoidance behaviours. A perceived lack of self-efficacy in providers perpetuated frustration and helplessness, and further contributed to stigmatizing labels. Participants endorsed education as a key element of stigma reduction and focused on interventions at the patient-provider level. 


\section{Sociocultural and organizational influences on stigma}

Stigma was a consequence of complex forces that interact with each other at the sociocultural, organizational and individual levels. On a systemic level, participants described the impact of media and history as well as factors unique to mental health services including a lack of adequate funding and fragmentation of existing services. Notably, both patients and providers mentioned a lack of resources for mental health as contributing to stigma. Providers were more likely than other participants to draw a direct connection between lack of resources in the community and patients presenting to the emergency department seeking care which they did not feel equipped to provide.

In healthcare field, and particularly working in emergency you like to help people. For the most part, there is a deficiency or a lack of any useful resources to help people. Emergency people don't like dealing with entities they can't help. (MD2)

All participants acknowledged that stigma is worse in emergency settings. They recognized the emergency department as a physically and psychologically stigmatizing environment. The experience of seeking help and support, yet waiting for several hours without provider contact, was described as increasing frustration and worsening stigma.

... We really do them an injustice in the emergency department because they get absolutely no treatment, they just sit there and wait and wait for hours and hours for psychiatry to come see them only to wait hours for a bed. (RN5)

Even more broadly across every group of participants, fear was a predominant influence on the process of stigma. Individuals suffering with mental illness were afraid to disclose their illness and were prepared to be stereotyped. Similarly, staff mentioned their own fear and how it impacted their practice. One nurse described

... an overriding fear ... that somehow someone with a mental illness is going to negatively affect our lives. (RN4).

Participants suggested that stigma in an emergency context was perpetuated by compassion fatigue. Emergency physicians and nurses described facing a high clinical burden in their clinical setting, leading to fatigue and burnout. The impact was a sense of frustration and helplessness that sometimes resulted in reluctance to engage with individuals with mental illness, as one physician noted:

There's a lot of emotional currency and cost in the interaction that may colour our willingness to go in. I think it can delay care and lead to negative talking about the patient even without having seen the patient. (MD3) 


\section{Stigma at the individual level}

Although participant groups agreed on many themes, there was one striking difference: what physicians and nurses described as labelling, patients and caregivers perceived as judgment. Judgment was perceived to be a negative process that could internalize self-stigma including blame.

Stigma is when somebody is judged for what they might look like or the way they act without the person understanding. It's ignorance as far as I'm concerned. It's not taking the time to sit back and say, you know, there is something wrong with that person (CG6)

Many participants, particularly physicians and nurses, reflected that they associated patients with mental illnesses in the emergency setting with being unfixable. Additionally, some participants - particularly physicians - associated patients with mental illness as time-consuming, which was especially challenging in the efficiency-driven emergency department environment. The frustration caused by these labels appeared to increase stigma.

A broken arm - I can fix it ... With mental illness, there's no sense of satisfaction whatsoever, because you emerge feeling despondent and like you're despairing the family because we have nothing good to offer them. (MD4)

\section{Reducing stigma through educational interventions}

Participants agreed that a lack of education through health professions training contributed to stigma and shared that educating providers could reduce stigma by emphasizing humanism and teaching core empathy and communication skills. Several participants suggested that educational interventions that humanized mental health patients were more likely to succeed. They recognized that stigma was both a result of dehumanization and a contributor, and proposed that interventions fostering open dialogue and increasing empathy and compassion were important. Healthcare providers stressed the need to 'treat every patient with respect' and to avoid being 'clouded by past negative experiences' (MD3). And caregivers and service users reminded us that individuals with mental health problems 'are humans too' (SU5), and commented that physicians and nurses should approach them with compassion, and should ask 'how can I communicate with this person more effectively in a kind and quiet manner?' (CG2).

Participants identified a number of features they felt would enhance educational interventions: intervening early, increasing awareness of mental health presentations, promoting understanding of behaviours that result from mental illness, and being inclusive of all types of providers and staff. While participants recognized the impact of system issues such as lack of resources, inadequate funding, and fragmentation of services on stigma, they tended to perceive these factors as outside their sphere of influence; thus, their suggested educational interventions 
tended not to address these contextual forces. Instead, they focused on the patientprovider relationship, perhaps because they felt that was an area where they had the power to effect useful change.

\section{Figure 1}
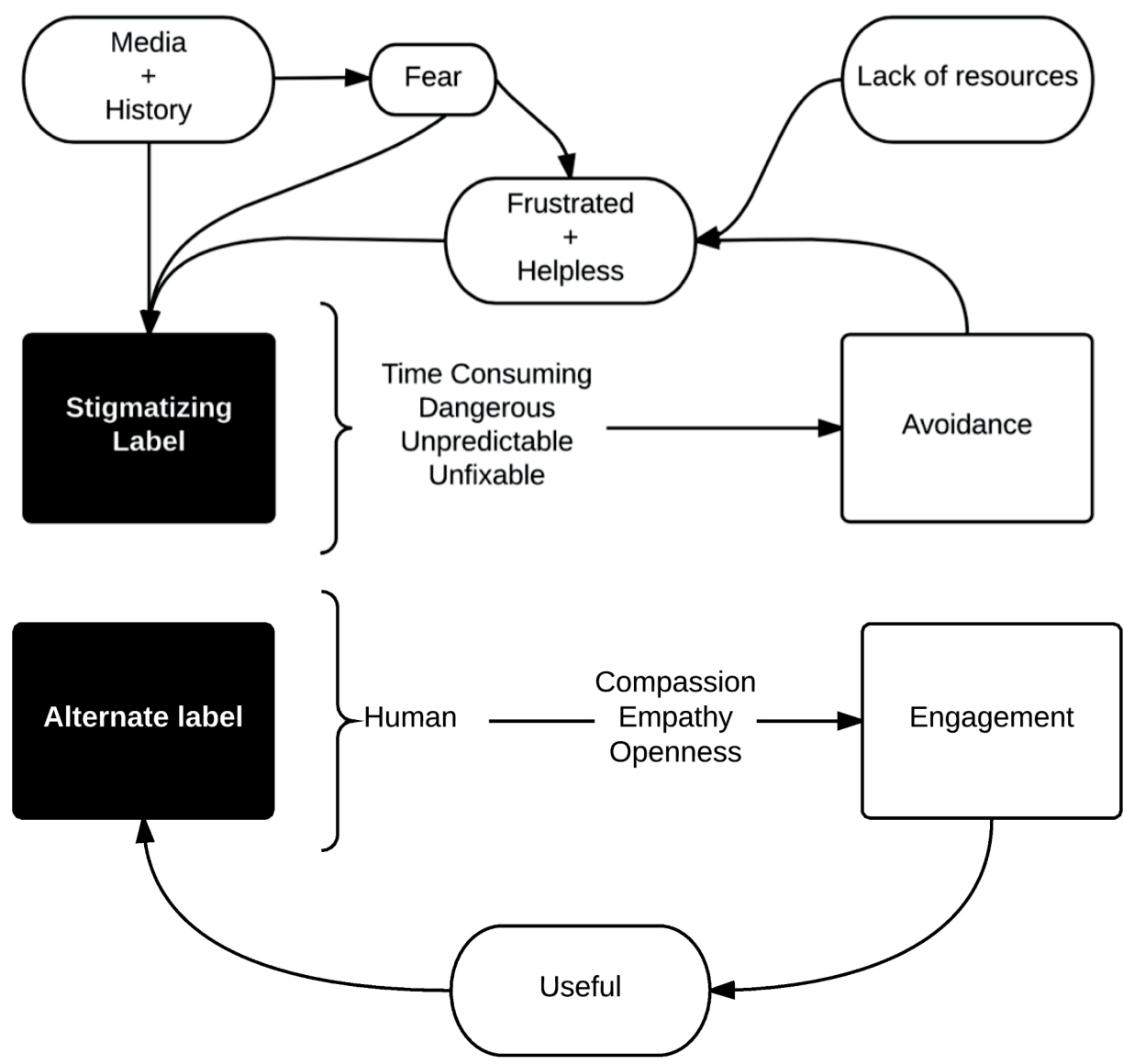

The confluence of socio-cultural forces and fear, frustration and helplessness lead to stigmatizing labels being attached to patients with mental illness and further avoidance behaviours which perpetuate frustration and helplessness. Possible solutions include re-framing patient-provider interactions towards humanizing labels, emphasizing compassion, empathy and openness. Fostering engagement may enhance provider self-efficacy 


\section{Discussion}

Our findings suggest that stigma in a paediatric emergency department results from a dynamic interaction between individual and sociocultural factors. A lack of system resources contributes to presentations of what are often complex, chronic problems to an acute-care, emergency setting that is perceived as unhelpful. Health providers experience frustration with recurring presentations, labelling patients with mental illness as time-consuming, unpredictable or unfixable. These labels result in avoidance behaviours which perpetuate fear, frustration and helplessness. How can we mitigate the effects of stigma and break this cycle? Educational interventions that bolster provider empathy and awareness of mental health may foster more alternative, humanizing labels and promote engagement instead of avoidance. We caution, however, that education of individual providers is not enough to reduce stigma; system, organization, and culture also demand attention. The model derived from this work (Fig. 1) illustrates the process of stigma as well as possible interventions.

\section{Labelling theory revisited: social context and relational power dynamics}

Modified labelling theory emphasizes how labelling difference perpetuates discrimination and adversely impacts equitable and compassionate care for individuals with mental illness 17,18. Our results suggest that providers' emotions and poor selfefficacy may perpetuate stigmatizing labels, and worsen distancing behaviours. Given this insight, we speculate that educational interventions that correct attributions and promote compassionate engagement may reduce stigma.

A focus on the patient-provider relationship resonates with labelling theory, which suggests that stigma is the result of a social process that involves a differential power dynamic between patient and provider 45 , 46. For example, in an emergency department a patient with mental illness who perceives prejudice from a provider may act more defensively, resulting in strained social interactions that perpetuate the process of stigma ${ }^{47}$. Existing literature reflects that labelling patients as 'difficult' may promote the process of social control for nurses who seek the prevention or resolution of deviance ${ }^{48}$. An emerging model proposed by Major and $0^{\prime}$ Brien ${ }^{49}$ suggests that stigma is relationship and context specific and resides within a specific social context, rather than within individuals. Our findings shed light on the stigma-related behaviours of providers in the unique social context of an emergency department, where frustration is associated with a mismatch between a culture that emphasizes rapid symptom alleviation and a patient population that requires an inherently different approach.

Understanding the relationship between labels and context fits well with explanatory models that emphasize how stigma may play a role in protecting threat to psychological self by rationalizing negative group-based attitudes and discrimi- 
nation 50,51. Using this model, patients with mental illness may be perceived as a threat against a culture that emphasizes time-limited medical interventions with immediate resolution. Therefore, emergency providers may be threatened by a large volume of patients that challenge their self-efficacy ${ }^{52}$. Existing research on attitudes towards mental health patients in emergency department highlights this issue, describing an environment that is not conducive to good mental health care 53. Set in the context of a clinical environment where there are intrinsic and extrinsic incentives based on rapid response time and tangible outcomes ${ }^{54-57}$, our findings suggest that this process may perpetuate further avoidance, rejection, frustration and stigmatization.

\section{Educational interventions should enhance self-efficacy and focus on patient- provider relationships}

Existing research emphasizes that educational interventions that equalize power dynamics and address patients' experiences of discrimination and prejudice may reduce stigma 58,59 . Our findings add that provider self-efficacy may also be a useful target of educational interventions; deliberate efforts at perspective-taking and engagement, for example, may enable providers to more effectively mitigate the power differential that feeds stigma. Educational interventions that emphasize selfawareness and social perspective-taking may also limit unintentional avoidance behaviours. In short, interventions rooted in empathy may counter stigma. That healthcare providers, caregivers, and service users perceive that the relational aspects of care fall within their influence suggests that meaningful change in this realm is possible.

\section{Education is not enough to reduce stigma}

Ultimately, any approach to reduce stigma must be multi-faceted and multi-level ${ }^{18}$. Our findings emphasize that educational interventions targeted at the individual level without considering the culture in which they are implemented are destined to fail. Any educational interventions in a healthcare environment should also consider the extrinsic incentives that reward briefer provider-patient interactions and perpetuate stigmatizing labels. Our results underscore the importance of realigning incentives, rewards and extrinsic motivators to promote the success of interventions that are designed to facilitate behavioural change.

Finally, our results draw attention to the continuing gap in training healthcare providers to be adept in managing and improving health systems. Despite our participants' recognition of the social and organizational dimensions of stigma, they expressed an unsettling sense of helplessness to effect system-level change. 


\section{Strengths and limitations}

This study was designed as an exploratory study and sampled diverse groups of participants. Our limitations included the difficulty of capturing stigmatizing experiences for culturally and linguistically complex patients and families, as well as patients with communication difficulties. To address seasonal variation in paediatric mental health presentations, we attempted to sample across a prolonged timespan; however, our staff interviews took place in the fall-winter which includes the busier months of the year. While we attempted to address reflexivity by constructing a diverse team, our research team did not include patients and caregivers and therefore another potential limitation is the lack of patient/caregiver input into study design and results.

\section{Acknowledgements}

This study was funded by grants from the London Health Sciences Children's Health Foundation, Associated Medical Services - Phoenix Fellowship and the Academic Medical Organization for Southwest Ontario's Opportunities Grant. We would also like to acknowledge the help and support of Dr. Sandra Fisman, Dr. Lorelei Lingard and Dr. Paul Links and all our participants. 


\section{References}

(1) Crisp AH, Gelder MG, Rix S, Meltzer HI, Rowlands OJ. Stigmatisation of people with mental illnesses. Br J Psychiatry. 2000;177:4-7. doi: 10.1192/bjp.177.1.4.

(2) Martin JK, Pescosolido BA, Tuch SA. Of fear and loathing: the role of 'disturbing behavior', labels, and causal attributions in shaping public attitudes toward people with mental illness. J Health Soc Behav. 2000;41:208-223. doi: $10.2307 / 2676306$.

(3) Pescosolido BA, Monahan J, Link BG, Stueve A, Kikuzawa S. The public's view of the competence, dangerousness, and need for legal coercion of persons with mental health problems. Am J Public Health. 1999;89:1339-1345. doi: 10.2105/AJPH.89.9.1339.

(4) Stuart HL, Arboleda-Flórez J. Homeless shelter users in the postdeinstitutionalization era. Can J Psychiatry. 2000;45:55. doi: 10.1177/070674370004500108.

(5) Clement S, Schauman O, Graham T, et al. What is the impact of mental healthrelated stigma on help-seeking? A systematic review of quantitative and qualitative studies. Psychol Med. 2015;45:11-27. doi: 10.1017/S0033291714000129.

(6) Mechanic D, McAlpine D, Rosenfield S, Davis D. Effects of illness attribution and depression on the quality of life among persons with serious mental illness. Soc Sci Med. 1994;39:155-164. doi: 10.1016/0277-9536(94)90324-7.

(7) Markowitz FE. The effects of stigma on the psychological well-being and life satisfaction of persons with mental illness. J Health Soc Behav. 1998;39:335347. doi: $10.2307 / 2676342$.

(8) Wright ER, Gronfein WP, Owens TJ. Deinstitutionalization, social rejection, and the self-esteem of former mental patients. J Health Soc Behav. 2000;41:68-90. doi: $10.2307 / 2676361$.

(9) Markowitz FE, Angell B, Greenberg JS. Stigma, reflected appraisals, and recovery outcomes in mental illness. Soc Psychol Q. 2011;74:144-165. doi: $10.1177 / 0190272511407620$.

(10) Mittal D, Sullivan G, Chekuri L, Allee E, Corrigan PW. Empirical studies of selfstigma reduction strategies: A critical review of the literature. Psychiatr Serv. 2012;63:974-981. doi: 10.1176/appi.ps.201100459.

(11) Farnam CR, Zipple AM, Tyrrell W, Chittinanda P. Health status risk factors of people with severe and persistent mental illness. J Psychosoc Nurs Ment Health Serv. 1999;37:16.

(12) Abdullah T, Brown TL. Mental illness stigma and ethnocultural beliefs, values, and norms: An integrative review. Clin Psychol Rev. 2011;31:934-948. doi: 10.1016/j.cpr.2011.05.003. 
(13) Sartorius N, Schulze H. Reducing the stigma of mental illness: A report from a Global Programme of the World Psychiatric Association. Cambridge: Cambridge University Press; 2005.

(14) Corrigan P. Changing stigma through contact. Adv Schizophr Clin Psychiatr. 2005;1:54-58.

(15) Pescosolido BA, Martin JK, Lang A, Olafsdottir S. Rethinking theoretical approaches to stigma: a Framework Integrating Normative Influences on Stigma (FINIS) Soc Sci Med. 2008;67:431-440. doi: 10.1016/j.socscimed.2008.03.018.

(16) Pescosolido BA, Perry BL, Martin JK, McLeod JD, Jensen PS. Stigmatizing attitudes and beliefs about treatment and psychiatric medications for children with mental illness. Psychiatr Serv. 2007;58:613-618. doi: 10.1176/ps.2007.58.5.613.

(17) Crocker J, Major B, Steele C. Social stigma. In: Fiske S, Gilbert D, Lindzey G, editors. Handbook of Social Psychology. New York: McGraw-Hill; 1998.

(18) Link BG, Phelan JC. Conceptualizing stigma. Annu Rev Sociol. 2001;27:363385. doi: 10.1146/annurev.soc.27.1.363.

(19) Hinshaw SP, Stier A. Stigma as related to mental disorders. Annu Rev Clin Psychol. 2008;4:367-393. doi: 10.1146/annurev.clinpsy.4.022007.141245.

(20) Scambler G. Epilepsy, stigma and quality of life. Neurol Asia. 2011;16:35-36.

(21) Corrigan PW, Shapiro JR. Measuring the impact of programs that challenge the public stigma of mental illness. Clin Psychol Rev. 2010;30:907-922. doi: 10.1016/j.cpr.2010.06.004.

(22) Link B, Phelan J, Bresnahan M, Stueve A, Pescosolido B. Public conceptions of mental illness: Labels, causes, dangerousness and social distance. Am J Public Health. 1999;89:1328-1333. doi: 10.2105/AJPH.89.9.1328.

(23) Corrigan P, Markowitz FE, Watson A, Rowan D, Kubiak MA. An attribution model of public discrimination towards persons with mental illness. J Health Soc Behav. 2003;44:162-179. doi: 10.2307/1519806.

(24) Corrigan PW, Green A, Lundin R, Kubiak MA, Penn DL. Familiarity with and social distance from people who have serious mental illness. Psychiatr Serv. 2001;52:953-958. doi: 10.1176/appi.ps.52.7.953.

(25) Yamaguchi S, Wu SI, Biswas M, et al. Effects of short-term interventions to reduce mental health-related stigma in university or college students: a systematic review. J Nerv Ment Dis. 2013;201:490-503. doi: 10.1097/NMD.0b013e31829480df.

(26) Aronson E, Blaney N, Stephin C, Sikes J, Snapp M. The jigsaw classroom. Thousand Oaks CA: SAGE; 1978.

(27) Weigel RH, Wiser PL, Cook SW. The impact of cooperative learning experiences on cross-ethnic relations and attitudes. J Soc Issues. 1975;31:219244. doi: 10.1111/j.1540-4560.1975.tb00754.x. 
(28) Blanchard FA, Cook SW. Effects of helping a less competent member of a cooperating interracial group on the development of interpersonal attraction. J Pers Soc Psychol. 1976;34:1245-1255. doi: 10.1037/0022-3514.34.6.1245.

(29) Cook SW. Experimenting on social issues. The case of school desegregation. Am Psychol. 1985;40:452-460. doi: 10.1037/0003-066X.40.4.452.

(30) Stubbs A. Reducing mental illness stigma in health care students and professionals: a review of the literature. Australas Psychiatry. 2014;22:579584. doi: 10.1177/1039856214556324.

(31) Stull LG, McGrew JH, Salyers MP, Ashburn-Nardo L. Implicit and explicit stigma of mental illness: attitudes in an evidence-based practice. J Nerv Ment Dis. 2013;201:1072. doi: 10.1097/NMD.0000000000000056.

(32) Stier A, Hinshaw SP. Explicit and implicit stigma against individuals with mental illness. Aust Psychol. 2007;42:106-117. doi: 10.1080/00050060701280599.

(33) Rüsch N, Corrigan PW, Todd AR, Bodenhausen GV. Implicit self-stigma in people with mental illness. J Nerv Ment Dis. 2010;198:150-153. doi: 10.1097/NMD.0b013e3181cc43b5.

(34) Wang X, Huang X, Jackson T, Chen R. Components of implicit stigma against mental illness among Chinese students. PLOS ONE. 2012;7:46016. doi: 10.1371/journal.pone.0046016.

(35) O’Driscoll C, Heary C, Hennessy E, McKeague L. Explicit and implicit stigma towards peers with mental health problems in childhood and adolescence. J Child Psychol Psychiatry. 2012;53:1054-1062. doi: 10.1111/j.14697610.2012.02580.x.

(36) Dovidio J, Kawakami K, Johnson C, et al. On the nature of prejudice: Implicit and controlled processes. J Exp Soc Psychol. 1997;33:510-540. doi: 10.1006/jesp.1997.1331.

(37) Greenwald A, Banaji M. Implicit social cognition: Attitudes, self-esteem, and stereotypes. Psychol Rev. 1995;102:4-27. doi: 10.1037/0033-295X.102.1.4.

(38) Greenwald AG, McGhee DE, Schwartz JLK. Measuring individual differences in implicit cognition: the implicit association test. J Pers Soc Psychol. 1998;74:1464-1480. doi: 10.1037/0022-3514.74.6.1464.

(39) Charmaz K. Constructing grounded theory: a practical guide through qualitative analysis. Thousand Oaks CA: SAGE; 2006.

(40) Clarke DE, Dusome D, Hughes L. Emergency department from the mental health clients perspective. Int J Ment Health Nurs. 2007;16:126-131. doi: 10.1111/j.1447-0349.2007.00455.x.

(41) Wand T, Happell B. The mental health nurse: contributing to improved outcomes for patients in the emergency department. Int Emerg Nurs. 2001;9:166-176. doi: 10.1054/aaen.2000.0248. 
(42) Kleinman A, Kleinman J, Wang W-Z, et al. The social course of epilepsy: Chronic illness as social experience in interior China. Soc Sci Med. 1995;40:1319-1313. doi: 10.1016/0277-9536(94)00254-Q.

(43) Schneidre JW. Disability as moral experience: epilepsy and self in routine relationships. J Soc Issues. 1988;44:63-78. doi: 10.1111/j.15404560.1988.tb02049.x.

(44) Morse JM. The significance of saturation. Qual Health Res. 1995;5:147-149. doi: 10.1177/104973239500500201.

(45) Corrigan P. How stigma interferes with mental health care. Am Psychol. 2004;59:614-625. doi: 10.1037/0003-066X.59.7.614.

(46) Link BG, Phelan JC. Stigma and its public health implications. Lancet. 2006;367:528-529. doi: 10.1016/S0140-6736(06)68184-1.

(47) Farina A, Allen JG, Saul BBB. The role of the stigmatized person in affecting social relationships1. J Pers. 1968;36:169-182. doi: 10.1111/j.14676494.1968.tb01467.x.

(48) Wood AL. Deviant behavior and control strategies: Essays in sociology. Lexington MA: Lexington Books; 1974.

(49) Major B, O’Brien L. The Social Psychology of Stigma. Annu Rev Psychol. 2005;56:393-421. doi: 10.1146/annurev.psych.56.091103.070137.

(50) Biernat M, Dovidio JF, et al. Stigma and stereotypes. In: Heatherton TF, Kleck RE, Hebl MR, et al., editors. The social psychology of stigma. New York: Guilford Press; 2000. pp. 88-125.

(51) Stangor C, Crandall C, et al. Threat and the social construction of stigma. In: Heatherton TF, Kleck RE, Hebl MR, et al., editors. The social psychology of stigma. New York: Guilford Press; 2000. pp. 62-87.

(52) Neuberg SL, Smith DM, Asher T, et al. Why people stigmatize: toward a biocultural framework. In: Heatherton TF, Kleck RE, Hebl MR, et al., editors. The social psychology of stigma. New York: Guilford Press; 2000. pp. 31-61.

(53) Clarke D, Usick R, Sanderson A, Giles-Smith L, Baker J. Emergency department staff attitudes towards mental health consumers: A literature review and thematic content analysis. Int J Ment Health Nurs. 2014;23:273-284. doi: 10.1111/inm.12040.

(54) Johnston A, Abraham L, Greenslade J, Thom O, Carlstrom E, Wallis M, et al. Review article: staff perception of the emergency department working environment: integrative review of the literature. Emerg Med Australas. 2016;28:7-26. doi: 10.1111/1742-6723.12522.

(55) Person J, Spiva L, Hart P. The culture of an emergency department: an ethnographic study. Int Emerg Nurs. 2013;21:222-227. doi: 10.1016/j.ienj.2012.10.001.

(56) Crowley JJ. A clash of cultures: A\&E and mental health. Int Emerg Nurs. 2000;8:2-8. doi: 10.1054/aaen.1999.0061. 
(57) Karshmer JF, Hales A. Role of the psychiatric clinical nurse specialist in the emergency department. Clin Nurse Spec. 1997;11:264-268. doi:

10.1097/00002800-199711000-00012.

(58) Cross HA, Heijnders M, Dalal A, Sermrittirong S, Mak S. Interventions for stigma reduction - part 2: practical applications. Disabil CBR Incl Dev. 2012;22:71-80.

(59) Knaak S, Patten S. A grounded theory model for reducing stigma in health professionals in Canada. Acta Psychiatr Scand. 2016;134:53-62. doi: 10.1111/acps.12612. 



\section{CHAPTER 4 \\ The Idealized versus Actual Self: Exploring Responses to Feedback about Implicit Bias in Health Professionals}

Published as:

Sukhera, J., Milne, A., Teunissen, P.W., Lingard, L., Watling, C. The Actual Versus Idealized Self: Exploring Responses to Feedback About Implicit Bias in Health Professionals. Acad Med. 93(4) April 2018, p 623-629

(C) 2018 the Association of American Medical Colleges 


\begin{abstract}
Purpose: Implicit bias can adversely affect health disparities. The implicit association test (IAT) is a prompt to stimulate reflection; however, feedback about bias may trigger emotions that reduce the effectiveness of feedback interventions. Exploring how individuals process feedback about implicit bias may inform bias recognition and management curricula. The authors sought to explore how health professionals perceive the influence of the experience of taking the IAT and receiving their results.
\end{abstract}

Method: Using constructivist grounded theory methodology, the authors conducted semistructured interviews with 21 pediatric physicians and nurses at the Schulich School of Medicine and Dentistry, Western University, Ontario, Canada, from September 2015 to November 2016 after they completed the mental illness IAT and received their result. Data were analyzed using constant comparative procedures to work toward axial coding and development of an explanatory theory.

Results: When provided feedback about their implicit attitudes, participants described tensions between acceptance and justification, and between how IAT results relate to idealized and actual personal and professional identity. Participants acknowledged desire for change while accepting that change is difficult. Most participants described the experience of taking the IAT and receiving their result as positive, neutral, or interesting.

Conclusions: These findings contribute to emerging understandings of the relationship between emotions and feedback and may offer potential mediators to reconcile feedback that reveals discrepancies between an individual's actual and idealized identities. These results suggest that reflection informed by tensions between actual and aspirational aspects of professional identity may hold potential for implicit bias recognition and management curricula. 


\section{Introduction}

Implicit bias among health professionals may have adverse implications for the health of minority, underserved, and stigmatized populations. For example, implicitly held attitudes about certain groups can result in biased clinical decisions, ${ }^{1-3}$ erosion of trust due to poor interpersonal interactions, and biased behaviors that are perceived as discriminatory or prejudicial by patients and caregivers. ${ }^{4-6}$ In response to growing recognition that implicit attitudes influence behavior despite consciously formed goals, a nascent literature is emerging on strategies for implicit bias recognition and management in health professions education. Bias management strategies may involve enhancing internal motivation, confidence, and emo-

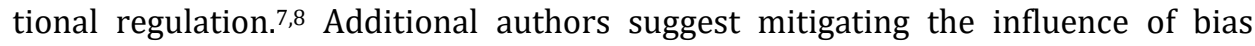
through improving perspective taking and empathy, ${ }^{7}$ identifying common group identities, promoting counterstereotypes, 9 and recognizing that the removal of all bias is impossible. ${ }^{10}$

Before implicit bias can be effectively managed, however, it must be made visible. Among the tools that can facilitate implicit bias recognition, the implicit association test (IAT) is an instrument that measures response time and can be completed online by individuals to measure their degree of implicit bias regarding a specific group or concept. Van Ryn and colleagues ${ }^{11}$ found that completing an IAT with feedback was a significant predictor of decreases in implicit bias. Other research has suggested that feedback through the IAT can facilitate an individual's awareness of their implicit attitudes. ${ }^{12-15}$ While the IAT is useful for revealing deeper biases that shape behavior outside of conscious awareness, there may be immediate defensive responses associated with bringing implicit bias into awareness. ${ }^{16}$

Several authors have described how confronting individuals with evidence that they are biased can incite a defensive response. ${ }^{17-19}$ For example, when individuals are provided with feedback about their implicit bias, participants respond by denigrating measures of implicit bias ${ }^{20,21}$ or avoiding feedback altogether. ${ }^{20}$ Using such strategies serves to maintain consciously formed egalitarian beliefs despite contrary factual evidence. ${ }^{19,22}$ Because these defenses can adversely affect internalization of feedback, ${ }^{20,23,24}$ more research is needed in this area. For example, if an individual is given feedback that demonstrates they hold negative bias toward a marginalized group, this may not align with their self-perception and consciously held beliefs. Because of this knowledge, learners may experience an emotional reaction that strongly influences subsequent efforts to leverage the IAT to foster future change. This resonates with research on feedback in health professions education, which highlights that when encountering negative feedback that is incongruent with self-perceptions of performance, physicians often disagree, experience negative emotional reactions, and have difficulty assimilating this information. ${ }^{25-27}$ In a series of studies, Sargeant and colleagues ${ }^{28}$ found that physicians who encountered such feedback experienced intense and long-lasting emotions, stimulating a call for 
facilitated reflection to reconcile challenging feedback. ${ }^{28-30} \mathrm{~A}$ central challenge related to feedback relates to the dilemma that those who need feedback the most may be the least receptive to it and find it the least useful. ${ }^{31}$ This issue is further compounded by the immense complexity and contextual variation related to feedback and self-assessment.

Unless we develop a sound understanding of how individuals process and integrate their IAT results, we cannot fully appreciate the potential of the IAT and its role in fostering bias management and personal and professional development in health professions education. We set out to study how health professionals perceive the experience of completing the IAT and receiving their results, as a prelude to better understanding the affordances and challenges of this novel educational approach.

\section{Method}

We used constructivist grounded theory methodology to explore the influence of promoting conscious awareness of implicit bias on health care professionals using interviews. Constructivism assumes that researchers and participants construct the realities in which they participate, and grounded theory is a method to learn about the worlds under study and develop theories to understand them. Constructivist grounded theory is well suited to explore a social process that is not currently explained by a well-established theoretical construct. ${ }^{32}$

We defined implicit bias as associations toward a specific social grouping that are outside of an individual's conscious awareness. ${ }^{33}$ More specifically, our study explored implicit dangerousness bias toward individuals with mental illness. To our knowledge, existing studies relating to implicit bias recognition and management have not explored implicit bias related to mental illness. We chose implicit dangerousness bias toward individuals with mental illness bias for our research, anticipating that implicit dangerousness bias might be a commonly arising issue that could adversely influence trusting relationships and clinical decisions.

The mental illness IAT is an online measure of response time that measures implicit associations between the concepts of physical illness and dangerousness versus mental illness and dangerousness. ${ }^{33}$ At the end of the test, participants receive a result that indicates they either hold no dangerousness bias related to mental or physical illness, or that they hold mild, moderate, or strong dangerousness bias. The mental illness IAT is available online to the public at Project Implicit (https://implicit.harvard.edu/implicit/user/pimh/index.jsp).

The IAT measures response time and latency and has typically demonstrated good internal consistency, ${ }^{34-37}$ insensitivity to procedural variation, ${ }^{33,38}$ high test-retest reliability, ${ }^{39}$ and significantly less susceptibility to faking compared with explicit measures such as surveys. ${ }^{40}$ Criticism of the IAT suggests that instead of 
reflecting authentic negative attitudes, IAT scores may stem from other associations such as victimization, maltreatment, and oppression. ${ }^{41-45}$

We invited pediatric physician and nurse participants at the Schulich School of Medicine and Dentistry, Western University, through recruitment notices posted internally and through electronic means to participate in 60 minute, semistructured, one-on-one interviews. Participants were informed that they would be part of a study exploring implicit bias and mental illness. We obtained approval from the Western University Research Ethics Board to conduct the study. Team member composition included the principal investigator (J.S.), a child and adolescent psychiatrist, faculty member, and PhD candidate in health professions education; as well as nursing staff (A.M.); and three experts in health professions education (C.W., L.L., and P.T.).

We initially chose the pediatric emergency department of an accredited Canadian academic health science center to explore health professional responses to feedback from the mental illness IAT. An emergency department is a useful setting to explore feedback about implicit bias due to the fast-paced nature of emergency practice. There is often considerable pressure on providers to make highstakes clinical decisions within limited time, ${ }^{46,47}$ and therefore the potential influence of implicit bias on patient-provider relationships and clinical decisions is more overt in this specific type of acute health care context. ${ }^{48-52}$ A pediatric setting provided a sample with an appropriate size and scope to conduct the study and begin the process of purposeful theoretical sampling while remaining open to recruiting additional participants.

During the first few interviews, participants were asked open-ended questions about the experience of taking the IAT, whether their results were expected/unexpected, and about the relationship between attitudes toward mental illness and implicit bias. We deliberately informed participants that they were not required to share their IAT results with us. This decision was motivated by the desire to foster a nonjudgmental interview and facilitate open discussion. We emphasized that we were interested in participants' interpretation of and reaction to their result, rather than the result itself.

In our analysis of the first interviews, however, we found a striking range of emotional reactions to the test itself, which we decided required further elaboration. In keeping with a purposeful theoretical sampling strategy, we expanded our recruitment and altered our interview approach to elaborate perspectives on the IAT experience more fully. We broadened our sample to include physicians and nurses who worked outside of the emergency department but still worked in pediatric inpatient and outpatient settings. We chose to expand beyond an emergency setting to consider responses in different clinical contexts with less acuity, but remained restricted to pediatric providers to continue our exploration within a similar social grouping of health professionals.

Interviews were conducted from September 2015 to November 2016 and followed a discussion guide developed from an initial literature review. The discus- 
sion guide was adapted iteratively as the study proceeded in accordance with a constructivist grounded theory approach (the final version is available in Supplemental Digital Appendix 1 at http://links.lww.com/ACADMED/A504).32 We initially explored participants' understanding of their implicit attitudes about mental illness and responses to the IAT results. Our next interviews expanded to explore more about emotions and cognition both during the administration of the test and the presentation of the result. Discussion expanded to include questions relating to perspective change and whether changing implicit attitudes and associated behaviors was possible and how to achieve it. Each participant was assigned a number based on which stakeholder group they belong to.

Once transcribed, coding and analysis was conducted by a team consisting of J.S. and A.M., beginning with line-by-line coding by J.S. and using constant comparative analysis to develop focused codes and working toward major themes. Key themes were shared with the entire team as analysis shifted to relating codes and categories to one another and the development of an explanatory theory that accounted for possible relationships between themes. Data collection continued until the authors felt that sufficient data had been collected to enable a coherent and logical conceptual understanding of the process under study. ${ }^{53}$ A synthesis of results was shared in writing with a representative group of participants to ensure that the results were consistent with the research questions and their experience and perspectives.

\section{Results}

To achieve adequate elaboration of the core thematic patterns we identified, we completed a total of 21 interviews with 10 nurse and 11 physician participants. Four of 21 participants (19\%) were male, and 17/21 participants (81\%) were female. Although they were not required to reveal their IAT results, 15/21 (71\%) participants shared that their result demonstrated implicit dangerousness bias toward mental illness. Six of 11 physician participants and 2/10 nurse participants classified their results as being what they expected, while 4/11 physicians and $7 / 10$ nurses classified their results as being unexpected. Nine of $11(81 \%)$ of those with an unexpected result also acknowledged that their result demonstrated implicit dangerousness bias toward mental illness. Nineteen of 21 participants $(90 \%)$ described the experience of taking the IAT as positive, neutral, or interesting, while only $1 / 21$ described the experience as negative.

\section{Acceptance versus justification}

Most participants justified or rationalized their results as being due to experience. They described how external influences in both personal and professional domains 
shaped their implicitly held beliefs over time. One participant who was given a result that described implicit dangerousness bias suggested that their bias is a natural result of experiencing violent patients in their work as a pediatric emergency physician:

Well, for sure, it affects how I treat people. I mean, the 12-year-old kid who comes in snarling at me, spitting at me, lunging at me to bite me, because she has anxiety, depression, et cetera and that's her way of acting out, is just going to elicit a different response from me than the 12-year-old who is sitting there, you know, cooperative for the exam and has a pneumonia or whatever. It's just a different ... you react to how you're getting treated. (MD4)

Participants described a continuum of responses ranging from acknowledging their result to accepting it, criticizing it, and denying it. While some participants were generally quite accepting that they held implicit dangerousness bias in congruence with their IAT result, some participants were more critical and denied the validity of their result. Denial and criticism of the IAT were more prominent among individuals who had "unexpected" results. Some participants described the IAT as "silly" and suggested that the test was not helpful (MD5) or accurate (MD1). One nurse stated:

No, like I know who I am and that's not going to impact anything about me. (RN9)

\section{Idealized versus actual personal and professional identity}

There was a prominent sense of tension in responses to the IAT across all groups. Tension was more evident in participants who had unexpected results. In addition to the tension between acceptance and justification, two additional tensions emerged: the difference between participants' actual and ideal self-perceptions, and the difference between attitudes demonstrated in personal versus professional contexts.

Many participants shared that they were unhappy with their IAT result because it was not consistent with their self-perceptions. Some of these participants described being disappointed and seemed to accept their result while struggling with what their result meant for their desired self-image. Others suggested that while they found the test "disturbing," their experience "opened some ideas" and caused them to examine some of their "deepest feelings" (RN4). Another acknowledged that they know themselves yet simultaneously acknowledged that they might have negative attitudes toward individuals who are not compliant with their medications (RN3). One participant shared that the result conflicted with a "fantasy" of themselves:

Everyone has expectations, right? And everyone has sort of this fantasy of themselves and they always think, you know, maybe they should be better or 
they are better than they are, right? In reality they're aspiring to a higher state of being. (MD8)

Others shared how the experience of the test highlighted the discrepancy between personal and professional contexts. Specific IAT questions about encountering individuals with mental illness outside of a hospital setting provoked reflection and discussion about the differences between personal and professional experiences, attitudes, and behaviors. Some participants expressed that as a physician or nurse, they are expected not to demonstrate bias and that biased attitudes and behaviors are inconsistent with their professional identity:

I just feel like I'm fairly open-minded and eager to learn. I don't want to find myself seeing people and prejudging. It's not a role that I think is healthy in my own personal life, and I know it's not a healthy role in the work that I do. (RN8)

If I think where I am coming from and how I was raised and now I am a physician, I am sure that I try very hard not to be biased. (MD9)

In contrast with professional identity, most participants acknowledged that their implicit bias was influenced by their personal life experiences and relationships. One participant suggested that they were more "closed" to mental illness because of personal experiences with loved ones who have suffered (MD11). Another suggested that they have actively engaged in egalitarian activities in their personal lives in response to an upbringing that may have fostered implicit bias (MD9). A nurse participant who acknowledged that their result showed a "moderate" degree of implicit dangerousness bias stated that they would not let their children play on the sidewalk if there was a mentally ill patient who lived on their street (RN1). Another acknowledged that after having children, they were more conscious of individuals with mental illness in public and that they would not fear for their own safety, but that of their child (RN4):

In order for me to be a good nurse, to be a good advocate, it's important for me to examine my deepest darkest feelings of mental illness ... there is a part of me having worked in the emergency department that knows that there are people with mental illnesses who could be aggressive and dangerous. You know what I mean it's hard, because I want to say of course I would let her [my daughter] walk by [people with mental illness] and I mean people with a broken leg or whatever could be aggressive and dangerous and things like that. So yeah so there you go. (RN4)

\section{Desire to change, while acknowledging that change is difficult}

When discussing the influence of their IAT result on future attitudes, most participants felt that changing implicit attitudes was necessary but difficult. Several par- 
ticipants suggested that implicit biases about mental illness have become "embedded" through experience and were therefore difficult to overcome:

And part of the unconscious part of it is also, like personally like what you've grown up seeing, hearing, you know that kind of gets embedded in it, and I think to overcome that you have to be very active and diligent about it. I think it's very hard because, especially if you've had 25 years, right, from a physician's perspective before you start training, so to deconstruct all those stigmas, I mean that takes a while, and it has to be done, you have to actively seek it out and do it. (MD1)

Sometimes a certain way of thinking becomes so engrained in our mind and psyches that we don't question it, you see, and that's the dangerous bit ... when we become so engrained in something that we think this is the only right way ... therefore I'm doing it right and my attitude is right and my opinion is the right one and not be willing to change and to, you know, to reconsider your norms, your standards, your values, your beliefs. (MD8)

Changing implicit attitudes was not something participants described as being easily accomplished:

I think there has to be a strong drive to want it to change... I think there has to be an openness and a willingness to address the fact that you do have them [biases] and that you understand that they might be wrong. And then I don't know how you would go about changing them but I think addressing them or sort of acknowledging that they're there and that it's a problem is probably the first step. (MD11)

Some suggested that bringing implicit attitudes into conscious awareness was the first step which could trigger "constant self-feedback and self-evaluation" (MD8) and that openness to express their feelings would facilitate improved reflection and self-awareness (MD10). Several participants described the experience as positive and a worthwhile endeavor, as one comment illustrates:

It was a little shocking to me... It was disturbing, because it opened up some ideas about myself that I don't like to think that are there ... So it was very good, it is really worthwhile, because it causes you [to] examine some of your deepest feelings and some of the things that you don't perhaps like to recognize about yourself. (RN4) 
Figure 1

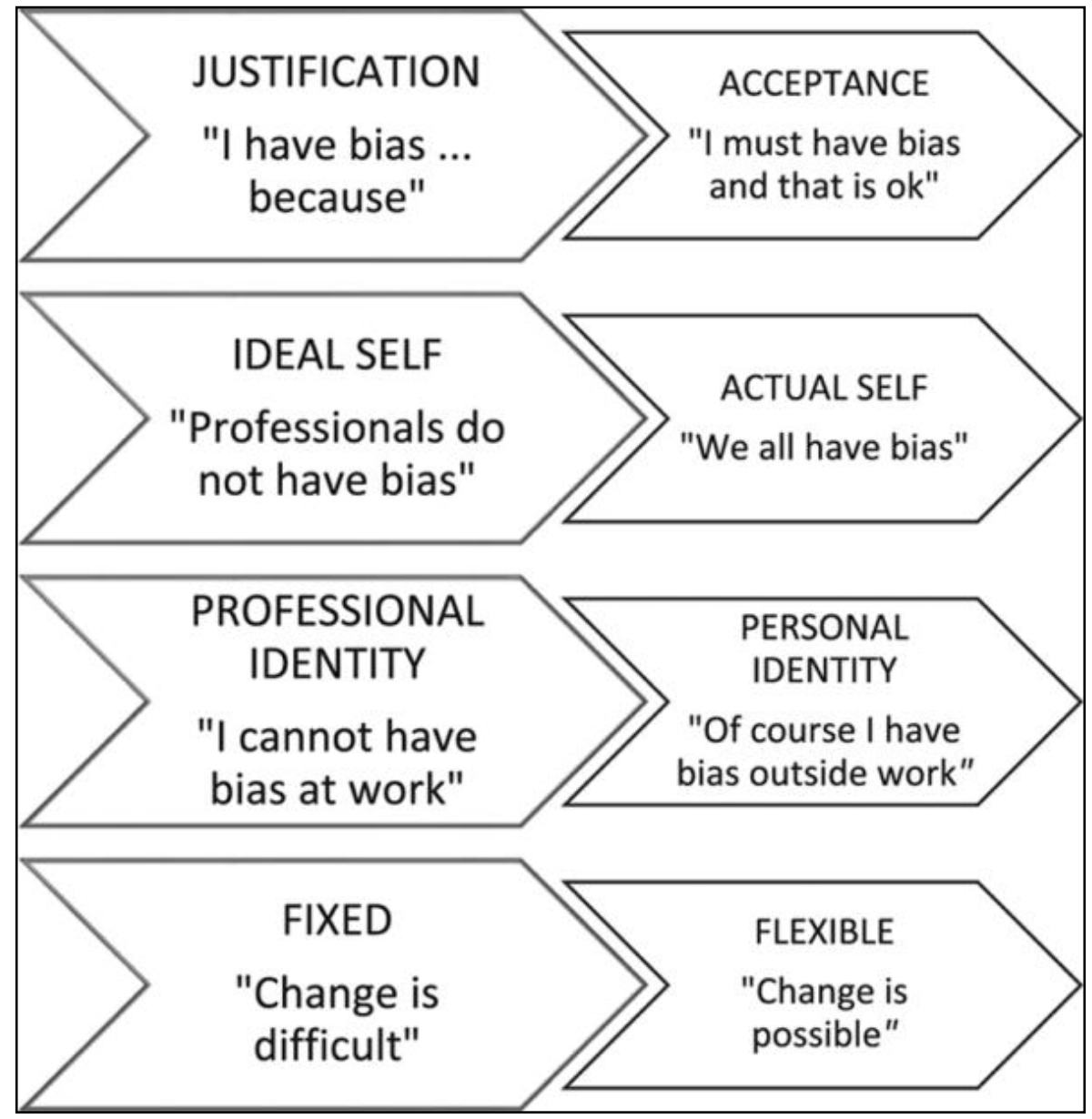

Figure 1. Participants' responses to receiving results of the implicit association test for mental illness, demonstrating tensions between justification and acceptance, idealized and actual self-perceptions, personal and professional identity, and the idea that individual biases are fixed versus flexible. From a study of responses to feedback regarding implicit bias in pediatric health care professionals, Schulich School of Medicine and Dentistry, Western University, Ontario, Canada, 2015-2016. 


\section{Discussion}

The multiple tensions identified in our analysis of health professionals' responses to IAT results resonate with existing literature on methods to facilitate the acceptance and integration of emotionally charged feedback. Figure 1 provides a visual depiction of our key findings. Our findings provide insights relating to personal and professional identity that merit further discussion.

\section{Difficult and emotional nature of IAT feedback}

Kluger and Denisi's ${ }^{54}$ feedback intervention theory emphasizes that the effectiveness of any feedback intervention depends on the level (task learning, task motivation, or self) at which the intervention focuses our attention. In accordance with Kluger and Denisi's hierarchy principle, if the feedback intervention addresses high-level processes related to the learners' beliefs about themselves, this may produce a strong emotional reaction such as despair, disappointment, or elation that interferes with task performance. ${ }^{55-59}$ The work of Sargeant and others ${ }^{28}$ suggests that, when discerning whether feedback is negative or positive, physicians compare this feedback with global self-perceptions of performance. Because we know that any feedback information about the "self" is emotionally charged and being objective about it is difficult, ${ }^{60}$ reactions to negative feedback are influenced by perceptions of accuracy and credibility of data and usefulness of feedback. Feedback leads to shame when the recipient internalizes negative evaluation of self and shamed individuals feel inferior and defective.61,62 While existing literature on feedback at the self level would suggest that the IAT may be a particularly challenging tool to provide feedback information, our participants largely engaged with and reflected on their IAT results.

Our participants expressed tension between accepting their bias and justifying attitudes that are embedded through experience. Our participants wanted to believe that they did not hold implicit dangerousness bias; however, they struggled with accepting feedback that conflicted with the professional they wished to be. Unlike previous research that has demonstrated tension when negative feedback does not align with self-appraisal, our participants were challenged with feedback that created tension between their actual and aspirational identities.

\section{Unique findings from IAT provide insights on how to manage reaction to negative feedback}

Existing research suggests that emotional reactions to charged feedback need to be managed through guidance and facilitation. Facilitated reflection can contribute to assimilation and acceptance of negative and emotionally charged feedback. ${ }^{29} \mathrm{Re}-$ flection can facilitate the difficult process of reconciling tensions within one's self 
through explicit recognition of the emotional aspect of receiving feedback and the difficulty of reconciling self-appraisal with contradictory feedback. ${ }^{63}$

While participants' responses did not specifically mention guided reflection, the finding of prominent tension related to actual and idealized professional identity provides guidance on how to inform facilitated reflection related to challenging or emotional feedback. Feedback about an individual's implicit bias is an opportunity to explore how health professionals negotiate and navigate information discordant with a fantasy version of themselves as free from prejudice and stereotyping. Health professional identity views bias and stereotyping as antithetical to the values that comprise the "ideal" health professional.64-66 Indeed, many of our participants described aspiration toward a "fantasy" of themselves as a "higher state of being," as informing their responses to IAT feedback. Further research is needed to define how health professionals reconcile feedback information discordant from the idealized and unattainable aspects of their professional identity.

\section{Openness to change is challenging but possible}

Despite the challenges related to implicit bias recognition, we were struck that only 1 out of our 21 participants found the experience of receiving IAT results to be negative. This finding contrasts with literature on negative and emotional feedback related to the self. We anticipated that more participants would have identified the IAT as distressing or unpleasant. While our sample size was limited, there may be several explanations for this finding that have implications for future research.

Among the many variables associated with feedback such as task nature, source, context, complexity, or form, ${ }^{67}$ credibility is often a key factor in determining whether feedback is influential. ${ }^{31,68}$ Our study provided feedback through a computer-based test with a simple message; however, we also immediately provided an opportunity for reflection through a qualitative interview designed to foster open disclosure by a researcher who was explicitly focused on creating a nonjudgmental setting to explore participant responses. Several of our interviews reflected a developmental trajectory from denial to defense, minimization, and eventually acceptance, which has been previously described in the literature. ${ }^{8}$

Another possibility is that participants were influenced by social desirability bias. ${ }^{69}$ We found that participant responses reflected a desire to conform with an ideal professional identity. Given the taboo associated with prejudice and bias, there may have been a tendency to appear reflective and accepting of feedback while minimizing defenses. Further research that focuses on how attributes of the feedback source relate to the personal and professional identities of all parties involved in feedback conversations may help elaborate on these possibilities. Perhaps our participants noted that change was possible in the presence of the interviewer, yet did not integrate the feedback information into future behavioral change. Further longitudinal data may also improve our understanding of how feedback related to implicit biases changes over time. 


\section{The role of the IAT and controversies regarding its use}

Our findings regarding the use of the IAT should be interpreted in the context of mixed views regarding its use and the issue of implicit bias. Critics suggest that an online IAT does not demonstrate an accurate or authentic representation of individually held biases..$^{70}$ The IAT can only measure relative associations and is not a definite measure of implicit biases. ${ }^{71}$ For example, our participants were given a measure of their associations between "dangerousness" relative to mental or physical illness, whereas the concept of mental illness has multiple nuances and groups several distinct illness categories into a broad sweeping generalization. While some have proposed the implicit relational assessment procedure (IRAP) as a tool to address flaws in the IAT, the IRAP is strongly influenced by how tasks are framed to participants, and newer procedures are emerging in the social psychology literature. ${ }^{72}$

Despite these critiques, we did not use the IAT as a definitive metric but, rather, as a tool to prompt reflection and discussion. Therefore, we believe that our study emphasizes that there is potential for the IAT to provide a window into individual biases to facilitate change. As assessment science progresses toward advanced measures of implicit bias, our findings may therefore further the application of implicit bias recognition and management to health professions curricula. Although other types of negative feedback have been found to be perceived as unnecessarily confrontational or challenging, our study demonstrates the potential for feedback related to implicit bias to inform further research and exploration on promoting acceptance and integration of emotionally laden feedback.

\section{Limitations}

Because we explicitly informed participants to not reveal their IAT results, this raised the possibility that our participants were given information that they either had implicit dangerousness bias or did not. We reconciled this information by coding our transcripts according to what participants shared regarding whether they found their results to be expected or unexpected, and conducting a supplemental analysis that confirmed that most participants received an IAT result that revealed implicit dangerousness bias. Further, there is some controversy regarding the use of the IAT and whether results represent authentic biases or associations from experience that are shaped by forces such as victimization or oppression. Our study also drew exclusively from a limited pediatric sample, and we acknowledge that there may be aspects of the professional identity of pediatricians that uniquely contributed to our results. Also, the demographic breakdown of our sample included a limited number of male participants, and therefore further exploration of our findings with demographically diverse participants and medical specialties is needed for the future. 


\section{Conclusions}

Health professionals' responses to feedback about their implicit bias reveals insights related to the processing and integration of emotionally charged feedback information that creates tension between actual and ideal professional identity. Reconciling this tension and reflecting on IAT results offers a promising approach to incorporate implicit bias recognition and management into health professions education.

\section{Acknowledgments}

The authors would like to acknowledge first and foremost the study participants. Further acknowledgments include Rod Lim, Paul Atkison, Alicia Cooper, Christina Scerbo, and Kristina Miller for their support related to this work. 


\section{References}

(1) Green AR, Carney DR, Pallin DJ, et al. Implicit bias among physicians and its prediction of thrombolysis decisions for black and white patients. J Gen Intern Med. 2007;22:1231-1238.

(2) Sabin JA, Greenwald AG. The influence of implicit bias on treatment recommendations for 4 common pediatric conditions: Pain, urinary tract infection, attention deficit hyperactivity disorder, and asthma. Am J Public Health. 2012;102:988-995.

(3) Chapman EN, Kaatz A, Carnes M. Physicians and implicit bias: How doctors may unwittingly perpetuate health care disparities. J Gen Intern Med. 2013;28:1504-1510.

(4) Dovidio JF, Kawakami K, Gaertner SL. Implicit and explicit prejudice and interracial interaction. J Pers Soc Psychol. 2002;82:62-68.

(5) Fazio RH, Jackson JR, Dunton BC, Williams CJ. Variability in automatic activation as an unobtrusive measure of racial attitudes: A bona fide pipeline? J Pers Soc Psychol. 1995;69:1013-1027.

(6) Sukhera J, Miller K, Milne A, et al. Labelling of mental illness in a paediatric emergency department and its implications for stigma reduction education. Perspect Med Educ. 2017;6:165-172.

(7) Burgess D, van Ryn M, Dovidio J, Saha S. Reducing racial bias among health care providers: Lessons from social-cognitive psychology. J Gen Intern Med. 2007;22:882-887.

(8) Teal CR, Gill AC, Green AR, Crandall S. Helping medical learners recognise and manage unconscious bias toward certain patient groups. Med Educ. 2012;46:80-88.

(9) Stone J, Moskowitz GB. Non-conscious bias in medical decision making: What can be done to reduce it? Med Educ. 2011;45:768-776.

(10) Burgess DJ, Fu SS, van Ryn M. Why do providers contribute to disparities and what can be done about it? J Gen Intern Med. 2004;19:1154-1159.

(11) van Ryn M, Hardeman R, Phelan SM, et al. Medical school experiences associated with change in implicit racial bias among 3547 students: A Medical Student CHANGES Study report. J Gen Intern Med. 2015;30:1748-1756.

(12) Boysen GA. Integrating implicit bias into counselor education. Couns Educ Superv. 2010;49:210-227.

(13) Hillard AL, Ryan CS, Gervais SJ. Reactions to the implicit association test as an educational tool: A mixed methods study. Soc Psychol Educ. 2013;16:495516.

(14) Jackson SM, Hillard AL, Schneider TR. Using implicit bias training to improve attitudes toward women in STEM. Soc Psychol Educ. 2014;17:419-438. 
(15) Morris KA, Ashburn-Nardo L. The Implicit Association Test as a class assignment: Student affective and attitudinal reactions. Teach Psychol. 2009;37:6368.

(16) Teal CR, Shada RE, Gill AC, et al. When best intentions aren't enough: Helping medical students develop strategies for managing bias about patients. J Gen Intern Med. 2010;25(suppl 2):S115-S118.

(17) Frantz CM, Cuddy AJ, Burnett M, Ray H, Hart A. A threat in the computer: The race implicit association test as a stereotype threat experience. Pers Soc Psychol Bull. 2004;30:1611-1624.

(18) Monteith MJ, Voils CI, Ashburn-Nardo L. Taking a look underground: Detecting, interpreting, and reacting to implicit racial biases. Soc Cogn. 2001;19:395417.

(19) O’Brien LT, Crandall CS, Horstman-Reser A, Warner R, Alsbrooks A, Blodorn A. But I'm no bigot: How prejudiced white Americans maintain unprejudiced selfimages. J Appl Soc Psychol. 2010;40:917-946.

(20) Howell J, Ratliff K. Implicit-Explicit Attitude Discrepancy Prompts Defensive Responding to IAT Feedback [doctoral dissertation]. 2014.Gainesville, FL: University of Florida

(21) Howell JL, Gaither SE, Ratliff KA. Caught in the middle: Defensive responses to IAT feedback among whites, blacks, and biracial black/whites. Soc Psychol Personal Sci. 2015;6:373-381.

(22) Crandall CS, Eshleman A, O’Brien L. Social norms and the expression and suppression of prejudice: The struggle for internalization. J Pers Soc Psychol. 2002;82:359-378.

(23) Epton T, Harris PR, Kane R, van Koningsbruggen GM, Sheeran P. The impact of self-affirmation on health-behavior change: A meta-analysis. Health Psychol. 2015;34:187-196.

(24) Sherman DK, Cohen GL. The psychology of self-defense: Self-affirmation theory. Adv Exp Soc Psychol. 2006;38:183-242.

(25) Fidler H, Lockyer JM, Toews J, Violato C. Changing physicians' practices: The effect of individual feedback. Acad Med. 1999;74:702-714.

(26) Lockyer J, Violato C, Fidler H. Likelihood of change: A study assessing surgeon use of multisource feedback data. Teach Learn Med. 2003;15:168-174.

(27) Bennett H, Gatrell J, Packham R. Medical appraisal: Collecting evidence of performance through 360 feedback. Clin Manag. 2004;12:165-172.

(28) Sargeant J, Mann K, Sinclair D, Van der Vleuten C, Metsemakers J. Understanding the influence of emotions and reflection upon multi-source feedback acceptance and use. Adv Health Sci Educ Theory Pract. 2008;13:275-288.

(29) Sargeant JM, Mann KV, van der Vleuten CP, Metsemakers JF. Reflection: A link between receiving and using assessment feedback. Adv Health Sci Educ Theory Pract. 2009;14:399-410. 
(30) Sargeant J, McNaughton E, Mercer S, Murphy D, Sullivan P, Bruce DA. Providing feedback: Exploring a model (emotion, content, outcomes) for facilitating multisource feedback. Med Teach. 2011;33:744-749.

(31) Watling CJ, Lingard L. Toward meaningful evaluation of medical trainees: The influence of participants' perceptions of the process. Adv Health Sci Educ Theory Pract. 2012;17:183-194.

(32) Charmaz K. Constructing Grounded Theory: A Practical Guide Through Qualitative Research. 2006.London, UK: Sage Publications Ltd.

(33) Greenwald AG, McGhee DE, Schwartz JL. Measuring individual differences in implicit cognition: The implicit association test. J Pers Soc Psychol. 1998;74:1464-1480.

(34) Bosson JK, Swann WB Jr, Pennebaker JW. Stalking the perfect measure of implicit self-esteem: The blind men and the elephant revisited? J Pers Soc Psychol. 2000;79:631-643.

(35) Dasgupta N, McGhee DE, Greenwald AG, Banaji MR. Automatic preference for white Americans: Eliminating the familiarity explanation. J Exp Soc Psychol. 2000;36:316-328.

(36) Greenwald AG, Nosek BA, Banaji MR. Understanding and using the implicit association test: I. An improved scoring algorithm. J Pers Soc Psychol. 2003;85:197-216.

(37) Greenwald AG, Farnham SD. Using the implicit association test to measure selfesteem and self-concept. J Pers Soc Psychol. 2000;79:1022-1038.

(38) Nosek BA, Greenwald AG, Banaji MR. Understanding and using the Implicit Association Test: II. Method variables and construct validity. Pers Soc Psychol Bull. 2005;31:166-180.

(39) Nosek BA, Greenwald AG, Banaji MR. The Implicit Association Test at age 7: A methodological and conceptual review. Autom Process Soc Think Behav. January 2007:265-292.

(40) Steffens MC. Is the implicit association test immune to faking? Exp Psychol. 2004;51:165-179.

(41) Blanton H, Jaccard J, Christie C, Gonzales PM. Plausible assumptions, questionable assumptions and post hoc rationalizations: Will the real IAT, please stand up? J Exp Soc Psychol. 2007;43:399-409.

(42) Andreychik MR, Gill MJ. Do negative implicit associations indicate negative attitudes? Social explanations moderate whether ostensible "negative" associations are prejudice-based or empathy-based. J Exp Soc Psychol. 2012;48:1082-1093.

(43) Banaji MR, Nosek BA, Greenwald AG. No place for nostalgia in science: A response to Arkes and Tetlock. Psychol Inq. 2004;15:279-289. 
(44) Uhlmann EL, Brescoll VL, Paluck EL. Are members of low status groups perceived as bad, or badly off? Egalitarian negative associations and automatic prejudice. J Exp Soc Psychol. 2006;42:491-499.

(45) Nosek BA, Hansen JJ. The associations in our heads belong to us: Searching for attitudes and knowledge in implicit evaluation. Cogn Emot. 2008;22:553-594.

(46) Thompson C, Dalgleish L, Bucknall T, et al. The effects of time pressure and experience on nurses' risk assessment decisions: A signal detection analysis. Nurs Res. 2008;57:302-311.

(47) Gunnarsson BM, Warrén Stomberg M. Factors influencing decision making among ambulance nurses in emergency care situations. Int Emerg Nurs. 2009;17:83-89.

(48) Chen EH, Shofer FS, Dean AJ, et al. Gender disparity in analgesic treatment of emergency department patients with acute abdominal pain. Acad Emerg Med. 2008;15:414-418.

(49) Cone DC, Richardson LD, Todd KH, Betancourt JR, Lowe RA. Health care disparities in emergency medicine. Acad Emerg Med. 2003;10:1176-1183.

(50) Beach C, Croskerry P, Shapiro M; Center for Safety in Emergency Care. Profiles in patient safety: Emergency care transitions. Acad Emerg Med. 2003;10:364367.

(51) Croskerry P. Cognitive forcing strategies in clinical decisionmaking. Ann Emerg Med. 2003;41:110-120.

(52) Lehmann JB, Wehner PS, Lehmann CU, Savory LM. Gender bias in the evaluation of chest pain in the emergency department. Am J Cardiol. 1996;77:641644.

(53) Morse JM. The Significance of Saturation. 1995.Thousand Oaks, CA: Sage Publications

(54) Kluger AN, Denisi AS. The effects of feedback interventions on performance: A historical review, a meta-analysis and a preliminary feedback intervention theory. Psychol Bull. 1994;119:254-284.

(55) Carver CS, Scheier MF. Origins and functions of positive and negative affect: A control-process view. Psychol Rev. 1990;97:19.

(56) Brett JF, Atwater LE. 360 degree feedback: Accuracy, reactions, and perceptions of usefulness. J Appl Psychol. 2001;86:930-942.

(57) Atwater LE, Waldman DA, Brett JF. Understanding and optimizing multisource feedback. Hum Resour Manage. 2002;41:193-208.

(58) Smither JW, London M, Reilly RR. Does performance improve following multisource feedback? A theoretical model, meta-analysis, and review of empirical findings. Pers Psychol. 2005;58:33-66.

(59) Eva KW, Armson H, Holmboe E, et al. Factors influencing responsiveness to feedback: On the interplay between fear, confidence, and reasoning processes. Adv Health Sci Educ Theory Pract. 2012;17:15-26. 
(60) Ashford SJ, Blatt R, Walle DV. Reflections on the looking glass: A review of research on feedback-seeking behavior in organizations. J Manag. 2003;29:773799.

(61) Bynum WE 4th.. Filling the feedback gap: The unrecognised roles of shame and guilt in the feedback cycle. Med Educ. 2015;49:644-647.

(62) Tangney JP. Conceptual and methodological issues in the assessment of shame and guilt. Behav Res Ther. 1996;34:741-754.

(63) Mann K, van der Vleuten C, Eva K, et al. Tensions in informed self-assessment: How the desire for feedback and reticence to collect and use it can conflict. Acad Med. 2011;86:1120-1127.

(64) Notzer N, Soffer S, Aronson M. Traits of the "ideal physician" as perceived by medical students and faculty. Med Teach. 1988;10:181-189.

(65) Arkes HR, Tetlock PE. Attributions of implicit prejudice, or "would Jesse Jackson 'fail' the Implicit Association Test?" Psychol Inq. 2004;15:257-278.

(66) Westgate E, Riskind R, Nosek B. Implicit preferences for straight people over lesbian women and gay men weakened from 2006 to 2013. Collabra Psychol. 2015;1:1-10.

(67) van de Ridder JM, McGaghie WC, Stokking KM, ten Cate OT. Variables that affect the process and outcome of feedback, relevant for medical training: A meta-review. Med Educ. 2015;49:658-673.

(68) Watling C, Driessen E, van der Vleuten CP, Vanstone M, Lingard L. Beyond individualism: Professional culture and its influence on feedback. Med Educ. 2013;47:585-594.

(69) Nederhof AJ. Methods of coping with social desirability bias: A review. Eur J Soc Psychol. 1985;15:263-280.

(70) Singal J. Psychology's favorite tool for measuring racism isn't up to the job. N Y Mag. January 11, 2017. http://nymag.com/scienceofus/2017/01/psychologys-racismmeasuring-tool-isnt-up-to-the-job.html. Accessed October 29, 2017.

(71) Blanton H, Jaccard J. Arbitrary metrics in psychology. Am Psychol. 2006;61:27-41.

(72) O'Shea B, Watson DG, Brown GD. Measuring implicit attitudes: A positive framing bias flaw in the Implicit Relational Assessment Procedure (IRAP). Psychol Assess. 2016;28:158-170. 



\section{CHAPTER 5 Exploring the Influence of Feedback about Implicit Bias in Mental Health Professionals}




\begin{abstract}
Introduction: One of the prominent challenges related to feedback and health professions education is that feedback information related to self that is emotionally charged may be dismissed or denied, diminishing its potential usefulness. Little research has examined how to address feedback that threatens an individual's identity. The implicit association test provides feedback to individuals regarding their implicit biases. Anticipating that feedback about implicit bias might be potentially emotionally charged or identity-threatening for mental health professionals, we explored their experience of taking the implicit association test and receiving their results. In so doing, we hoped to gain a better understanding of the challenges of identity-threatening feedback.
\end{abstract}

Methods: We utilized a constructivist grounded theory approach and conducted semi-structured interviews with psychiatric residents, physicians and nurses $(n=32)$ after they completed the mental illness IAT and received their result.

Results: While participants critiqued the IAT and questioned its credibility, they also described the experience of receiving feedback about their implicit biases as positive or neutral. Most justified their implicit biases but also described motivation to better manage them.

Conclusions: Our study highlights a feedback paradox, calling into question assumptions regarding self-related feedback in the literature. Our participants' reactions to the IAT suggest that potentially threatening self-related feedback may still be useful to participants who question its credibility.

\title{
Submitted for publication:
}

Sukhera, J., Wodzinski, M., Milne, A., Teunissen, P.W., Lingard, L., Watling, C., Exploring the Influence of Feedback about Implicit Bias with Mental Health Professionals. Academic Medicine, July 13, 2018 


\section{Introduction}

Feedback in health professions education is fraught with multiple tensions. Often the most challenging feedback information is disconfirming to self-perceptions, leading recipients to react unfavorably and limiting the usefulness of such information $^{1-7}$. Negative performance feedback viewed as personal information is often difficult to reconcile and may potentially hurt an individual's self-esteem and pride 8. Such self-related feedback may also produce strong emotions such as disappointment or despair ${ }^{9-11}$, which may be internalized as guilt or shame ${ }^{12}$, and interfere with task performance ${ }^{13}$. Several authors propose reconciling emotionally charged feedback information through nurturing self-monitoring, reflection and an iterative process of feedback-mediated change, ${ }^{14-17}$ facilitated through discussion 18,19 .

Among the most emotionally challenging feedback relates to how individuals view themselves and their group identity. Since being a good doctor appears central to the self-concept of physicians, any feedback information that threatens this ideal is difficult to reconcile ${ }^{20}$. Recent research regarding implicit-bias related feedback also found that providing physicians and nurses with feedback information regarding their implicit biases could conflict with an idealized version of their professional identity ${ }^{21}$. Feedback regarding an individual's negative implicit biases can provoke defensiveness ${ }^{22-24}$ leading recipients to avoid feedback altogether ${ }^{25}$.

Identity related feedback may also influence perceptual judgments about the credibility of feedback information ${ }^{26}$ and certain groups may be more vigilant to subtle cues that threaten their social identity ${ }^{27}$. Social identity also contributes to stereotype threat when individuals experience unease related to confirming a negative stereotype about their group ${ }^{28}$. Payne \& Hysong found that the intense emotions associated with clinical feedback for physicians often emanated from the assessment process itself, rather than solely feedback information ${ }^{29}$. Multiple contextual, socio-cultural and identity related variables therefore influence feedback acceptance, and perceived need for practice and behaviour change once feedback is received. Certain circumstances, such as when discussing racial biases or professional misconduct, pose a challenge because self-related feedback information cannot be uncoupled from performance related information. An exploration of the relationship between identity and feedback may yield useful insights to address this challenge.

An example of a group where feedback and identity intersect involves providing feedback related to stigmatizing attitudes about individuals with mental illness to mental health professionals. Such professionals may still hold implicitly negative attitudes towards individuals with mental illness ${ }^{30}$ that have a negative impact on care despite best intentions ${ }^{31}$. In several reviews, views of mental health profes- 
sionals about individuals with mental illness did not differ greatly from the general population ${ }^{32-35}$. We chose to explore how mental health professionals process feedback about their implicit biases related to mental illness because their identity includes destigmatizing as part of their role and we anticipated that feedback about such implicit biases may be especially challenging for these individuals.

An investigation of how mental health professionals perceive the influence of receiving implicit-bias related feedback may therefore provide a deeper understanding of how to recognize and manage self-related feedback. Our study endeavored to explore how mental health professionals process and integrate feedback about implicit bias that be perceived as threatening.

\section{Methods}

For the purposes of this study we defined implicit bias as associations, attitudes or beliefs that exist and enact their influence outside of an individual's conscious awareness ${ }^{36}$. We defined feedback information as data from a computer-based test related to an individual's implicit bias.

We utilized constructivist grounded theory ${ }^{37}$ to conduct our research as we worked upon existing research to build theory related to processes that are not currently well explained. In our study, the process we sought to explore related to processing and integrating feedback information about an individual's implicit biases. Building upon our earlier research that explored how health professionals process implicit-bias related feedback ${ }^{21}$, we posted and shared recruitment notices among mental health professionals working within an academic health sciences centre in Ontario, Canada. Initially we recruited mental health nurses (11). We then expanded our sample to include both practicing psychiatrists (10) and psychiatry residents (11). In total we completed a total of 32 semi-structured interviews. One of the participants did not complete the IAT due to technical issues and was excluded from the analysis. Approval was obtained from the Western University Research Ethics Board to conduct the study.

Our semi-structured interviews consisted of reviewing the letter of information and consent followed by the completion of the online version of the mental illness implicit association test (IAT). Whenever possible, the interviewer left the room during IAT completion. The IAT asks participants to associate words and assess automatic associations between certain concepts ${ }^{38}$. The IAT measures response time latency and has typically demonstrated insensitivity to procedural variation, suitable internal consistency, high test-retest reliability and less susceptibility to social desirability than explicit measures ${ }^{38-45}$. Once our participants completed the IAT, they received a result that assessed the extent to which participants associated mental illness with dangerousness, physical illness with dangerousness, or held no strong bias either way, therefore offering a measure of implicit bias to- 
wards individuals with mental illness or physical illness. A sample of IAT questions is included as an appendix to this article.

During the first set of interviews, nurse participants were asked open ended questions about the experience of taking the IAT and whether their results were expected or unexpected. In order to foster a non-judgmental and safe interview, we let participants know that they were welcome to share their IAT result with us but their result itself was not the focus of our inquiry. All participants shared their results freely. Interviews then proceeded in accordance with a discussion guide from previous research ${ }^{21}$. As we moved from our initial purposeful sample, we expanded to include practicing psychiatrists and psychiatry residents and revised our discussion guide accordingly. We anticipated that expanding the sample would help explore unique dimensions of professional identity within diverse health professionals at various stages of their professional identity development. As our interviews and analysis proceeded, we discovered that our questions related to how our participants respond to computer based feedback data provoked emotion and a separate discussion unfolded on how individuals reconcile tensions. Early in our analysis, we felt that the two discussions were conceptually distinct and a separate study regarding a unique research question and distinctive methods was required to explore how identity tensions are reconciled.

Interviews took place from April 2017 to October 2017. Once recorded and transcribed, coding and analysis were conducted by a team consisting of JS and MW. The first 17 transcripts were transcribed and coded line-by-line by JS and MW. Subsequent transcripts were coded line-by-line by JS using constant comparative analysis and shifted towards focused and axial coding. Analysis was shared and discussed with the entire team who worked towards synthesizing overall findings. We collected data until the team felt we had achieved theoretical sufficiency based on findings and the original research question. A synopsis of results was shared in writing with selected participants through individual emails.

Team member composition included the principal investigator (JS), a child and adolescent psychiatrist, faculty member and $\mathrm{PhD}$ candidate in health professions education, as well as research staff (MW), nursing staff (AM), and three experts in health professions education (CW, LL and PT).

\section{Results}

10/32 participants demonstrated implicit dangerousness bias towards mental illness, 17/32 demonstrated implicit dangerousness bias towards physical illness while 4/32 demonstrated no implicit bias towards either group, and 1 did not complete the IAT so their results were not included in the analysis. 16/31 described the experience as positive, $11 / 31$ as neutral and $4 / 31$ as negative. 13/31 classified their results as what they expected, 18/31 as unexpected. 
During analysis we learned that dangerousness biases related to mentally ill patients was reported by approximately $1 / 3$ of our participants, as several mental health professionals associated dangerousness with physical illness. Our transcripts suggested that participants viewed any revealed bias as negative, whether it was toward mental illness or toward physical illness. For example, those who demonstrated a bias towards patients with physical illness were not relieved that their result showed an absence of a negative bias towards patients with mental illness. We engaged in further comparison between and across groups and noted that even the four participants who received a result with no bias responded to the exercise of completing the IAT in a manner that was relevant to our research question. All respondents reflected on their feedback and provided responses based on the exercise of completing the IAT and receiving their result. We therefore felt that an analysis of all data, regardless of IAT result, was useful and pertinent to the process we sought to explore. While each type of result was unique, we found overall that taking the online IAT and receiving a result led to questioning of the IAT's credibility while provoking reflection related to an individual's identity and how it relates to implicit bias recognition and management.

\section{Participants Questioned the Credibility of the IAT}

Our participants strongly critiqued the IAT. While some questioned the validity of the IAT, describing it as "rigged, misleading or tricky," most criticism described the IAT as too general or simplistic for a group of mental health professionals. For example, most participants shared that a test that measures their implicit biases by categorizing groups into mental illness and physical illness fails to address the continuum of mental illness and physical illness that lies within each category. One participant described the issue by saying that there is a "spectrum of suffering" that was too broad for the IAT to capture,

"Yeah, I mean, there's such a spectrum of suffering... a lot of people take their Paxil and go see their psychiatrist once every couple months and they're fine. And there's other people ... who go to inpatients, see a counsellor..." RN1

Physician and resident participants conveyed the same criticism, suggesting that dangerousness is an individual concept that may vary across populations and types of illness. One stated, "mental health patients are so individualized there's no way to generally indicate if a mental health patient is dangerous or not...its completely individualized" F03. Another participant described the test as "misleading" because it was too "general,"

"I found, the questions I found were quite misleading because of the question about mental illness in general. Whereas I do associate some mental illnesses with more dangerous behaviour, not all of them, for sure. And even the ones that are associated with somewhat increase in that kind of dangerous behaviour it's usually not acute." F06 
Participants' description of the IAT was also linked with their interpretation of their results. One physician shared,

"You know there could be dangerousness in certain sub segments of mental health patients, but definitely not as a generalization and definitely not as a whole...so the result or the interpretation of my answers was a bit surprising." F04

Along with participants who described the IAT as general were some participants who expressed negative emotions about the test and suggested their results should be interpreted considering their criticisms. One stated, "I found the test almost tried to create associations that were not there for me" F03. Another said, "it was like they're trying to trick you by moving the stuff around" RN1, while another stated, "you didn't have the options the way you think. I think that you were just very much directed to go aggressive always with mental health. Anything that was negative always went to mental health" RN4.

Among the participants who criticized the IAT as "tricky" or a "set-up" were those who received results indicating a dangerousness bias associated with mental illness as well as others who were told they had a bias towards physical illness. For example, a physician who received a result that they demonstrated bias towards physically ill patients suggested they "self-corrected" despite being "dragged" towards answers "preferred by the system" F10. In contrast, a nurse who demonstrated bias towards mentally ill patients stated,

"I felt like it was trying to trick me into doing that, so I was trying very hard not to; and then I was also, like, it said go as fast as you can, so I was kind of pressuring myself for speed thinking that that has something to do with it, when really I should have probably just gone slower, do you know I mean?" RN5

Another nurse with bias towards mentally ill patients dismissed their results and described the IAT as a "game,"

"So, taking that test reminded of the word association game, where as fast as you can you say the word that you think of, and that was the whole like pressing the letters to categorize them. And I found more accuracy, you do it a number of times, so the first half of the times my accuracy was perfect, but near the end, and I don't know if I just got annoyed of doing it so many times or I was just like over it, that I made a couple of errors. Do those errors necessarily imply anything, I really don't think so." RN8

\section{Despite their Critique, Many Acknowledged and Reflected upon their Results}

A visual depiction of our results is provided in figure 1. Across all groups, and despite the nature of feedback they received, most participants acknowledged and 
reflected on their results. They recognized that bias is inevitable and therefore receiving IAT feedback that they were biased was acknowledged and reflected upon.

When we analyzed our participants based on whether their IAT result was expected or unexpected, we learned that their description of taking the IAT and interpretation of their result varied. We conducted further analysis of participants who made critical statements about the IAT and those who made positive statements about the test and experience of taking it. We consistently found examples of participants who overlapped in both positive and negative statements. For example, there were some participants who emphatically denied the accuracy of their results while still describing their experience of taking the IAT as positive. There were also several participants who were both critical of the IAT and acknowledged and reflected upon their results.

One participant described the test as "frustrating, irritating," and when receiving their results that they had bias they stated, "I think that the results will never be fully accurate because of the specific vagueness in every question." They went on later in the interview to describe how they were "...struggling with the bias but being able to acknowledge where it came from." RN8

Another participant who learned they held bias towards patients with mental illness described their experience as negative and denied the accuracy of the results,

"My emotions when I saw my results were negative or...upsetting due to the fact of I am a healthcare provider that supports these individuals and my results show that I correlate dangerousness with mental health patients...I think the results are inaccurate." RN2

Later in the interview, the same participant was asked if their results would impact them and they initially said, "no," but later contradicted themselves, stating that the experience of taking the IAT would influence their attitudes and the way they practice,

"I think every day I can learn more. I don't know everything but I think my - I thought my emotions and attitudes towards mental illnesses was in the right direction and was positive, but obviously there's always room to improve...I may reflect each day more on how I could have changed the way that I cared for my patients or presented myself or the way I showed empathy towards my patients." RN2.

A physician participant who learned they had dangerousness bias towards patients with mental illness stated,

"I was surprised at the result, because I don't think it actually reflects my view of mental health patients as being automatically more dangerous. They can be for sure, but as a general view of mental health patients, I don't have the view that in general health patients are dangerous, whereas that seems to be what the result was implying." $\mathrm{F} 4$ 
They went on to reflect on how important it was for them to avoid generalizing all patients with mental illness by saying,

"So it's a balance, I mean you do have to recognize that there can be periods of time where the risk level is a bit higher, but you do need to continuously assess the situation. And you know the same patient who was very aggressive towards me and threatened this and that, once they're well will be a patient who walks into your office as an outpatient and you have a very pleasant conversation with them and it's almost forgotten that that happened." F4.

Our results suggest that the exercise of completing the IAT was perceived as useful despite the nature of feedback information and whether the information was expected or unexpected. Only 4 classified the experience of taking the IAT as negative, while most described the experience as positive or neutral. Some described the experience as challenging but useful.

"I think it's kind of a mixed experience. It was good for reflection, but like I said, I think there's a bit of anxiety sort of confronting that part of you, that piece of you." R1. 


\section{Figure 1}

A depiction of participant responses regarding feedback source, implicit association test (IAT) result and self. From a study of feedback to responses about implicit bias.

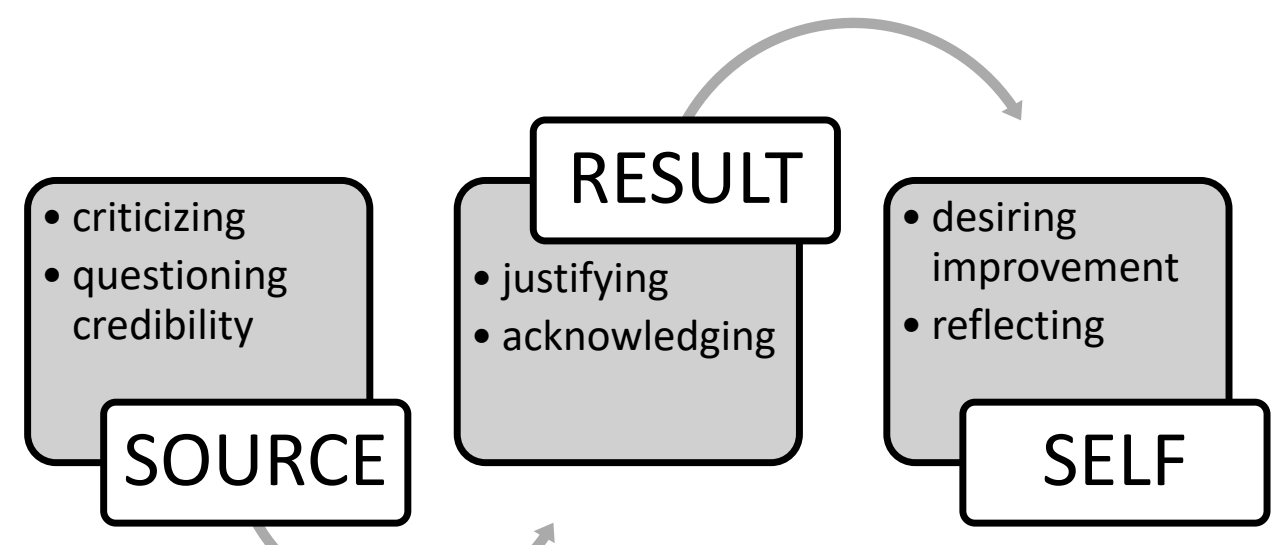




\section{Discussion}

When provided self-related feedback with the potential to threaten their identity, our participants engaged with this feedback information rather than discarding it. Their acknowledgment and reflection on such feedback information seemed to happen despite the threatening nature of the feedback and despite participants' questioning the credibility of the feedback source. An important factor which likely influenced their engagement with bias-related feedback information was the research interview itself.

Previous research offers that emotionally charged feedback information related to the self may reduce the effectiveness of feedback interventions ${ }^{13}$. As a response, educators are often encouraged to keep feedback information focused on the task rather than on the recipient's identity. This dilemma poses a challenge for health professions education when dealing with feedback information related to biases, prejudice or professional misconduct. Feedback intervention theory also suggests that feedback affects behaviour by changing the locus of control so that the learner feels a sense of agency as they become motivated towards change ${ }^{46}$. Therefore, there is still potential for self-related feedback to motivate change.

As we consider the paradoxical finding that participants engaged with bias related feedback despite distrusting this feedback information, our attention shifts back to variables of our feedback conversation. We provided participants with feedback data through a computer based test and a subsequent qualitative research interview. Perhaps helping individuals to learn from self-threatening information requires a facilitated conversation within a non-threatening learning environment. This is precisely what our research interview intended to achieve, however our goals were to facilitate reflection for research purposes rather than coaching for behaviour change. Our findings therefore suggest future research on feedback in health professions could consider the parallels between feedback conversations and semi-structured qualitative research interviews. Knowing that the research interview may serve as a therapeutic debriefing conversation has important implications when interpreted through previous research on how feedback conversations can facilitate reflection and coach towards performance change 18,19,47-49. We speculate that in addition to a safe learning environment, our interviews were unique because they de-emphasized feedback content while facilitating reflection.

While reactions to IAT feedback have been studied using questionnaires and surveys, little research has explored responses to IAT feedback through qualitative, in-person interviews. Consistent with our findings, Morris et al suggest that even though most students exhibited implicit bias against African Americans, they reported more positive than negative affect ${ }^{50}$. In other research, students who answered essay questions after completing the IAT initially did not believe the IAT was accurate; when readings about the IAT's methodological and theoretical underpinnings were provided to students, many changed their views towards the IAT, 
with a greater proportion of students supporting its validity ${ }^{51}$. A recent study exploring how pharmacist students responded to IAT feedback used a survey rather than a feedback conversation. This study found that participants either agreed or disagreed with their results and did not engage or reflect on such feedback in the manner that our participants described ${ }^{52}$. Changing paradigms related to the competency based medical education movement provoke the need for a deeper understanding of assessments within clinical workplaces. Achieving meaningful learning through feedback debriefing and reflection within such contexts cannot be accomplished by quantitative feedback alone, as learners could demand more feedback and face negative emotions that require debriefing and reconciliation ${ }^{53}$.

Literature on implicit bias recognition and management emphasizes the importance of feedback information to recognize and address the negative impact of implicit biases on health equity 21,54,55. Previous authors have warned that the feedback triggered by the IAT can provoke cognitive dissonance related to both an individual's beliefs and behaviours ${ }^{56}$. Research on addressing implicit gender bias proposes a framework called the "Conscious Competence Ladder," which suggests IAT feedback helps learners move from "unconscious incompetence" to "conscious incompetence," as they become aware of their biases, experience discomfort and work to instill new habits ${ }^{57}$. Teal and colleagues suggest a developmental continuum from acceptance to integration moving through stages of denial and minimization (55), while our previous work suggests that IAT related feedback provokes tensions related to personal and professional identity ${ }^{21}$. Our exploration of IAT feedback with mental health professionals suggests that despite the threatening nature of the IAT, a computer based metric of response latency, such as the IAT, remains a useful prompt to trigger reflection and discussion on the importance of addressing implicit biases to advance equity and reduce disparities.

Our study was not without limitations. As noted in our results, we found that all participants who completed the IAT and received their results engaged with feedback information, regardless of whether they received feedback that they held dangerousness bias or not. We believe our findings are useful in circumstances when self-related feedback cannot be detached from task-related feedback, however, future research on various types of implicit bias related feedback would add further insights. Our participants were also limited to a group of psychiatrists, psychiatry residents and mental health nurses. Therefore, our choice to utilize dangerousness bias may or not be perceived differently due to participants' roles, however sampling for participants' identity was an important component of our study design to explore how identity influences processing of IAT related feedback.

Despite these limitations, the implications of this work are important to consider in the context of the existing body of research on feedback in health professions. Our findings highlight a feedback paradox, calling into question some of our assumptions and knowledge regarding self-related feedback in the literature. Our study indicates that potentially threatening self-related feedback may still be useful to participants who question its credibility, and the research interview is an 
important component of the process that merits further study. These results call for future research on which attributes of the feedback conversation facilitate reflection on emotionally challenging feedback information.

\section{Acknowledgements:}

This work was supported by grants from Associated Medical Services - Phoenix Fellowship and the London Health Sciences Centre Children's Health Foundation 


\section{References}

(1) Bennett H, Gatrell J, Packham R. Medical appraisal: collecting evidence of performance through 360 feedback. Clinician in Management. 2004;12(4):165-72.

(2) Eva KW, Armson H, Holmboe E, Lockyer J, Loney E, Mann K, et al. Factors influencing responsiveness to feedback: on the interplay between fear, confidence, and reasoning processes. Advances in Health Sciences Education. 2012;17(1):15-26.

(3) Fidler H, Lockyer JM, Toews J, Violato C. Changing physicians' practices: the effect of individual feedback. Academic Medicine. 1999;74(6):702-14.

(4) Lockyer J, Violato C, Fidler H. Likelihood of change: a study assessing surgeon use of multisource feedback data. Teaching and learning in medicine. 2003;15(3):168-74.

(5) Overeem K, Wollersheimh HC, Arah OA, Cruijsberg JK, Grol RP, Lombarts KM. Factors predicting doctors' reporting of performance change in response to multisource feedback. BMC medical education. 2012;12(1):52.

(6) Sargeant J, Macleod T, Sinclair D, Power M. How do physicians assess their family physician colleagues' performance?: creating a rubric to inform assessment and feedback. Journal of Continuing Education in the Health Professions. 2011;31(2):87-94.

(7) Sargeant J, Mann K, Sinclair D, van der Vleuten C, Metsemakers J. Challenges in multisource feedback: intended and unintended outcomes. Medical Education. 2007;41(6):583-91.

(8) Ashford SJ, Blatt R, Walle DV. Reflections on the looking glass: A review of research on feedback-seeking behavior in organizations. Journal of Management. 2003;29(6):773-99.

(9) Atwater LE, Waldman DA, Brett JF. Understanding and optimizing multisource feedback. Human Resource Management. 2002;41(2):193-208.

(10) Brett JF, Atwater LE. $360^{\circ}$ feedback: Accuracy, reactions, and perceptions of usefulness. Journal of Applied Psychology. 2001;86(5):930.

(11) Smither JW, London M, Reilly RR. Does performance improve following multisource feedback? A theoretical model, meta-analysis, and review of empirical findings. Personnel Psychology. 2005;58(1):33-66.

(12) Bynum WEt. Filling the feedback gap: the unrecognised roles of shame and guilt in the feedback cycle. Med Educ. 2015;49(7):644-7.

(13) Kluger AN, Denisi AS. The Effects of Feedback Interventions on Performance: A Historical Review, a Meta-Analysis and a Preliminary Feedback Intervention Theory. Psychol Bull. 1994;119(2):254-84.

(14) Archer JC. State of the science in health professional education: effective feedback. Medical education. 2010 Jan;44(1):101-8. 
(15) Sargeant JM, Mann KV, Van der Vleuten CP, Metsemakers JF. Reflection: a link between receiving and using assessment feedback. Advances in Health Sciences Education. 2009 Aug 1;14(3):399-410.

(16) Sargeant J, Mann K, Sinclair D, Van der Vleuten C, Metsemakers J. Understanding the influence of emotions and reflection upon multi-source feedback acceptance and use. Advances in Health Sciences Education. 2008 Aug 1;13(3):275-88.

(17) Sargeant J, Mann K. Feedback in medical education: Skills for improving learner performance. ABC of Learning and Teaching in Medicine. 2010 Jun 3;2:29-32.

(18) Telio S, Ajjawi R, Regehr G. The "educational alliance" as a framework for reconceptualizing feedback in medical education. Academic Medicine. 2015 May 1;90(5):609-14.

(19) Telio S, Regehr G, Ajjawi R. judgments of Supervisor Credibility Based on Qualities of the Teaching Relationship: An Influence on Feedback Effectiveness and Engagement in the Learning Process: ob3-4. Medical Education. 2015 Apr 1;49:45-6.

(20) Sargeant J, Mann K, van der Vleuten C, Metsemakers J. "Directed" selfassessment: practice and feedback within a social context. Journal of Continuing Education in the Health Professions. 2008;28(1):47-54.

(21) Sukhera J, Milne A, Teunissen PW, Lingard L, Watling C. The Actual Versus Idealized Self: Exploring Responses to Feedback About Implicit Bias in Health Professionals. Acad Med. 2017.

(22) Frantz CM, Cuddy AJ, Burnett M, Ray H, Hart A. A threat in the computer: The race implicit association test as a stereotype threat experience. Personality and Social Psychology Bulletin. 2004;30(12):1611-24.

(23) Monteith MJ, Voils CI, Ashburn-Nardo L. Taking a look underground: Detecting, interpreting, and reacting to implicit racial biases. Social Cognition. 2001;19(4):395-417.

(24) O'Brien LT, Crandall CS, Horstman-Reser A, Warner R, Alsbrooks A, Blodorn A. But I'm no bigot: How prejudiced White Americans maintain unprejudiced self-images. Journal of Applied Social Psychology. 2010;40(4):917-46.

(25) Howell JL, Gaither SE, Ratliff KA. Caught in the Middle: Defensive Responses to IAT Feedback Among Whites, Blacks, and Biracial Black/Whites. Social Psychological and Personality Science. 2015;6(4):373-81.

(26) Watling C, Driessen E, van der Vleuten CP, Lingard L. Learning from clinical work: the roles of learning cues and credibility judgements. Med Educ. 2012;46(2):192-200.

(27) Kaiser CR, Vick SB, Major B. Prejudice expectations moderate preconscious attention to cues that are threatening to social identity. Psychological science. 2006;17(4):332-8. 
(28) Steele CM, Aronson J. Stereotype Threat and the Intellectual Test Performance of African Americans. Journal of Personality and Social Psychology. 1995;69(5):797-811.

(29) Payne VL, Hysong SJ. Model depicting aspects of audit and feedback that impact physicians' acceptance of clinical performance feedback. BMC health services research. 2016;16(1):260.

(30) Peris TS, Teachman BA, Nosek BA. Implicit and explicit stigma of mental illness: Links to clinical care. The Journal of nervous and mental disease. 2008;196(10):752-60.

(31) Sukhera J, Miller K, Milne A, Scerbo C, Lim R, Cooper A, et al. Labelling of mental illness in a paediatric emergency department and its implications for stigma reduction education. Perspect Med Educ. 2017:1-8.

(32) Kealy D, Ogrodniczuk JS. Marginalization of borderline personality disorder. Journal of Psychiatric Practice®. 2010;16(3):145-54.

(33) Lauber C. Stigma and discrimination against people with mental illness: a critical appraisal. Epidemiology and psychiatric sciences. 2008;17(1):10-3.

(34) Lauber C, Rössler W. Stigma towards people with mental illness in developing countries in Asia. International review of psychiatry. 2007;19(2):157-78.

(35) Schulze B. Stigma and mental health professionals: a review of the evidence on an intricate relationship. International review of Psychiatry. 2007;19(2):13755.

(36) Greenwald AG, Banaji MR. Implicit social cognition: attitudes, self-esteem, and stereotypes. Psychol Rev. 1995;102(1):4.

(37) Charmaz K. Constructing grounded theory: A practical guide through qualitative research. SagePublications Ltd, London. 2006.

(38) Greenwald AG, McGhee DE, Schwartz JL. Measuring individual differences in implicit cognition: the implicit association test. Journal of personality and social psychology. 1998;74(6):1464.

(39) Nosek BA, Greenwald AG, Banaji MR. Understanding and using the Implicit Association Test: II. Method variables and construct validity. Personality and Social Psychology Bulletin. 2005;31(2):166-80.

(40) Bosson JK, Swann WB, Pennebaker JW. Stalking the perfect measure of implicit self-esteem: The blind men and the elephant revisited? Journal of personality and social psychology. 2000;79(4):631-43.

(41) Dasgupta N, McGhee DE, Greenwald AG, Banaji MR. Automatic preference for White Americans: Eliminating the familiarity explanation. Journal of Experimental Social Psychology. 2000;36(3):316-28.

(42) Greenwald AG, Farnham SD. Using the implicit association test to measure selfesteem and self-concept. Journal of personality and social psychology. 2000;79(6):1022.

(43) Greenwald AG, Nosek BA. Health of the Implicit Association Test at age 3. Zeitschrift für experimentelle psychologie. 2001;48(2):85-93. 
(44) Nosek BA, Greenwald AG, Banaji MR. The Implicit Association Test at age 7: A methodological and conceptual review. Automatic processes in social thinking and behavior. 2007:265-92.

(45) Steffens MC. Is the implicit association test immune to faking? Exp Psychol. 2004;51(3):165-79.

(46) Kluger AN, Van Dijk D. Feedback, the various tasks of the doctor, and the feedforward alternative. Med Educ. 2010;44(12):1166-74.

(47) Ramani S, Könings KD, Ginsburg S, van der Vleuten CP. Twelve tips to promote a feedback culture with a growth mind-set: Swinging the feedback pendulum from recipes to relationships. Medical teacher. 2018:1-7.

(48) Ramani S, Krackov SK. Twelve tips for giving feedback effectively in the clinical environment. Medical teacher. 2012;34(10):787-91.

(49) Sargeant J, Lockyer J, Mann K, Holmboe E, Silver I, Armson H, et al. Facilitated Reflective Performance Feedback: Developing an Evidence- and Theory-Based Model That Builds Relationship, Explores Reactions and Content, and Coaches for Performance Change (R2C2). Academic Medicine. 2015;90(12):1698-706.

(50) Morris KA, Ashburn-Nardo L. The Implicit Association Test as a class assignment: Student affective and attitudinal reactions. Teaching of Psychology. 2009 Dec 31;37(1):63-8.

(51) Casad BJ, Flores AJ, Didway JD. Using the Implicit Association Test as an unconsciousness raising tool in psychology. Teaching of Psychology. 2013 Apr;40(2):118-23.

(52) Avant ND, Weed E, Connelly C, Hincapie AL, Penm J. Qualitative Analysis of Student Pharmacists' Reflections of Harvard's Race Implicit Association Test. Currents in Pharmacy Teaching and Learning. 2018.

(53) Tekian A, Watling CJ, Roberts TE, Steinert Y, Norcini J. Qualitative and quantitative feedback in the context of competency-based education. Medical teacher. 2017;39(12):1245-9.

(54) Sukhera J, Watling C. A Framework for Integrating Implicit Bias Recognition Into Health Professions Education. Acad Med. 2018;93(1):35-40.

(55) Teal CR, Gill AC, Green AR, Crandall S. Helping medical learners recognise and manage unconscious bias toward certain patient groups. Medical education. 2012;46(1):80-8.

(56) Hernandez RA, Haidet P, Gill AC, Teal CR. Fostering students' reflection about bias in healthcare: Cognitive dissonance and the role of personal and normative standards. Medical teacher. 2013;35(4):e1082-e9.

(57) Fulmer CL. Unpacking evidence of gender bias. Journal of Women in Educational Leadership. 2010 Apr;8(2):81-97. 



\section{CHAPTER 6}

\section{Striving While Accepting: Exploring the Relationship Between Identity and Implicit Bias Recognition and Management}

Accepted for Publication as:

Sukhera, J., Wodzinski, M., Teunissen, P.W., Lingard, L., Watling, C., Striving while Accepting: Exploring the Relationship Between Identity and Implicit Bias Recognition and Management. Acad Med Supl.

(C) 2018 the Association of American Medical Colleges 


\begin{abstract}
Purpose: Implicit biases worsen outcomes for underserved and marginalized populations. Once health professionals are made aware of their implicit biases, a process ensues where they must reconcile this information with their personal and professional identities. The authors sought to explore how identity influences the process of implicit bias recognition and management.
\end{abstract}

Methods: Utilizing constructivist grounded theory, the authors recruited 11 faculty and 10 resident participants working at an academic health science center in Canada. Interviews took place from June to October 2017. Participants took an online version of the mental illness implicit association test (IAT) which provides users with their degree of implicit dangerousness bias towards individuals with either physical or mental illness. Once they completed the IAT, participants were invited to draw a rich picture and interviewed about their picture and experience of taking their IAT. Data were analyzed using constant comparative procedures to develop focused codes and work towards the development of a deeper understanding of relationships among themes.

Results: Once implicit biases were brought into conscious awareness, participants acknowledged vulnerabilities which provoked tension between their personal and professional identities. Participants suggested that they reconcile these tensions through a process described as striving for the ideal while accepting the actual. Relationships were central to the process; however, residents and faculty viewed the role of relationships differently.

Conclusion: Striving for self-improvement while accepting individual shortcomings may provide a model for addressing implicit bias among health professionals and relational dynamics appear to influence the process of recognizing and managing biases. 


\section{Introduction}

Bias is everywhere. Explicit biases include conscious attitudes or intentional discrimination towards certain groups ${ }^{1}$. In contrast, implicit biases include attitudes or behaviours that exert powerful influence over individuals outside their awareness 2-4. These implicit biases can perpetuate health disparities by widening inequities and decreasing trust between patients and health professionals. For example, implicit racial bias has been associated with inappropriate non-prescription of treat-

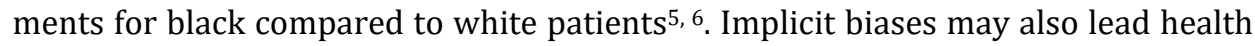
professionals to appear dishonest to marginalized and underserved populations ${ }^{1}$, leading to interactions that self-perpetuate cycles of distancing and disconnection $^{7,8}$.

In response, educators are identifying potential interventions to mitigate the adverse impact of implicit bias on healthcare ${ }^{9-16}$. Previous research describes how once biases are brought into awareness, there is an ensuing tension ${ }^{14}$, which triggers a process that requires reflection and reconciliation ${ }^{15-20}$. The first step in recognizing one's biases requires seeking feedback through reflection, discussion or tools such as the implicit association test (IAT), which is an online metric of response time that asks participants to associate words and assess automatic associations between certain concepts ${ }^{18}$. The IAT measures response latency and has demonstrated several psychometric properties that support its use as metric of implicit bias ${ }^{18,21-27}$. Feedback information from the IAT may trigger long-lasting and powerful emotions such as shame or guilt 28,29 , which require renegotiation each time they are encountered ${ }^{30-33}$.

In a recent study exploring health professional responses to feedback about implicit biases, we found that when physicians and nurses were provided with feedback about their implicit bias, this information evoked tensions related to their personal and professional identities. Participants struggled to reconcile feedback information about their biases, as they found it inconsistent with an aspirational version of themselves that seemed unrealistic to achieve ${ }^{19}$. The implications of our initial findings suggest that anti-bias education takes place within a culture where health professionals hold themselves to unrealistic and perfectionistic standards ${ }^{34}$, 35 , which contributes to psychological distress and self-doubt ${ }^{36}$. If recognizing implicit bias has the potential to trigger self-doubt, and identity influences the reflection and reconciliation required to manage biases, we must seek deeper understanding of the process.

As individuals process and integrate information about their biases, there are several identity-related influences on how they evaluate their beliefs and behaviour. They may appraise themselves according to their values and personal morals, or they may compare being biased to norms within their professional culture ${ }^{20}$. Hernandez and colleagues found that medical students drew on personal standards more than professional norms when critically reflecting about their implicit bias- 
es ${ }^{15}$. Personal and professional standards may also relate to how an individual views their identity according to themselves, their relationships with others or their social group ${ }^{28}$. For any health professional, learning that they hold implicit biases is unlikely to align with their ideal self-representation.

Without improving our knowledge about how identity influences implicit bias, we cannot leverage the full potential of implicit bias recognition and management curricula to reduce disparities and improve equity. To explore the relationship between identity and implicit bias management, we chose to explore implicit dangerousness biases towards individuals with physical or mental illness among psychiatry residents and faculty. Many mental health professionals view destigmatizing as part of their role and therefore hold explicitly positive biases towards their patients, which do not always align with their implicit biases ${ }^{37-39}$. This discrepancy between explicit attitudes and implicit biases about dangerousness may create tensions within an individual that must be processed and negotiated whenever they arise.

Negative attitudes towards patients with mental illness comprise a particularly pervasive and problematic set of implicit biases encountered in health care system; these biases have been shown to result in mental health patients being over diagnosed, undertreated, and more strongly associated with dangerousness when compared to patients with physical illnesses ${ }^{40-47}$. The stigma experienced by mental health patients, including feelings of stigmatization by mental health professionals, is a barrier to seeking and receiving sufficient medical care; thus, attempting to elucidate and address implicit biases held by mental health professionals is one potential route towards de-stigmatization and improvement of patient outcomes. The purpose of our study was to explore how learners and faculty reconcile identity tensions evoked during the process of implicit bias recognition and management. By exploring dangerousness bias within psychiatry we hoped to elicit insights into how identity-related tensions are reconciled for other health professionals.

\section{Methods}

In this study, we defined implicit bias as associations, attitudes or beliefs that exist and enact their influence outside of an individual's conscious awareness.

We electronically shared recruitment notices among mental health professionals working within an academic health sciences center in Ontario, Canada. We sought roughly equal participation between resident learners and teachers and 21 individuals ( 9 male and 12 female) responded with an interest in participation. We completed semi-structured interviews with 11 practicing psychiatrists involved in clinical education and 10 psychiatry residents. Interviews took place from June to October 2017. Approval was obtained from the Western University Research Ethics Board to conduct the study. 
Our semi-structured interviews lasted 30-90 minutes and consisted of reviewing the letter of information and consent followed by the completion of the online version of the mental illness implicit association test (IAT). Once participants completed the IAT, they received a result that indicated they held strong, moderate, mild or no dangerousness bias. During the initial interviews, participants were asked open ended questions about the experience of taking the IAT and were asked to draw rich picture which we discussed as part of their interview. A rich picture is a visual depiction of processes and human activity developed in systems engineering ${ }^{48}$. Rich pictures have been used previously in health professional research to better understand conceptualizations of complex or challenging situations ${ }^{49}, 50$. We chose a visual method to foster deeper exploration of what we believed was an emotionally challenging situation. In particular, we hoped that a rich picture may address difficulties and limitations with a qualitative interview related to making implicit assumptions explicit ${ }^{49}$. An example of a rich picture by one of our participants is provided as figure 1. All our participants except 1 drew rich pictures. We asked participants to describe their picture and probed for how their picture relates to questions in our discussion guide, which we adapted from previous research $^{19}$. Interviews were audio recorded, de-identified and transcribed verbatim before analysis. The final version of our discussion guide is included as an appendix.

Team member composition included the principal investigator (JS), a child and adolescent psychiatrist, faculty member and $\mathrm{PhD}$ candidate in health professions education, as well as research staff (MW), and three experts in health professions education (CW, LL and PT) who do not work in mental health.

We utilized constructivist grounded theory to conduct our study as we worked upon existing research to build theory towards a social process that is not well explained by an established theoretical construct ${ }^{51-53}$. Constructivism assumes that individuals construct their understanding and knowledge of the world through a cycle of experience, reflection and action ${ }^{54}$. Once interviews were recorded and transcribed, coding and inductive analysis was conducted by a team consisting of JS and MW. JS and MW met regularly, revising the discussion guide and ensuring that analysis was consistent with an effort to theoretically sample resident learners and faculty. Part-way through the analysis we found several participants struggled with visual representations so we chose to add visual prompts (figure 2) to encourage reflection. Due to limited number within our recruitment pool, we included fulltime and part-time faculty and junior and senior resident learners. The first 7 transcripts were transcribed and coded line-by-line by JS and MW. Subsequent transcripts were coded line-by-line by JS who used constant comparative analysis and shifted towards focused consolidation of codes and analysis of relationship among themes. At regular intervals, analysis was shared and discussed with the team who worked towards the development of an explanatory theory and synthesized overall findings. Any discrepancies were addressed through collaborative debate. We continued to collect data and revise our discussion guide until the team felt there was 
enough data for a robust conceptual understanding of the process under study ${ }^{55-57}$. Synthesis of results was shared in writing with all participants through individual emails. Those who reviewed the results described general agreement.

\section{Results}

Out of our 21 participants, 18 demonstrated IAT results that indicated implicit dangerousness bias towards either mental or physical illness while 3 showed no difference in their associations between dangerousness and physical or mental illness. The act of completing the IAT and receiving their result provoked reflection about bias in all participants, including those that demonstrated no bias in their result. There were no significant differences between groups.

\section{Acknowledging Identity Tensions}

Once they were provided feedback about their implicit biases, most of our participants acknowledged categorizing and compartmentalizing their identities as part of their experiences. The demands of working with patients with mental illness appeared to influence the pressure they place on themselves to strive for an ideal that was impossible to achieve. When asked how they reconcile bias, one resident described how they have compartmentalized personal and professional identities separated by a "filter" that they must constantly recalibrate to recognize and manage biases (R04). Another resident drew a "mountain" to depict the divide between their personal and professional identities (R07). Several participants also described weather metaphors using "clouds" to describe their actual self or with "sunshine" related to their ideal self (F02, R05, F06). Overall, participants contrasted an idealized professional identity that was calm, confident and unbiased with an actual identity that was vulnerable and a product of their personal experiences.

"So the idealized self will never have any bias. The idealized self will always be able to look at a situation and see it for its complexity and its various components. But the actual self, by virtue of the kind of society that we live in and our own personal environment or the conditions under which we grew up, we will always have these uncomfortable biases that inform our initial reaction to people. So the actual self I think will always have initial biases that we have to overcome." (R03)

The aspirational professional self was viewed as an ideal worth striving for. Some faculty described that they have developed a professional identity which contributes to "pressure" to not be biased (F03; F10). A faculty participant shared, "I feel like its part of my job to not be judgmental and that's something I want at 
work...its an ideal, you now, at home or outside of work too." (F07), while another stated,

"Yeah. I think there's a lot of pressure to, for a professional to be not biased and to treat all patients fairly and not give preference to some over others. And I do find myself sometimes, you know, having preference for seeing certain types of patients just because of how unpleasant the others are. And so ideally I'd live in a world where I would have equal feelings of wanting to help all my patients equally but the reality is that, you know, I do find myself caring for some patients more than others." (F03)

A resident described the professional identity as being a sort of superordinate identity that "supersedes" the development of their authentic self during residency training (R01). They went on to say, "I guess we all have bias but professionals do not have bias. Whatever biases I do have, I either want to kind of reduce or at the very least, be aware of." (R01) Both resident and faculty participants acknowledged that there was a process or struggle associated with striving towards their idealized self. 


\section{Figure 1}

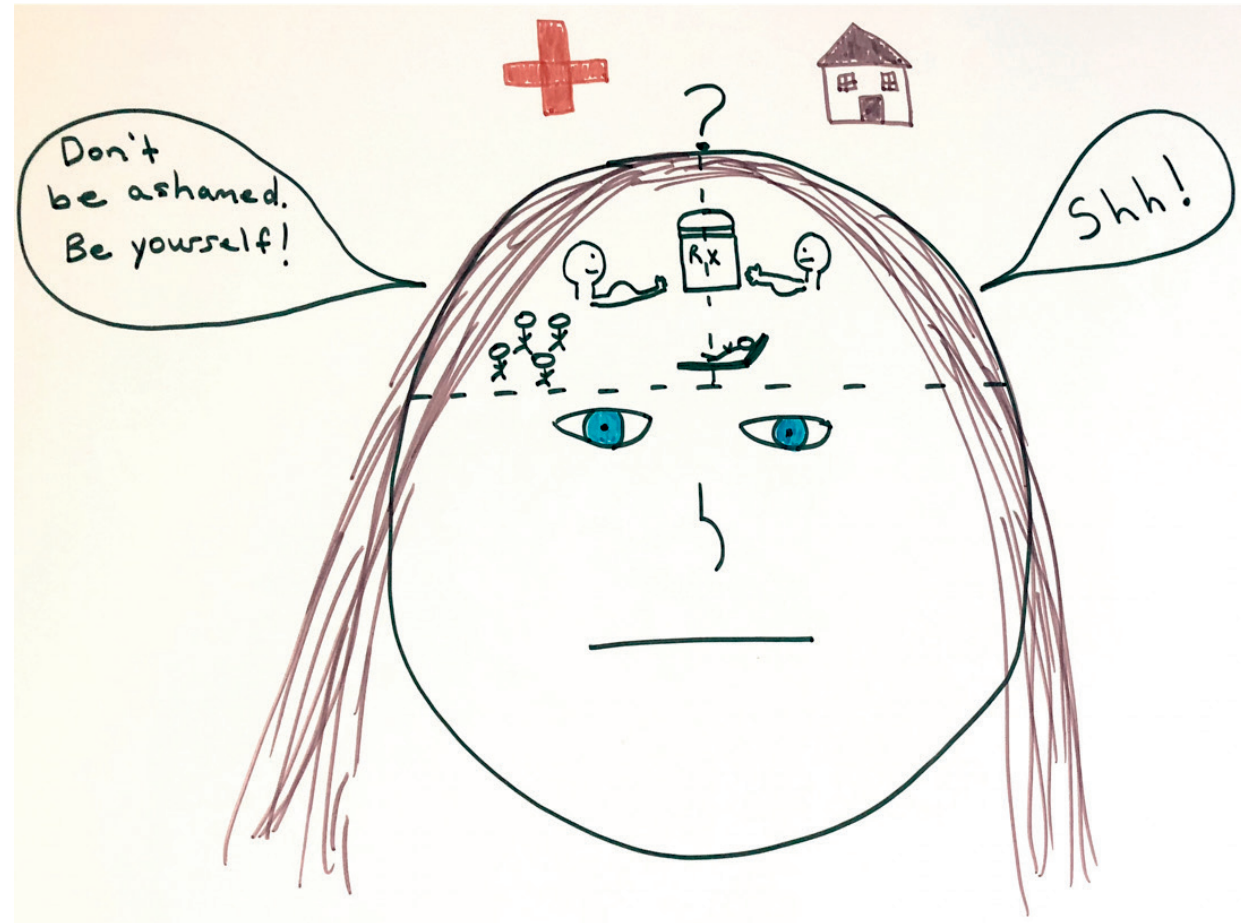

A rich picture drawn by a participant upon receiving results of the implicit association test for mental illness. The participant described a line representing a "discrepancy" between how they are in personal and professional contexts and depicted tension between advice they would give patients compared to how they treat themselves. From a study exploring the relationship between identity and implicit bias among health care professionals, Schulich School of Medicine and Dentistry, Western University, Ontario, Canada, 2017. 


\section{Striving while Accepting}

When asked to reflect on how implicit bias could be recognized and managed, participants described two salient but distinct processes. One was a constant striving for self-improvement that was intrinsic to most participants' identity. The other was a gradual acceptance of their flaws and humanity. Most participants described that through reflection and dialogue, an individual could strive for an idealized self while accepting the actual. A resident described accepting imperfections by saying,

"Its just the reality that no human is ever perfect... just because someone has bad qualities doesn't make them all bad and that good qualities can still exist and it doesn't destroy the good." (R02)

Once their implicit biases were revealed through the IAT, participants described reflecting on this information. Several participants described the "constant questioning" of themselves (F03) suggesting an ongoing process of reflection and action that was central to how they reconciled tensions related to implicit bias (F09). A resident described this process as checking themselves "on a daily basis" (R10), while a faculty participant described the process as "a journey" that required "being constantly vigilant" (F06). One resident described the process as working towards "self-betterment" (R03), while a faculty participant described "selfcompassion" (F05).

In addition to striving for betterment, most participants described a gradual acceptance of their own biases. One resident described working to be "more aware" of their biases while accepting they would not "dissipate" (R01), while another resident stated,

"I've come to terms with it...so working towards this means checking your biases, realizing when you might have let a bias come in between an interaction or a decision. I think its something you strive for. But I'm not going to wake up tomorrow and say, 'hey, nobody has biases' right? We all have them...so I think its something you strive for, accepting that its not necessarily going to be achieved." (R05)

There was variation in participants' description of how they balanced striving with accepting. Some emphasized the need to self-improve, some emphasized acceptance and one suggesting they had already reached what others strive for. One participant described that they had close to "full insight," and stated, "I pretty much know who I am, and with all the biases and everything, I am aware of this" F10. Although this individual felt they had come close to reaching what others strive for, they continued to emphasize the need to keep striving. Another faculty participant offered an alternative perspective stating that they reconcile tensions by,

“... growing myself, developing myself and understanding my own self better and talking with colleagues and being part of a community that kind of is working 
together on things I think that that helps me to get over to this place rather than just being isolated and on my own." (F11)

\section{The Role of Relationships}

Most participants reconciled identity tensions through relationships - emphasizing that implicit bias cannot be managed alone. Several faculty described how they valued sharing with others to reconcile their tensions. One faculty participant stated,

"So I think I need to recognize that I'm not the only person... who is in need of help with this endeavor. There are many other people who share the same sort of drive that I have so I'm not alone in this. I think as more and more people join forces we'll be able to achieve that idealized destination" F04.

Faculty and residents differed in their description of how reconciling is achieved through the relationships between teachers and learners. Most faculty participants described themselves as "role models" (F02; F03; F05; F06; F08; F10; F11), while most residents emphasized the need for guidance from faculty mentors. For example, when describing how they reconcile biases by "constantly introspecting and meditating," a faculty participant stated,

"So my role now for the rest of my life that I'm going to be working on professionally is to share the fact that our potential is huge and if I can get to be a role model for my residents, medical students and clinical professionals working with me to realize that they have a much bigger potential than they think they have, then I think I would have done a good job." (F06).

While most residents mentioned the potential of faculty mentors in helping them to recognize and manage implicit biases, there were variable responses on whether faculty could support these efforts. For residents, the potential support from their relationship with their teachers was colored with tension when mentors were not available. Residents also noted that mentors could only bring clarity and reassurance within the context of safety. One resident stated that variation in faculty mentors led to a constant sense of "unpredictability" (R01), while another mentioned that there were only " $f e w$ " faculty preceptors that encouraged reflecting on biases and questioned if faculty received enough "formalized training" on biases which motivated the resident to "seek external advice on this process" (R04). The lack of available guidance was clearly identified by resident participants as a barrier to addressing implicit biases that are incongruent with the health professional they aspired to be. Although faculty viewed themselves as role models, residents also suggested that there were issues limiting the availability and reflective capacity of some faculty to effectively role model how to address implicit biases. Another resident accepted the "humanity" of their teachers, emphasizing the importance of "sympathizing" with each other (R02). One resident went on to state, 
"I think it's invaluable to hear the mentor's own experiences as they were going through ... if they struggled with something similarly...because they have more expertise and more time that they've spent working with people and we're just novices. So I think that is an important piece. And it also, like I guess, creates a space where if they ... if you're willing ... you're opening up..." (R10)

\section{Figure 2}

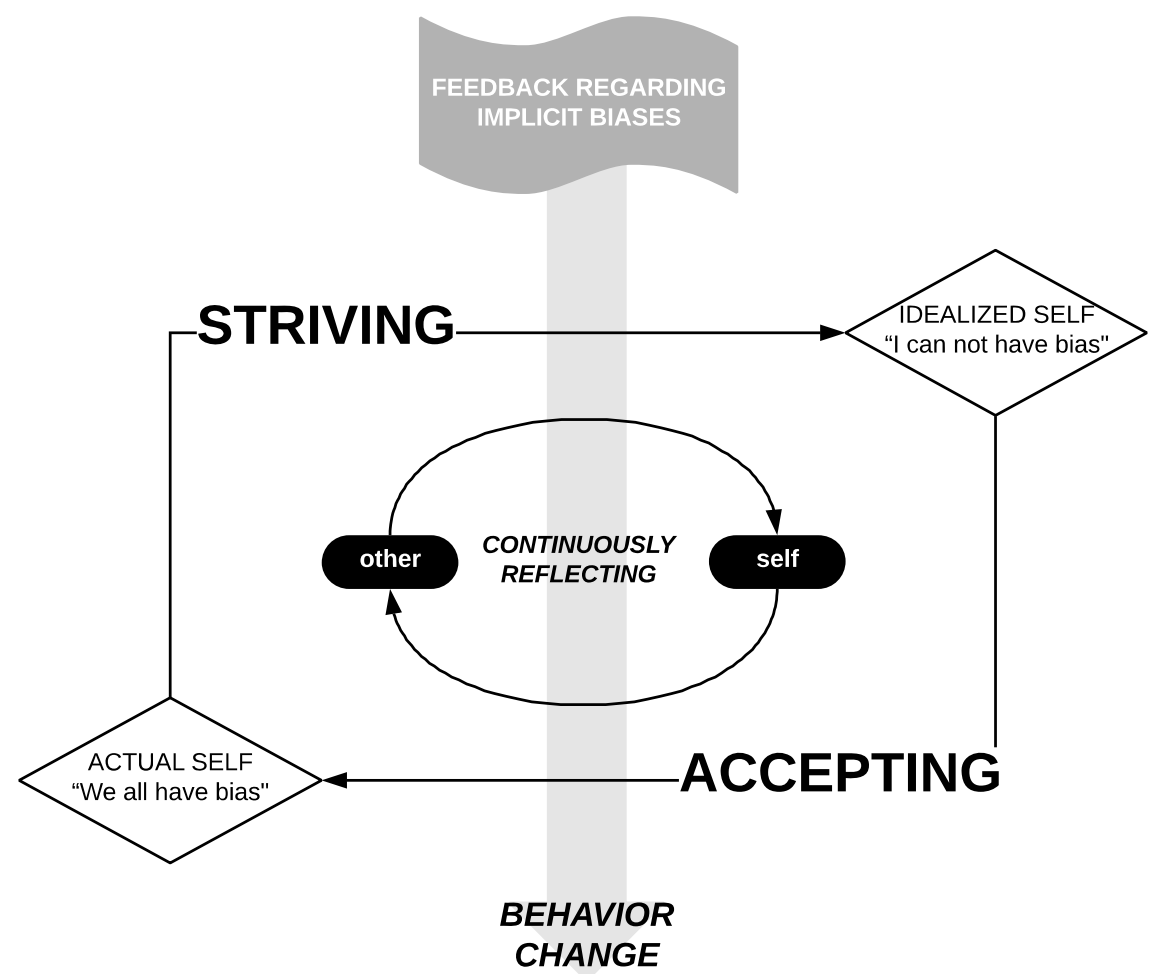

A model describing how feedback about implicit bias can foster behavior change among residents and faculty. Derived from the results of a study exploring the relationship between identity and implicit bias among health care professionals, Schulich School of Medicine and Dentistry, Western University, Ontario, Canada, 2017. 


\section{Discussion}

We learned from our participants that implicit bias recognition and management is fraught with challenges. Like previous research ${ }^{17,19,58}$, our results suggested that recognizing one's implicit biases triggers compartmentalization between the idealized professional identity and the actual personal identity. Successfully managing implicit biases requires reconciliation of these identities through safe and supportive relationships between teachers and learners, and the concept of "striving while accepting," may hold promise for faculty and learners engaging in the process.

\section{How Psychiatrists Describe Striving for the Ideal}

As part of their training, many psychiatrists undergo psychotherapy supervision where a framework is provided to question their assumptions and focus on unconscious aspects of their interactions with parents. Therefore, the identity of psychiatrists is likely to shape how our participants described their responses to feedback about implicit biases and influence how they reconcile these biases. Our participants described how their unique professional identity increased their selfimposed pressure to manage biases related to dangerousness involving their patients. They also shared how they interpreted striving for the ideal as a process of continuous reflection and improvement.

\section{Striving while accepting is challenging within health professions education}

Our finding that participants described a constant process of reflection and selfimprovement can be interpreted in the context of previous literature on professional identity formation. The health professional learner is gradually socialized through their experiences ${ }^{24,25,59}$, through the influence of role models ${ }^{60,61}$ and the formal and informal elements of their curriculum ${ }^{62}$. When health professionals face experiences that suggest they are not living up to expectations, they may face feelings of inadequacy ${ }^{63-65}$ and imposter syndrome ${ }^{36,66}$. Constantly striving to manage one's implicit biases within culture that rewards and incentivizes high achievement and perfectionism 66, 67 has the potential to produce psychological distress for learners. Since striving on its own may have negative consequences, what do we know about accepting?

Facilitated acceptance is currently described either in the context of the "struggling" learner or in the feedback literature ${ }^{68-70}$. Teal and colleagues suggest cognitive strategies are required to facilitate a developmental trajectory from denial of implicit bias to gradual acceptance ${ }^{14}$. Our study extends previous research to emphasize the importance of fostering acceptance throughout the continuum of health professions education. While our previous research highlighted how feedback about implicit bias triggers tensions related to health professional identity, 
our findings build upon previous theory to suggest that cognitive strategies that facilitate balance between seemingly opposite processes are integral to recognizing and managing implicit biases. We also learned that this process can be facilitated through relationships.

\section{Reconciling through relationships is different for faculty and learners}

We found that recognizing and managing implicit biases requires looking outside oneself towards relationships with others. Several authors have proposed models for facilitated reflection of negative or challenging feedback ${ }^{71}$, 72. For our participants, there was dissonance between how teachers and learners reconciled their implicit biases. While both groups brought up the importance of reconciling through relationships, they viewed role modeling differently. Residents desperately wanted guidance on bias management, and saw potential in their faculty mentors to provide it, but this potential is too often unrealized. While faculty may identify their own struggles, and see themselves as role models, they are not recognizing and managing their biases convincingly enough for many of their learners. If the potential for honest conversations between resident and faculty is not being actualized, we must investigate the role of relationships and implicit bias further. A deeper investigation into the relational dynamics of emotionally challenging topics such as implicit bias is necessary to advance efforts towards equity.

\section{Implications}

Leveraging an individual's desire to strive for an idealized professional self may facilitate practice changes related to implicit bias recognition if balanced through facilitated reflection on accepting one's shortcomings. These findings are useful for individuals and organizations looking for evidence-informed approaches to integrate implicit bias recognition and management.

\section{Limitations}

Our deliberate choice to sample psychiatrists from a single institution and explore implicit biases towards mental illness flavors the findings of this research. Future work could explore our findings among community psychiatrists who do not work in an academic setting and are not actively involved in working with resident or undergraduate learners The IAT has its own limitations as a measure and has been critiqued in the literature ${ }^{73-76}$. We therefore emphasized the use of the IAT as a prompt to trigger reflection. 


\section{Conclusions}

Discussions about implicit bias within health professional education trigger identity tensions, and striving for self-improvement while accepting individual shortcomings may provide a model for successfully reconciling such tensions and managing implicit biases. Enacting the concept of striving while accepting may require honest and authentic relationships between teachers and learners.

\section{Acknowledgments:}

This study was funded by grant support from Associated Medical Services. 


\section{References}

(1) Dovidio J, Fiske ST. Under the Radar: How Unexamined Biases in DecisionMaking Processes in Clinical Interactions can Contribute to Health Care Disparities. American Journal of Public Health. 2012;102(5):945-52.

(2) Institute of Medicine. Unequal treatment: confronting racial and ethnic disparities in health care. Washington DC: Federal Register; 2003.

(3) Ross HJ. Everyday bias: Identifying and navigating unconscious judgments in our daily lives: Rowman \& Littlefield; 2014.

(4) Staats C, Capatosto K, Wright RA, Contractor D. State of the science: Implicit bias review 2014. Kirwan Institute for the Study of Race and Ethnicity http://kirwaninstitute/osu edu/wp-content/uploads/2014/03/2014implicit-bias pdf. 2014.Accessed March 1, 2017.

(5) Green AR, Carney DR, Pallin DJ, Ngo LH, Raymond KL, Iezzoni LI, et al. Implicit bias among physicians and its prediction of thrombolysis decisions for black and white patients. Journal of general internal medicine. 2007;22(9):1231-8.

(6) Sabin JA, Greenwald AG. The influence of implicit bias on treatment recommendations for 4 common pediatric conditions: pain, urinary tract infection, attention deficit hyperactivity disorder, and asthma. American Journal of Public Health. 2012;102(5):988-95.

(7) Devine PG, Plant EA, Amodio DM, Harmon-Jones E, Vance SL. The regulation of explicit and implicit race bias: the role of motivations to respond without prejudice. Journal of personality and social psychology. 2002;82(5):835.

(8) Dovidio JF, Penner LA, Albrecht TL, Norton WE, Gaertner SL, Shelton JN. Disparities and distrust: the implications of psychological processes for understanding racial disparities in health and health care. Social science \& medicine (1982). 2008;67(3):478-86.

(9) Burgess D, van Ryn M, Dovidio J, Saha S. Reducing racial bias among health care providers: lessons from social-cognitive psychology. J Gen Intern Med. 2007;22(6):882-7.

(10) Burgess DJ, Beach MC, Saha S. Mindfulness practice: A promising approach to reducing the effects of clinician implicit bias on patients. Patient Educ Couns. 2016.

(11) Burgess DJ, Fu SS, Van Ryn M. Why do providers contribute to disparities and what can be done about it? Journal of General Internal Medicine. 2004;19(11):1154-9.

(12) Stone J, Moskowitz GB. Non-conscious bias in medical decision making: what can be done to reduce it? Med Educ. 2011;45(8):768-76.

(13) Sukhera J, Watling C. A Framework for Integrating Implicit Bias Recognition Into Health Professions Education. Acad Med. 2017. 
(14) Teal CR, Gill AC, Green AR, Crandall S. Helping medical learners recognise and manage unconscious bias toward certain patient groups. Medical education. 2012;46(1):80-8.

(15) Hernandez RA, Haidet P, Gill AC, Teal CR. Fostering students' reflection about bias in healthcare: Cognitive dissonance and the role of personal and normative standards. Medical teacher. 2013;35(4):e1082-e9.

(16) Teal CR, Shada RE, Gill AC, Thompson BM, Frugé E, Villarreal GB, et al. When best intentions aren't enough: helping medical students develop strategies for managing bias about patients. Journal of general internal medicine. 2010;25(2):115-8.

(17) van Ryn M, Hardeman R, Phelan SM, Ph DD, Dovidio JF, Herrin J, et al. Medical School Experiences Associated with Change in Implicit Racial Bias Among 3547 Students: A Medical Student CHANGES Study Report. J Gen Intern Med. 2015;30(12):1748-56.

(18) Greenwald AG, McGhee DE, Schwartz JL. Measuring individual differences in implicit cognition: the implicit association test. Journal of personality and social psychology. 1998;74(6):1464.

(19) Sukhera J, Milne A, Teunissen PW, Lingard L, Watling C. The Actual Versus Idealized Self: Exploring Responses to Feedback About Implicit Bias in Health Professionals. Acad Med. 2017.

(20) Stone J, Cooper J. A self-standards model of cognitive dissonance. Journal of Experimental Social Psychology. 2001;37:228-43.

(21) Bosson JK, Swann WB, Pennebaker JW. Stalking the perfect measure of implicit self-esteem: The blind men and the elephant revisited? Journal of personality and social psychology. 2000;79(4):631-43.

(22) Dasgupta N, McGhee DE, Greenwald AG, Banaji MR. Automatic preference for White Americans: Eliminating the familiarity explanation. Journal of Experimental Social Psychology. 2000;36(3):316-28.

(23) Greenwald AG, Farnham SD. Using the implicit association test to measure selfesteem and self-concept. Journal of personality and social psychology. 2000;79(6):1022.

(24) Greenwald AG, Nosek BA. Health of the Implicit Association Test at age 3. Zeitschrift für experimentelle psychologie. 2001;48(2):85-93.

(25) Greenwald AG, Nosek BA, Banaji MR. Understanding and using the implicit association test: I. An improved scoring algorithm. Journal of personality and social psychology. 2003;85(2):197.

(26) Nosek BA, Greenwald AG, Banaji MR. Understanding and using the Implicit Association Test: II. Method variables and construct validity. Personality and Social Psychology Bulletin. 2005;31(2):166-80.

(27) Steffens MC. Is the implicit association test immune to faking? Exp Psychol. 2004;51(3):165-79.

(28) Tracy J, Robins R. Putting the self into self-conscious emotions: a theoretical model. Psychological Inquiry. 2004;15:103-25. 
(29) Bynum WEt, Artino AR, Jr. Who Am I, and Who Do I Strive to Be? Applying a Theory of Self-Conscious Emotions to Medical Education. Acad Med. 2017.

(30) Bynum WEt, Goodie JL. Shame, guilt, and the medical learner: ignored connections and why we should care. Med Educ. 2014;48(11):1045-54.

(31) Cruess RL, Cruess SR, Boudreau JD, Snell L, Steinert Y. Reframing medical education to support professional identity formation. Acad Med. 2014;89(11):1446-51.

(32) Cruess RL, Cruess SR, Boudreau JD, Snell L, Steinert Y. A schematic representation of the professional identity formation and socialization of medical students and residents: A guide for medical educators. Academic Medicine. 2015;90(6):718-25.

(33) Mann K, van der Vleuten C, Eva K, Armson H, Chesluk B, Dornan T, et al. Tensions in informed self-assessment: how the desire for feedback and reticence to collect and use it can conflict. Academic Medicine. 2011;86(9):1120-7.

(34) Cope A, Bezemer J, Mavroveli S, Kneebone R. What attitudes and values are incorporated into self as part of professional identity construction when becoming a surgeon. Academic Medicine. 2017;92:544-49.

(35) Henning K, Ey S, Shaw D. Perfectionism, the imposter phenomenon and psychological adjustment in medical, dental, nursing and pharmacy students. Med Educ. 1998;32(5):456-64.

(36) LaDonna K, Watling C, Ginsburg S. "Rising to the Level of Your Incompetence" : Exploring What Physicians' Self-Assessment of Their Performance Reveals About the Impact of the Imposter Syndrome in Medicine. Academic Medicine. 2017(Published ahead of print).

(37) Ashburn-Nardo L. The Importance of Implicit and Explicit Measures for Understanding Social Stigma. 2010.

(38) Gershan D. Explicit and Implicit Stigma of Mental Illness in Mental Healthcare Settings. Norfolk, Virginia: College of William \& Mary; 2013.

(39) Sirota S. Implicit Stigma Against People With Mental Illness: Exploring Explicit and Implicit Beliefs of Clinical Psychology Graduate Students. Chicago School of Professional Psychology2014.

(40) Clement S, Schauman O, Graham T, Maggioni F, Evans-Lacko S, Bezborodovs N, et al. What is the impact of mental health-related stigma on help-seeking? A systematic review of quantitative and qualitative studies. Psychological Medicine. 2015;45(1):11-27.

(41) Corrigan P, Gelb B. Three programs that use mass approaches to challenge the stigma of mental illness. Psychiatr Serv. 2006;57(3):393-8.

(42) Corrigan P, Matthews A. Stigma and disclosure: Implications for coming out of the closet. Journal of mental health. 2003;12(3):235-48.

(43) Corrigan PW. On the stigma of mental illness: Practical strategies for research and social change: American Psychological Association; 2005. 
(44) Corrigan PW. Research and the elimination of the stigma of mental illness. British Journal of Psychiatry. 2012;201(1):7-8.

(45) Corrigan PW, Watson AC. Understanding the impact of stigma on people with mental illness. World psychiatry. 2002;1(1):16-20.

(46) Sukhera J, Miller K, Milne A, Scerbo C, Lim R, Cooper A, et al. Labelling of mental illness in a paediatric emergency department and its implications for stigma reduction education. Perspect Med Educ. 2017:1-8.

(47) Yap MB, Reavley N, Mackinnon AJ, Jorm AF. Psychiatric labels and other influences on young people's stigmatizing attitudes: Findings from an Australian national survey. Journal of Affective Disorders. 2013;148(2-3):299309.

(48) Boardman J, Sauser B. Systems thinking: Coping with 21st century problems. CRC Press; 2008 Jan 17.

(49) Cristancho S. Eye opener: exploring complexity using rich pictures. Perspect Med Educ. 2015;4:138-41.

(50) Cristancho S, Bidinosti S, Lingard L, Novick R, Ott M, Forbes T. Seeing in different ways: introducing "rich pictures" in the study of expert judgment. Qual Health Res. 2015;25(5):713-25.

(51) Charmaz K. Constructing grounded theory: A practical guide through qualitative research. SagePublications Ltd, London. 2006.

(52) Charmaz K. Developing grounded theory: The second generation: Left Coast; 2008.

(53) Charmaz K. Constructing Grounded Theory. 2nd ed. Los Angeles: SAGE; 2014.

(54) Watling CJ, Lingard L. Grounded theory in medical education research: AMEE Guide No. 70. Med Teach. 2012;34(10):850-61.

(55) Hennink M, Kaiser B, Marconi V. Code saturation versus meaning saturation: How many interviews are enough? Qualitative health research. 2017;27:591608.

(56) Morse JM. The significance of saturation. Sage Publications Sage CA: Thousand Oaks, CA; 1995.

(57) O'reilly M, Parker N. 'Unsatisfactory Saturation': a critical exploration of the notion of saturated sample sizes in qualitative research. Qualitative research. 2013;13(2):190-7.

(58) Schlachter S, Rolf S. Using the IAT: how do individuals respond to their results? International Journal of Social Research Methodology. 2017;20(1):77-92.

(59) Wald HS, Anthony D, Hutchinson TA, Liben S, Smilovitch M, Donato AA. Professional identity formation in medical education for humanistic, resilient physicians: pedagogic strategies for bridging theory to practice. Acad Med. 2015;90(6):753-60.

(60) Hafferty FW. Professionalism and the socialization of medical students. Cruess RL, Cruess SR, Steinert Y, editors. Cambridge, UK: Cambridge University Press; 2009. 
(61) Monrouxe LV. Identity, identification and medical education: Why should we care? Medical Education. 2010;44:40-9.

(62) Hafferty FW. Beyond curriculum reform: confronting medicine's hidden curriculum. Acad Med. 1998;73(4):403-7.

(63) Cohen MJ, Kay A, Youakim JM, Balaicuis JM. Identity transformation in medical students. Am J Psychoanal. 2009;69(1):43-52.

(64) McCranie EW, Brandsma JM. Personality antecedents of burnout among middle-aged physicians. Behavioral Medicine. 1988;14:30-6.

(65) Cole TR, Carlin N. The suffering of physicians. The Lancet. 2009;374:1414-5.

(66) Clance $P$, Imes $S$. The imposter phenomenon in high achieving women: Dynamics and therapeutic intervention. . Psychotherapy: Theory, Research \& Practice. 1978;15:241.

(67) Thompson T, Foreman P, Martin F. Impostor fears and perfectionistic concern over mistakes. Pers Individ Differ. 2000;29:629-47.

(68) Bynum WEt. Filling the feedback gap: the unrecognised roles of shame and guilt in the feedback cycle. Med Educ. 2015;49(7):644-7.

(69) Sargeant J, McNaughton E, Mercer S, Murphy D, Sullivan P, Bruce DA. Providing feedback: exploring a model (emotion, content, outcomes) for facilitating multisource feedback. Medical Teacher. 2011;33(9):744-9.

(70) Sargeant JM, Mann KV, van der Vleuten CP, Metsemakers JF. Reflection: a link between receiving and using assessment feedback. Advances in Health Sciences Education. 2009;14(3):399-410.

(71) Telio S, Ajjawi R, Regehr G. The "educational alliance" as a framework for reconceptualizing feedback in medical education. Acad Med. 2015;90(5):609-14.

(72) Sargeant J, Lockyer J, Mann K, Holmboe E, Silver I, Armson H, et al. Facilitated Reflective Performance Feedback: Developing an Evidence- and Theory-Based Model That Builds Relationship, Explores Reactions and Content, and Coaches for Performance Change (R2C2). Academic Medicine. 2015;90(12):1698-706.

(73) Andreychik MR, Gill MJ. Do negative implicit associations indicate negative attitudes? Social explanations moderate whether ostensible "negative" associations are prejudice-based or empathy-based. Journal of Experimental Social Psychology. 2012;48(5):1082-93.

(74) Banaji MR, Nosek BA, Greenwald AG. No place for nostalgia in science: A response to Arkes and Tetlock. Psychological Inquiry. 2004;15(4):279-89.

(75) Blanton H, Jaccard J, Christie C, Gonzales PM. Plausible assumptions, questionable assumptions and post hoc rationalizations: Will the real IAT, please stand up? Journal of Experimental Social Psychology. 2007;43(3):399-409.

(76) Singal J. Psychology's favorite tool for measuring racism isn't up to the job. NY Mag. 2017 January 11, 2017. 



\section{CHAPTER 7}

\section{Adaptive Reinventing: Implicit Bias and the Co-Construction of Social Change}

Published as:

Sukhera, J., Milne, A., Teunissen, P.W., Lingard, L., Watling, C. Adv in Health Sci Educ (2018). https://doi-org.proxy1.lib.uwo.ca/10.1007/s10459-018-9816-3

(C) 2018 Springer 


\begin{abstract}
INTRODUCTION: Emerging research on implicit bias recognition and management within health professions describes individually focused educational interventions without considering workplace influences. Workplace learning theories highlight how individual agency and workplace structures dynamically interact to produce change within individuals and learning environments. Promoting awareness of individual biases shaped by clinical learning environments may therefore represent a unique type of workplace learning. We sought to explore how individuals and the workplace learning environment interact once awareness of implicit biases are triggered within learners.
\end{abstract}

METHOD: In accordance with longitudinal case study methodology and informed by constructivist grounded theory, we conducted multiple longitudinal interviews with physician and nurse participants over 12 months.

RESULTS: Our results suggest that implicit bias recognition provokes dissonance among participants leading to frustration, and critical questioning of workplace constraints. Once awareness is triggered, participants began reflecting on their biases and engaging in explicit behavioural changes that influenced the perception of structural changes within the learning environment itself. Collaboration, communication and role modeling within teams appeared to facilitate the process as individual and workplace affordances were gradually transformed.

CONCLUSION: Our findings suggest a potential model for understanding how individual learners adaptively reinvent their role in response to disruptions in their learning environment. 


\section{Introduction}

Workplace learning theorists describe how social forces within clinical learning environments influence the interaction between individuals and their workplace. While some workplace learning theories emphasize social structures and minimize the role of individual agency, theorists such as Eraut and Billet describe learning as a process of real-world engagement between individuals and workplace environments ${ }^{1,2}$. Therefore, learning in the workplace will depend on the individual's preexisting cognitive experiences and the interaction between individual and social norms ${ }^{3}$. Any learning environment may also contain tacit influences including norms that impact individual behaviour ${ }^{4}$ while remaining unrecognized ${ }^{2}$ If a learning activity that provokes awareness of these norms is introduced, individual learners are likely to engage with and construct workplace practices as they negotiate and remake their learning environment ${ }^{3}$. Emerging literature on implicit bias within health professions education posits that implicit biases are the result of latent forces that lead to stereotype-based assumptions about certain patient groups ${ }^{5-7}$. Managing implicit biases among learners is often difficult because they enact their influence outside conscious awareness ${ }^{8,9}$. Despite recent efforts to integrate implicit bias into health professions education, research has largely centered on individual interventions without considering workplace influences ${ }^{10}$.

There are several reasons why implicit bias recognition curricula may involve a unique form of workplace learning. Exercises such as the implicit association test (IAT), which use response latency to bring implicit biases into conscious awareness for learners ${ }^{11}$ may trigger dissonance for learners. Once such awareness is triggered, exploring the process of negotiation that ensues may provide insight regarding the processes that shape and remake workplace practices. If extended further, fostering awareness of individual implicit biases includes awareness of how such biases are shaped by roles, norms and structures within the workplace environment. Therefore, increasing awareness of implicit bias may trigger both dissonance and critical reflexivity ${ }^{12-14}$, influencing the process of learning within the workplace in novel ways.

As part of our effort to grapple meaningfully with the issue of implicit bias in the workplace, we sought to explore how individuals and workplace learning environments influence each other to produce change following a learning activity that disrupts workplace norms. We hoped to draw out how the process of bringing implicit biases into conscious awareness influenced workplace learning and how implicit bias recognition and management could potentially shape workplace transformation.. 


\section{Methods}

Our study was designed utilizing the overarching methodology of an instrumental case study. Literature on qualitative case study research describes how to explore a topic through a rich and in-depth investigation. An instrumental case is used to improve an understanding about a question while the case plays a supportive or secondary role ${ }^{15}$. We adopted a longitudinal interviewing strategy, which provides an opportunity to explore change in both individual and group trajectories through time ${ }^{16}$.

Both Stake ${ }^{15}$ and Yin $^{17}$ have described case studies in accordance with a constructivist paradigm ${ }^{18}$. Constructivism assumes that individuals construct the realities in which they participate, and constructivist grounded theory affords the researcher an opportunity to engage in inductive analysis of themes. Our approach to collection and analysis of interview data was consistent with principles of constructivist grounded theory, as we iteratively collected data and engaged in constant comparative analysis to build a conceptual framework ${ }^{19,20}$.

Our intention from the inception of this study was to explore how individuals respond to change and exercise their agency within the workplace environment; it was not to evaluate a learning activity. Our intervention served as a prompt to explore the disruption in the workplace environment and how workplace learning proceeded from this disruption. Our approach to qualitative research was rooted in a desire to understand the dynamic social process of how our educational program could become adapted and embedded in routine practice ${ }^{21}$.

\section{Setting and intervention}

Our work began through the lived experience and observations of the principal investigator, which suggested that the emergency department is particularly suited to exploring interactions and change related to implicit bias. We anticipated that the cognitive pressures of an emergency department workplace ${ }^{22}$ would be a suitable setting to explore the dynamic influences between individuals and the workplace.

We conducted a 4-h learning activity for practicing physician and nurse attendees, which was informed by research suggesting that implicit labeling and avoidance behaviours by health providers are perceived as discriminatory by patients and caregivers ${ }^{23}$. Using these findings, and informed by existing literature on implicit bias recognition and management $24-29,6,8,10$, we designed a curriculum that included didactic lecture, group discussion, role play, debriefing and self-reflection exercises. The training aimed to bring implicit bias regarding individuals with mental illness into conscious awareness for learners, and to foster critical reflection while enhancing conscious efforts to overcome bias. The activity began with an individual and group reflection exercise on how cultural practices and history in- 
fluence the development of workplace norms. This exercise was followed by didactic teaching on the science of implicit bias which emphasized how implicit bias influences individual behaviours and patient outcomes in the context of an emergency department. Participants then engaged in a role-play exercise to foster empathy and perspective-taking, followed by case discussion using examples relevant to the participants' context. The activity concluded with group discussion that consolidated key points.

\section{Study participants}

We used purposeful theoretical sampling, seeking equal representation from physicians and nurses. Of the 21 workshop attendees (10 physicians and 11 nurses), 10 agreed to participate in longitudinal interviews and an additional 4 participants agreed to participate in a single interview approximately 12 months after the intervention. Of these 14 participants, 7 were nurses and 7 were physicians. Once two sets of longitudinal interviews were completed with the original 10 participants, the 4 additional participants were recruited to explore key themes identified in our initial data.

\section{Data collection and analysis}

After the April 2016 intervention, the first interviews took place from June to August of 2016. Participants took part in 45-60 min semi-structured interviews, with a physician conducting the physician interviews and a nurse conducting the nursing interviews. We asked participants to reflect on changes in their attitude or behaviour since the educational activity, and on how their individual learning was influenced by their workplace environment. Using the iterative approach characteristic of grounded theory, data collection and data analysis unfolded concurrently. For example, we revised the discussion guide after the first several interviews to include questions about perceived changes in self and observed changes in others, as we identified these ideas as potentially important in initial transcripts. We invited the same participants for longitudinal follow-up interviews, 8-10 months after their initial meeting.

Interviews were transcribed and analyzed using line by line coding, followed by selective and then axial coding to explore the relationships among codes. We used an analytic approach of constant comparison, consistent with grounded theory principles; by comparing data within and across codes, we were able to raise the level of analysis from the categorical to the conceptual. Data collection and analysis continued until theoretical sufficiency was established to support a conceptual model of results ${ }^{30}$. 


\section{Reflexivity}

Our research team included a child and adolescent psychiatrist and doctoral student in health professions education (JS), a registered nurse in paediatrics and mental health (AM), and three experienced qualitative health professions education researchers, two of whom are physicians with experience studying learning in clinical settings (PT and CW), and one of whom is a Ph.D.-trained researcher with a background in rhetoric and experience studying health care team function, professional identity formation and workplace learning (LL). AM provided research support and was recruited to participate as a registered nurse to ensure that both a physician and nurse were engaged in collection and analysis from the inception of the study. AM conducted the nurse interviews and JS conducted the physician interviews. JS completed line by line coding with regular consultation and discussion with AM. As selective and axial coding began and relationships emerged, CW was consulted and participated in analysis throughout the process. LL and PT provided input into study design and methods and were involved in discussions about results as they were synthesized and nascent theory was developed. The authors remained attentive to discrepant examples during analysis, ensuring that any theory building could account for their occurrence.

\section{Results}

As illustrated by Fig. 1, our results suggest that, once individual biases were brought into conscious awareness, participants experienced dissonance between their idealized role and their current practices. Participants' initial helplessness and frustration prompted reflection on workplace factors that constrained their efforts to create change. The cultivation of a safe environment for discussing bias allowed participants to critically reflect, and motivated them to make behavioural changes, even if these changes challenged sociocultural norms. Over time, small behavioural changes were modeled and observed by others, workplace norms were questioned, and gradual shifts within individuals, teams, and the environment itself were noted. 


\section{Figure 1}

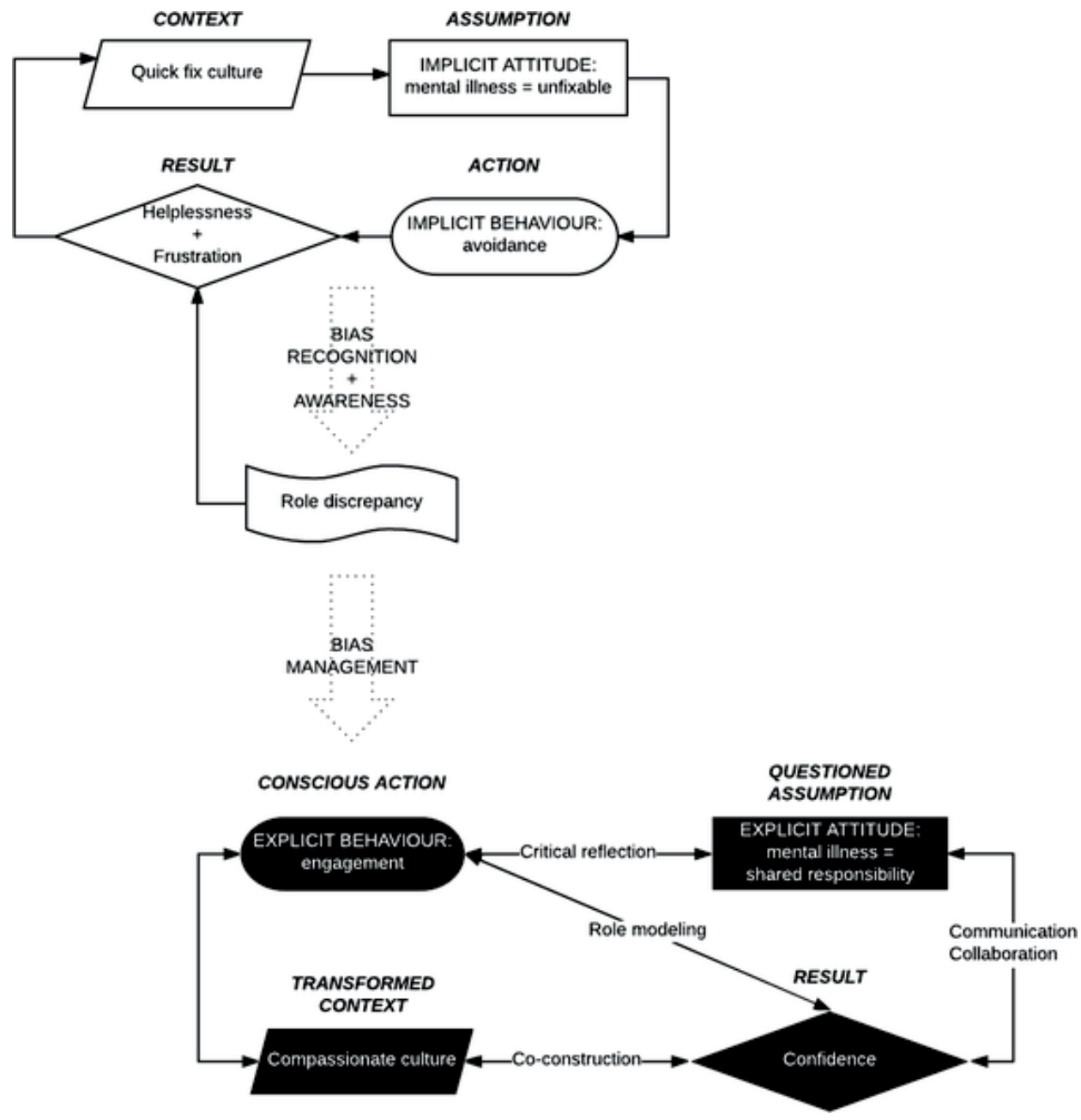

Figure 1 - Illustrates existing workplace norms, behaviours and how implicit bias recognition and management provoked adaption of behaviours through critical questioning of assumptions. Percieved changes were reinforced through role modeling, communication and collaboration 


\section{Awareness triggers frustration, highlighting workplace constraints}

As implicit biases were brought into conscious awareness, most participants described a sense of frustration that they were not fulfilling their idealized role with individuals with mental illness. They knew that patients with mental illness were often avoided, and they perceived themselves as unable and ineffective with this patient population. One physician described an "inability to cope," leading to a desire to avoid patients and send residents to interact with them instead (MD1), while another physician noted that the workshop raised questions about whether patients with mental illness are "in the right place," stating, "Do I have the skills to deal with this? Like, I wish I knew more!" (MD2) Another physician described how the workshop exposed feelings of helplessness, highlighting a "lack of control" over the "patient's journey," as a "recipe for frustration." (MD3).

Several nurses also acknowledged that awareness of their biases was related to feelings of doubt and helplessness:

Because I can't fix them. I can't give them an Advil and make them better. I can't hook them up to a monitor to check that their heart is okay. I have no resources and no things to help them so that will foster a bias for everybody. (RN5)

In addition to frustration, all participants described in their initial interviews that their ability to apply what they had learned was subject to workplace constraints that were outside their individual control. For example, participants did not believe that mere awareness of implicit biases towards individuals with mental illness would change an emergency room culture that emphasizes time and efficiency. One physician described a "hidden curriculum" in the emergency department, where the incentives provided for efficient care delivery restrict physicians' ability to engage.(MD1). A nurse described how patients with mental illness pose a challenge within such a culture:

...unfortunately some things take time and mental health sometimes is not something you can fix in a two-minute conversation or an hour-long conversation... and I think that's where we struggle because we want people in and out of our emergency department really quickly because then we know that we've helped them. (RN2)

\section{Once bias is recognized, participants adapt through explicit changes in behaviour}

Participants' heightened awareness of how implicit biases influence the healthcare experience for patients with mental illness, coupled with their own frustration at the realities of their workplace, often triggered cognitive dissonance. Over time, 
participants appeared to reflect on this dissonance and to share their frustration with their peers. We found that this process of reflection-particularly when a safe environment to do so was present-seemed to motivate participants to adaptively reinvent their role within their workplace environment.

Participants reflective efforts were directed both inward, toward the self, and outward, toward peers and the workplace. Participants described a reflective process that was conscious and included critical questioning of assumptions and roles:

I think that's what the workshop was really good at, opening people's mind to the fact that maybe not everything - maybe they do need to be self-analyzed a little more because maybe a lot of these ingrained habits are not based on the ideals that they would necessarily want them to be based on. (MD3)

Most participants highlighted questioning as a force that both motivated change and reinforced new behaviours. Questioning facilitated a shift in thinking, away from the idea that patients with mental illness cannot be fixed, and toward the idea of shared responsibility for providing high quality patient care. Several months after the intervention, for example, one nurse participant described questioning a policy that required them to fill out a violence sheet for all mental health patients (RN4), and a physician described how their awareness led to consistent questioning when differences in care were identified,

...if there's any kind of patient that is not being seen as timely as another patient, I always look through the lens of why this could be happening...So every time I see that happening, every shift that I have, I think to myself 'Are we being biased against this patient?' (MD3)

Awareness fostered behavioural changes among our participants; many described consciously replacing their biased behaviours with new ones, such as engaging with patients instead of avoiding them. A physician described how their new awareness shaped a change in their behaviours:

I probably am going into the rooms a little bit more, like having empathy for the fact that these patients have been somewhat marginalized to the house staff. Whereas ... we tend to show more of an interest in the medical patients, because that's our thing. (MD5)

Several participants shared that talking about bias in an open and safe environment promoted reflection and discussion. One physician stated that they were more likely to "volunteer" information about their biases and that the subsequent discussion promoted further reflection (MD3), and another noted that promoting a learning environment where individuals would not feel "judged" by others reduced their feeling of being "threatened" and promoted open discussion (MD5). By inviting dialogue, participants described a process of collaboration and sharing with their peers. One nurse stated that they previously felt alone and now they realized 
that their colleagues are "in the same boat" (RN4). The same participant shared that knowing that "people that I work with who are just as uncomfortable as I am," helped to provide "courage" to change (RN4).

\section{Behaviour changes are reinforced through communication, collaboration and role modeling among peers}

Communication and collaboration among peers were also perceived as important to sustaining change. For example, one physician participant suggested that if change agents were individuals with "social" influence, then their involvement in learning activities would have a greater impact on the workplace environment (MD3), while a nurse participant mentioned how change can persist despite barriers if change agents are "persuasive enough talkers." (RN4). Another physician described a specific instance where, after the intervention, a nurse stood up to advocate for a teen who was struggling with mental illness and colleagues perceived her actions as "a small act of advocacy" that made a significant difference to those who witnessed it:

But this nurse, I remember her saying 'No, you need to go back into the department and we're going to find a bed for this kid." She was very good about advocating for this patient rather than letting them sit out in the waiting room... I'm not sure if more than a year ago I would've seen that. So small acts of advocacy, even when we're limited in space makes a difference and I think that slowly does trickle down to everyone else who-Because a lot of, especially our junior nurses are learning by example and if you get the good example then they're going to follow it. (MD2)

More specifically, once individual awareness of implicit bias was brought into explicit awareness and behaviors adapted, discussion and observation among and between peers helped to decrease fear and improve confidence. Participants described how modifying communication patterns influenced behaviours and promoted change. Most noted that there were changes in communication with both patients and peers, which gradually shifted behaviour across the workplace:

If you highlight a problem and you do it in enough that where it's broad enough that people have the same language, I think it's much more likely to stick and become the new norm. I think if you have like two people and they're advocating for a certain change, I think it's harder to get that momentum going where people have that license to say "Oh yeah, we talked about this workshop, remember?" or, you know, that kind of stuff. I think when you have enough penetrance into the group, I think you're much more likely to have change. (MD3)

Most participants described the role of the team and how team members influence one another to promote and sustain change. 
It's a team effort so the fact that if one person forgets to check on them (patient with mental illness)...then there's someone to be like, 'hey we can't forget this person,' and then I think the next time they get someone (with mental illness), they're more like to be like, 'right, this is something that is important and I need to pay attention... (RN7).

Participants increasingly recognized the value of role-modeling in supporting change. Discussion of the influence of role models was more prominent in the later than earlier interviews. Nurse participants made several references to the difference between junior and senior staff. One described the importance of influencing junior nurses because senior staff are "set in their ways." (RN2). Several participants also suggested that newer staff model the behaviours of more senior nurses. As one nurse explained,

I think that there is more change. I think that the newer staff kind of look at how some of our older staff treat -not older staff, but other staff treat the patients and I think they are trying to make their practice similar to that. So I see a lot of the newer staff offering stuff like food and drinks and making sure that they have everything they need for their patients. (RN1)

Several nurse participants also described how role-modeling occurred across and between generations of nurses. For example, one nurse described the importance of role modeling a "calming influence" on others, stating,

I am at a point in my career where not only can I role model for people who have less experience than me, but I can also do that to people who have more experience than by by how I interact with them and how I can ask questions...I don't think it's effective to just challenge them straight up; I think that if you can get people to be slightly reflective in that moment, that they'll probably come to the right conclusions on their own. (RN4)

\section{When confidence increases, some individuals become affordances}

During the initial interviews, participants' confidence that they could influence the workplace learning environment was variable. Some participants felt that individual change could transform culture and structures, while others initially felt individuals could not change the learning environment. For those who felt they could influence their workplace, the idea that they were a role model to younger staff and trainees increased their sense of self-efficacy, thereby providing increased impetus for change. Some participants even expressed a sense of control over structural barriers. For example, one physician affirmed their personal value of finding patient-centered solutions, despite the emergency department's emphasis on efficiency:

My bias is to minimize my exposure to them, but that that is not necessarily the best for the patient, so just trying to work actively to overcome that...I 
remind myself that there is a possibility that this is not going to be as time consuming...that helps me kind of say...Let's go see this patient and get things going. (MD5)

In their follow up interviews, participants described that individuals and environments influenced each other in mutually reciprocal ways. While initial interviews suggested that structural and cultural forces influenced learners and diminished changes in perspective and practice, follow-up data suggested that learners with high confidence and agency might influence change in structures and cultures. One nurse participant who after the initial interview stated, "I know I'm not the greatest mental health nurse" stated that despite "systemic barriers" they felt change was possible even several months after the initial education (RN2). For example, this nurse acknowledged how time is a barrier to change yet stated, "I think that sometimes you may not be able to spend like a long period but you need to make sure that it's quality time that you're spending...sometimes it's not like quantity over quality" (RN2). They went on to state, "I think there's always going to be barriers no matter what and we're always going to have to figure out how to get around them (RN2)."

A physician participant denied that time and emergency culture was a barrier to change, emphasizing that when a patient with mental health difficulties may potentially experience unequal treatment, there should be a commitment to "making it work." (MD2). A nurse stated,

I think any little bit that we can try to do to overcome them (barriers) is going to be positive, and I don't think that because of the barriers we should stop trying to do it. Yes, there still are some major barriers...But I think that some of the tools that we've learned in the workshop and the perspectives that we've gained from it that the barriers will still be there, but we can still take from that and utilize that. (RN5)

While all participants described a change in their workplace over time, their characterizations of the degree of change within the learning environment varied. One described the change as "slight" (MD2), while another described change as a "passive observation" of "less pushback" from staff regarding engaging with mental health patients (MD6). When asked about more specific examples of how change was sustained over time, there was contradiction among most participants. Upon analyzing this contradiction further, it appeared that participants acknowledged some type of change while denying change in other domains. Participants who were the most critical of change also acknowledged that their awareness of biases in themselves and their learning environment had shifted. For example, one nurse participant initially stated: "Nothing has really changed as far as my ability to guide the patient and to assist all the team members and work together. I don't feel like my role has really changed that much." (RN5) They shared in the same interview that their "awareness" of their biases increased and they reflected more about 
how their biases influenced their patients, "I'm realizing 'okay this is why you're thinking this' and 'this is what you've seen' so I'm more aware instead of just automatically not being aware..." (RN5).

One physician noted that the change became less noticeable over time because new behaviours were replaced with new attitudes that became "assumed" and "automatic." They went on to explain:

So if there's a change in the culture, the way you described that here's a new dominant force, that this is not what we're going to do. This is a new normal. (MD3)

Overall, participants described a process where, through initial questioning, they communicated and collaborated with colleagues to co-construct change within themselves and their learning environment, transforming themselves and their workplace over time.

\section{Discussion}

Our participants suggested that, as education brings implicit bias to explicit awareness for individual learners, the resulting dissonance between the individual and their learning environment prompts critical reflection. As individuals adapt with new behaviours, observing and discussing with peers can decrease fear and improve confidence. Eventually, behaviours that are modeled through social influence are perceived to increase, and individuals describe the process of remaking their learning environment. Our findings illuminate the relational interdependence between individuals and workplaces described by other theorists, while emphasizing the critical role of role models as key workplace affordances. We illustrate a conceptual model derived from these findings in Fig. 1.

Efforts to promote awareness of implicit bias and to manage its impact demand a particularly challenging kind of workplace learning-one that provokes critical questioning of norms. Our participants described a gradual process from the dissonance triggered once implicit biases were brought into conscious awareness, and a suggested resolution through the adoption of more egalitarian and empathic behaviour. Barriers to this behavior change, although daunting at first, tended to be perceived as less salient over time.

Our participants described an initial resistance to change that was influenced by the culture and structure of the emergency environment. This observation reinforces previous descriptions of the structures that can influence individual learning. For example, social and cultural structures embedded in practice may constrain or enable opportunities for participation ${ }^{31}$. Recurrent patterns of activities over time give rise to a shared and negotiated system of socially and culturally meaningful structures that become reified over time; as a result, healthcare environments often 
resist change ${ }^{32}$. In response to educational experiences, learners therefore have the potential to re-create the environments in which they work and learn, and to shape what opportunities there are for change ${ }^{33}$.

Once confronted with awareness about their biases, our participants seemed to approach their dilemma with a new behaviour. The specific process of change described by our participants provides an example of how individual agency is shaped by social forces. Exercising agency requires effort and conscious intentions by learners ${ }^{3}$. Through workplace participation, learners encounter a series of behaviours that they try out which may or may not produce change. These behaviours involve social interaction and are always set within social and cultural contexts 34,35 . Our participants appear to have been influenced by the social context of their nearpeers, fostered through open communication, confidence building and shared experience. This process of "co-construction" of knowledge through relational interaction with a social source ${ }^{36}$, is illustrated in our participants who perceived their ability to influence social and structural change within their learning environment.

Our findings also call attention to how role models shape the process by which individuals become affordances. The social process of sharing, modifying communication and explicit role modeling may thereby increase agency and shape the development of a more equitable workplace culture. Over time, individuals may become affordances and shape tacit knowledge for future participants. Almost all our participants referenced how awareness of their role as teachers for junior staff reinforced the modeling of new behaviours despite workplace constraints.

The role of a safe space in which to grapple with the challenge of implicit bias across the professions merits attention. We deliberately created our intervention with equal numbers of both physician and nurse participants. Several participants noted that this learning activity was the only activity since they have entered into practice where physicians and nurses learned together. This information is useful to consider for future research as continuing medical education activities outside of the workplace at conferences or seminars may not facilitate sharing and coconstruction in the same manner as delivering implicit bias recognition and management programs within workplace environments.

There are several limitations to this work. Most notably, we conducted a research study with a group of participants that engaged in a learning activity that was designed and led by two of the authors. This creates a dilemma related to social desirability and should be considered as part of the interpretation of our results. Most co-authors had no role in the educational intervention, which helped filter data analysis and interpretation through multiple perspectives. Our data were also limited to interviews, and not all workshop participants agreed to be interviewed. Thus, we acknowledge both the inherent limitation that interviews represent selfreport and that those who participated may have had views that were distinct from those who did not. Despite these limitation, our study provides a detailed description on how individual and social interactions may shape what Billet describes as

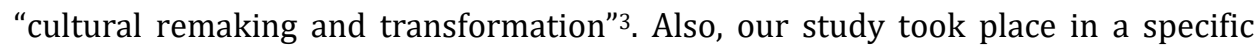


workplace setting and culture of a paediatric emergency department and results are necessarily a product of that context. However, our thick and explicit descriptions of contextual factors, methods and analysis of raw data ${ }^{15,37}$ should facilitate consideration of transferability by our audience.

Our exploration of implicit bias as a type of workplace learning underscores the need for further research on how individual agency is fostered to facilitate cultural, structural and social change. Our experience suggests that since the ability to exercise agency to effect change may be gradually acquired and deployed, research approaches that can address the temporal dynamics of change, such as longitudinal interviewing, may be especially valuable.

\section{Acknowledgements}

This study was supported by grants from the Academic Medical Organization of Southwestern Ontario, Childrens' Health Foundation London Health Sciences Centre and Associated Medical Services—Phoenix Fellowship 


\section{References}

(1) Billett S. Workplace participatory practices: conceptualising workplaces as learning environments. J Workplace Learn. 2004;15(5/6).

(2) Eraut M. Informal learning in the workplace. Studies in continuing education. 2004;26(2):247-73.

(3) Billett S. Subjectivity, Self and Personal Agency in Learning Through and for WOrk. In: Malloch M, Cairns L, Evans K, O'Connor B, editors. The SAGE Handbook of Workplace Learning: Sage Publications; 2010. p. 60-72.

(4) Doornbos AJ, Bolhuis S, Simons PR-J. Modeling work-related learning on the basis of intentionality and developmental relatedness: A noneducational perspective. Hum Resour Dev Rev. 2004;3(3):250-74.

(5) Greenwald AG, Banaji MR. Implicit social cognition: attitudes, self-esteem, and stereotypes. Psychol Rev. 1995;102(1):4.

(6) Zestcott CA, Blair IV, Stone J. Examining the Presence, Consequences, and Reduction of Implicit Bias in Health Care: A Narrative Review. Group Process Intergroup Relat. 2016;19(4):528-42.

(7) Chapman EN, Kaatz A, Carnes M. Physicians and implicit bias: how doctors may unwittingly perpetuate health care disparities. J Gen Intern Med. 2013;28(11):1504-10.

(8) Teal CR, Gill AC, Green AR, Crandall S. Helping medical learners recognise and manage unconscious bias toward certain patient groups. Medical education. 2012;46(1):80-8.

(9) Dovidio JF, Gaertner SL. Aversive racism and selection decisions: 1989 and 1999. Psychol Sci. 2000;11(4):315-9.

(10) Sukhera J, Watling C. A Framework for Integrating Implicit Bias Recognition Into Health Professions Education. Acad Med. 2018;93(1):35-40.

(11) Greenwald AG, McGhee DE, Schwartz JL. Measuring individual differences in implicit cognition: the implicit association test. Journal of personality and social psychology. 1998;74(6):1464.

(12) Hernandez R. Medical Students' Implicit Bias and the Communication of Norms in Medical Education. Teach Learn Med. 2018;30(1):112-7.

(13) Hernandez RA, Haidet P, Gill AC, Teal CR. Fostering students' reflection about bias in healthcare: Cognitive dissonance and the role of personal and normative standards. Medical teacher. 2013;35(4):e1082-e9.

(14) Sukhera J, Milne A, Teunissen PW, Lingard L, Watling C. The Actual Versus Idealized Self: Exploring Responses to Feedback About Implicit Bias in Health Professionals. Acad Med. 2017.

(15) Stake RE. The art of case study research: Sage; 1995.

(16) Balmer DF, Richards BF. Longitudinal qualitative research in medical education. Perspect Med Educ. 2017;6(5):306-10.

(17) Yin RK. Case study research: Design and Methods: SAGE publications; 2009.

(18) Baxter P, Jack S. Qualitative case study methodology: Study design and implementation for novice researchers. The qualitative report. 2008;13(4):544-59. 
(19) Charmaz K. Constructing grounded theory: A practical guide through qualitative research. SagePublications Ltd, London. 2006.

(20) Kennedy TJ, Lingard LA. Making sense of grounded theory in medical education. Medical education. 2006;40(2):101-8.

(21) Teherani A, Martimianakis T, Stenfors-Hayes T, Wadhwa A, Varpio L. Choosing a qualitative research approach. Journal of graduate medical education. 2015;7(4):669-70.

(22) Chan T, Mercuri M, Van Dewark K, Sherbino J, Schwartz A, Norman G, et al. Managing Multiplicity: Conceptualizing Physician Cognition in Multi-Patient Environments. Acad Med. 2017.

(23) Sukhera J, Miller K, Milne A, Scerbo C, Lim R, Cooper A, et al. Labelling of mental illness in a paediatric emergency department and its implications for stigma reduction education. Perspect Med Educ. 2017:1-8.

(24) Ross HJ. Everyday bias: Identifying and navigating unconscious judgments in our daily lives: Rowman \& Littlefield; 2014.

(25) Schlachter S, Rolf S. Using the IAT: how do individuals respond to their results? International Journal of Social Research Methodology. 2017;20(1):77-92.

(26) Staats C, Capatosto K, Wright RA, Contractor D. State of the science: Implicit bias review 2014. Kirwan Institute for the Study of Race and Ethnicity http://kirwaninstitute/ osu edu/wp-content/uploads/2014/03/2014implicit-bias pdf. 2014.

(27) Stone J, Moskowitz GB. Non-conscious bias in medical decision making: what can be done to reduce it? Med Educ. 2011;45(8):768-76.

(28) Teal CR, Shada RE, Gill AC, Thompson BM, Frugé E, Villarreal GB, et al. When best intentions aren't enough: helping medical students develop strategies for managing bias about patients. Journal of general internal medicine. 2010;25(2):115-8.

(29) van Nunspeet F, Ellemers N, Derks B. Reducing implicit bias: How moral motivation helps people refrain from making "automatic" prejudiced associations. Translational Issues in Psychological Science. 2015;1(4):382-91.

(30) O'reilly M, Parker N. 'Unsatisfactory Saturation': a critical exploration of the notion of saturated sample sizes in qualitative research. Qualitative research. 2013;13(2):190-7.

(31) Wearne S, Dornan T, Teunissen PW, Skinner T. General practitioners as supervisors in postgraduate clinical education: an integrative review. Med Educ. 2012;46(12):1161-73.

(32) Teunissen PW. Experience, trajectories, and reifications: an emerging framework of practice-based learning in healthcare workplaces. Adv Health Sci Educ Theory Pract. 2015;20(4):843-56.

(33) van der Zwet J, Zwietering PJ, Teunissen PW, van der Vleuten CP, Scherpbier AJ. Workplace learning from a socio-cultural perspective: creating developmental space during the general practice clerkship. Adv Health Sci Educ Theory Pract. 2011;16(3):359-73.

(34) Teunissen P, Boor K, Scherpbier A, Van der Vleuten C, Diemen-Steenvoorde V, Van Luijk S, et al. Attending doctors' perspectives on how residents learn. Medical education. 2007;41(11):1050-8. 
(35) Teunissen P, Scheele F, Scherpbier A, Van Der Vleuten C, Boor K, Van Luijk S, et al. How residents learn: qualitative evidence for the pivotal role of clinical activities. Medical education. 2007;41(8):763-70.

(36) Valsiner J. Culture and human development: A co-constructionist perspective. Annals of theoretical psychology: Springer; 1994. p. 247-98.

(37) Popay J, Rogers A, Williams G. Rationale and standards for the systematic review of qualitative literature in health services research. Qualitative health research. 1998 May;8(3):341-51. 
CHAPTER 8

\section{Discussion}




\section{Summary of Research Findings}

Five interconnected research studies contained within this thesis sought to explore the process of teaching and learning about implicit bias as it relates to individuals and clinical learning environments.

In chapter three we learned that implicit labeling of patients with mental illness as time-consuming or unfixable led to unintentional avoidance behaviours from physicians and nurses, which were perceived as prejudicial and discriminatory by patients and caregivers. This study found that education that focuses on patientprofessional relationships and fosters common human identities has the potential to improve empathy and reduce disparities.

Chapter four described how participants experienced tension when provided with feedback about their implicit bias. Participants found that learning about their implicit biases might conflict with an idealized version of themselves that was impossible to achieve. They also described how as health professionals, they felt they should not hold biases, while in their personal lives, they acknowledged that biases are pervasive. This study suggested that once individuals were made aware of their implicit biases through education, they needed to confront and negotiate the tension between their professional and their idealized selves in order to manage these biases effectively.

Chapters five and six explored how potentially threatening feedback about implicit biases is processed and integrated and how resulting tensions are reconciled. In these studies participants critiqued the implicit association test (IAT) and questioned its credibility, but also described the experience of receiving feedback about their biases as positive or neutral. Once implicit biases were brought into conscious awareness, participants suggested that they reconciled identity tensions through a process described as striving for the ideal while accepting the actual. They also reported that relational dynamics appeared to influence the process.

Chapter seven provided a longitudinal exploration of how individuals and their clinical learning environment dynamically influence one another once hidden biases have been revealed. Consistent with previous chapters, implicit bias recognition provoked dissonance leading to frustration and critical questioning of workplace constraints. As participants reflected on their biases, they began engaging in explicit behavioural changes that contributed to the perception of structural changes within the environment itself. Collaboration, communication and role modeling within interprofessional teams appeared to facilitate the process of perceived change as individual and workplace affordances gradually transformed. 
Together, this body of research proposes:

1) Implicit biases may provoke behaviours that are perceived by patients as discriminatory or prejudicial, despite the best intentions and conscious goals of the health professionals involved.

2) Facilitating conscious awareness of an individual's implicit biases is a unique form of feedback that may provoke tension, trigger reflection and motivate behaviour change.

3) Reconciling bias-related feedback requires striving for the ideal version of an individual's professional identity while accepting their intrinsic humanity and vulnerability.

4) Implicit bias recognition and management for health professions involves an iterative process of feedback seeking, role reflection, and practice change that centers upon sharing and dialogue. 


\section{General Discussion}

\section{Advancing Implicit Bias Recognition and Management Curricula}

Mitigating bias through education is complicated, and some previous research has attempted to grapple with the challenge. Several authors have described how bringing biases into awareness through exercises such as completing the IAT and engaging in discussion and reflection may be useful ${ }^{1-6}$ yet multiple reviews acknowledge that such activities may prompt negative reactions and defensive attitudes from health professionals ${ }^{7,8}$ Others describe how fostering mindful practice ${ }^{9}$ or slowing clinical decision making ${ }^{10}$ may be sufficient. A further educational strategy involves breaking bias habits through changing habitual responses ${ }^{11}$. Longitudinal strategies may be required; for example, Byrne \& Tanesini suggest that single interventions have limited potential to effect meaningful change, and instead promote the inculcation of new habits through ongoing efforts to couple critical reflection and automatic stereotypic suppression ${ }^{12}$. Therefore, addressing implicit bias through education involves awareness, reflection and practice.

Our research adds several new insights to the understanding of how education might be effectively applied to the problem of implicit bias. We found that feedback seeking, role reflection, goal setting and role modeling can be supported and sustained through sharing and dialogue. Recognizing and managing implicit biases also requires a balance between striving for ideals while accepting shortcomings. The process cannot be achieved by individuals alone. Figure 1 below depicts a synthesis of all findings as an integrated theory of implicit bias recognition and management. 


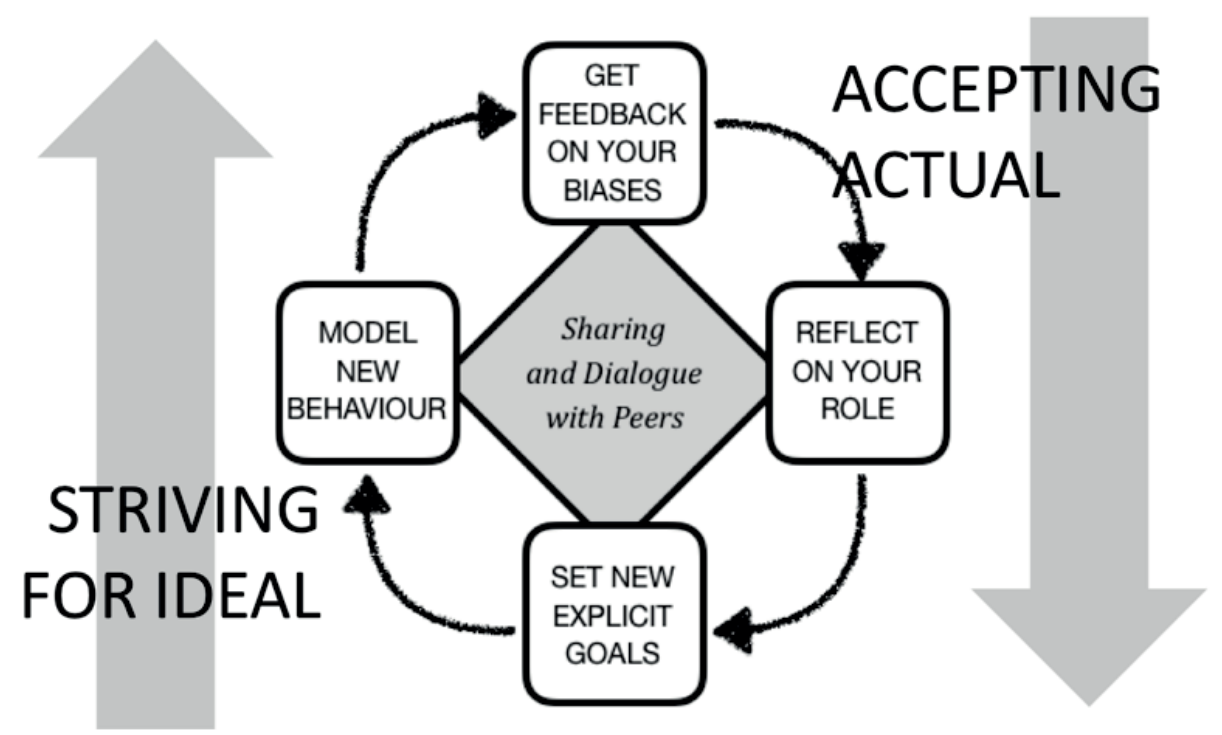

Figure 1- A Model for Implicit Bias Recognition and Management

Our findings advance existing knowledge by introducing a dilemma not previously explored related to implicit bias and education: How do we break bias without breaking ourselves? While we know that bringing an individual's implicit biases into conscious awareness may also have unintended consequences, our participants described deeply emotional reactions. When they were afforded an opportunity to look in the mirror, they were confronted with a vulnerability that they were not expecting. The resulting reflection, reconciliation and behavioural changes related to the tensions between who they are and who they strive to be.

\section{Mitigating Bias through cultivation of a Shared Human Identity}

Much of what we know about implicit bias comes from the work of authors such as Gaertner and Dovidio who suggest that the juxtaposition of good intentions and negative bias towards different racial groups produces a unique pattern of discriminatory behaviour called aversive racism that is difficult to address through education 13,14 . If applied to implicit bias within healthcare, authors have described two distinct types of aversion. First, health professionals may avoid interactions with members of stigmatized patient groups because of the professionals' discomfort and anxiety, and second, health professionals may have an aversive reaction when 
they realize that they might harbor implicit bias themselves ${ }^{15}$. The latter selfaversion may be experienced as a kick-back or defense reaction. Self-aversion involves distancing oneself from the aspects of their identity that may demonstrate bias or racism. For example, if a health professional authentically believes in egalitarian values and wishes to promote equitable treatment of patients from all groups, the suggestion that they demonstrate bias forces them to confront something about themselves they do not wish to acknowledge or accept.

Implicit bias is too complex for existing models for cultural competence education which emphasize over-simplistic thinking about prejudice. Suggesting that there are "good" people who can educate "bad" people to stop their discriminatory behaviours perpetuates stereotypes by attributing undesirable attitudes and behaviours to a social group that no one wants to identify with. Confronting bias in that way therefore has the potential to trigger experiences of blame and shame. In contrast, Gaertner \& Dovidio explored strategies to mitigate bias and suggested that mechanisms that reduce indifference and increase the perception of connectedness between both stigmatized and privileged groups may be more effective ${ }^{15}$. Instead of perpetuating disconnection between health professionals and patients, reversing the social categorization from "us" and "them" to "we" may improve relatedness and decrease the negative impact of bias ${ }^{16}$.

Our findings are consistent with Gaertner and Dovidio's work, and suggest that implicit bias recognition and management involves looking in the mirror instead of pointing the finger. Chapter three described the unintentional avoidance behaviours that resulted from confluence of helplessness, frustration and resource constraints. Participants suggested that education to address implicit bias must promote an intentional shift away from discriminatory labels, and towards a shared human identity. Participants also mentioned that fostering intentional behaviour change was an important tool in managing bias. In Chapter seven, physicians and nurses responded to the distress and anxiety that was evoked by their awareness of implicit biases by questioning sociocultural norms, explicitly changing their biased behaviours and resisting structural and organizational forces that perpetuate biases and stigma.

Along our journey, chapter four introduced a wrinkle in the process. When our participants were confronted with their biases, their reflection was drawn back to their identity. Having bias meant they did not belong, because this knowledge conflicted with an idealized version of themselves that they aspired towards, yet could struggle to achieve. This information was difficult for them to reconcile. In contrast with previous research on feedback, their experiences of self-doubt and their compelling emotional reactions did not appear to distract from their learning and the process of behavioural change that was triggered. 


\section{Feedback, Reflection and Identity Intersect}

Consistent with the process described above, awareness is the first step to breaking our biased habits. However, I propose that bringing implicit biases into conscious awareness for learners is more intricate than the educational strategies currently described within health professions education literature. Biases are developed over time and many become ingrained, automatic and difficult to access. Therefore, brief educational interventions such as completing IAT cannot advance meaningful and sustainable change within individuals and learning environments. If conceptualized as a form of feedback, implicit bias recognition expands from a singular curricular activity to a constant and iterative process of cultivating feedback and reflection on how behaviours, decisions and communication may be misperceived by patients who have had stigmatizing experiences with healthcare professionals.

Most educational interventions to reduce bias involve some form of reflection. While a detailed discussion regarding reflection within health professions education is outside the scope of this thesis, $\mathrm{Ng}$ et al's review suggests that reflection may be conceptualized as a theory of reflective practice or a form of critical social inquiry ${ }^{17}$. Our findings suggest that teaching and learning about implicit bias may be considered from both perspectives.

Implicit bias recognition and management may be positioned as a form of iterative, continuous, yet transformative reflective practice. The constant, iterative nature of feedback, reflection and action is familiar to audiences from several disciplines that seek improvement processes. Several theorists describe how continuous cycles of experience, reflection and action relate to individuals and learning environments 1822. Described in other terms, promotion of continuous recognition and management of implicit biases may align with a "way of being," that is shared, modeled and internalized through relationships between teachers and learners.

In contrast, critical reflection considers how broader forces contribute to oppression, marginalization and power imbalances. Chapter seven describes how implicit bias awareness triggered critical questioning of workplace constraints and facilitated the re-shaping of workplace structures. Consistent with the call for moving beyond cultural competence towards "critical consciousness" described in the thesis introduction ${ }^{23}$, implicit bias recognition and management may facilitate transformation in power relations.

Our research sheds light on the intersection between reflection and group identity. Participants reflected not only on how their biases might influence their role as professionals seeking optimal outcomes for their patients, but also on what their biases revealed about their true selves. The bias they see in the mirror thus reflects 
their shortcomings, defects and vulnerabilities. In this powerful moment, the aversion suggested by Gaertner and Dovidio became a form of self-aversion that provoked fear and helplessness. Thus, reflecting on implicit biases is an area of health professions education where personal and professional become intertwined. This poses a challenge to traditional advice regarding effective feedback, which suggests that because feedback directed at the self may threaten identity and distract from learning, it is best avoided. But in this circumstance, identity and behavior are so linked that feedback cannot but approach the self.

Set in the context of feedback research, our findings draw links between feedback research and implicit bias recognition and management. Several studies on feedback in health professions highlight the importance of facilitated feedback conversations ${ }^{24-32}$. For example, Sargeant and colleagues propose the R2C2 model, suggesting that reflective performance feedback can be facilitated through developing a relationship, exploring the recipient's reaction and content of feedback data to coach towards performance change ${ }^{28}$. Sargeant's model acknowledges the importance of asking non-judgmental questions and exploring emotional reactions, yet suggests remaining focused on "one or two specific opportunities from the feedback data" to address. Our findings on implicit bias related feedback demonstrate that there are certain types of feedback that are particularly difficult to navigate. For example, two individuals may react very differently to feedback information about being biased. Even our participants who received feedback that they did not demonstrate implicit bias were still provoked through the exercise of taking the IAT to consider that they might hold biases. Therefore, our research provides insight regarding how to address self-related feedback that may threaten an individual's ideals. In learning they have or may have bias, they are also learning that they are flawed and will never achieve perfection. While existing research on feedback in health professions emphasizes how to coach towards change, we suggest considering how feedback conversations can balance striving for the ideal while accepting one's shortcomings.

\section{Disruption, Dissonance and Transformative Learning}

We found that feedback, reflection and practice change related to implicit bias involves disruption and dissonance. Throughout several of our studies, participants describe the frustration and helplessness evoked when they realize they may demonstrate implicit bias despite their best intentions. The discrepancy that develops between an individual's idealized and actual self-appraisal can serve as a useful tool to motivate reflection and practice change. Consistent with motivational interviewing techniques, our research suggests that developing discrepancy is a tool that can be utilized to motivate behaviour change 33,34 . 
Thus, implicit bias recognition and management may be positioned as a form of transformative learning. In contrast to additive learning, transformative learning seeks to increase awareness of how we construct reality, and how we become "critically aware of how and why our assumptions have come to constrain the way we perceive, understand, and feel about the world. ${ }^{35}$ ".Through this process, Mezirow suggests that we change our "structures of habitual expectation to make possible a more inclusive, discriminating and integrative perspective ${ }^{35}$ ". Mezirow argued that transformative learning occurs through painful experiences that may trigger individual learners to question deeply held beliefs and assumptions, followed by sharing and dialogue ${ }^{36,37}$. He argued that transformative learning is a process and requires triggering experiences along with critical reflection and dialogue with others 35.

Our findings suggest that implicit bias related feedback is an example of a stressful experience that may trigger a transformative process. We found that once feedback is received, the resulting dissonance and disruption has a significant impact on the learner. Participants described emotional reactions to IAT related feedback and sought reconciliation. They found that discussing and sharing their biases openly within a safe learning environment helped them feel comfortable and motivated to address their biases. This finding aligns with models for facilitating debriefing after feedback is received where relational dynamics and a non-judgmental approach are important components of the feedback conversation ${ }^{24,28}$. Therefore, we suggest that implicit bias recognition and management requires discussion and facilitation.

Our participants also described a paradox between justifying their biases while acknowledging that biases exist and should be managed. They experienced challenging emotions, yet described their experience as positive. The resulting tension provoked discussion, reflection and a desire to seek reconciliation. In previous research on public encounters with the IAT, Yen and colleagues propose that discussions of implicit bias and reflection on one's bias may serve to reconcile the selfaversion that results from bias awareness. They argue that presenting oneself as tolerant and open-minded provides individuals with an opportunity to reconcile their biases by taking a moral high ground ${ }^{38}$. While previous research is relevant for a general audience, our findings highlight that health professionals learn about bias within a context that considers bias a uniquely undesirable trait. The moral high ground for health professionals is a Shangri-La that will never be discovered. If bias awareness triggers self-doubt and provokes learners to work harder towards an impossible goal, then we caution about the implications that bias awareness may have for learner well-being.

Bias awareness is also a unique form of transformative learning because it disrupts both the individual and the learning environment. Health professionals must accept 
that they have bias, can never eliminate their bias, and are learning within an environment that reinforces and contributes to these biases. As chapter seven describes, reconciling bias involves changing behaviour while critically questioning the norms and assumptions that developed biases and perpetuated discrimination within the workplace. All while accepting one's flaws and seeking improvement. Always practicing, forever reflecting, never perfect.

\section{Practicing, Role Modeling and Sustaining Behavioural Change}

While most educational interventions focus on individual biases, several authors also emphasize the need to consider how implicit bias functions within organizations and institutions, and how sociocultural factors may sustain or inhibit bias mitigation targeted at an individual level 2,4,5,39,40. In addition, little research thus far identifies how interventions to reduce implicit bias may produce change. A 2018 review only found two studies of interventions to reduce implicit bias and only one of the two demonstrated a decrease in implicit biases as measured by the IAT ${ }^{41}$. Moving from role reflection to practice, our work provides insights on how implicit bias recognition and management curricula may not only initiate but also sustain change.

Chapter seven highlights how practicing behaviour change is intrinsically related to the discussion and social reinforcement of practice changes through peers within inter-professional teams. Role modeling was also related to participants' perceptions of how practice change was initiated and sustained. While chapter seven noted how role modeling influenced practice change, chapter six illustrated a gap between student and teacher perceptions of how role modeling may be enacted. Residents desperately sought support from faculty mentors to manage biases, yet faculty were not recognizing and managing biases sufficiently for residents to learn from them. Each chapter touches upon relationships in varying ways. Chapters four, five and six hint at relationships between teachers and learners, and chapter seven emphasizes relationships among peers within the workplace, chapter three centers upon the relationship between health professionals and patients.

Relationships were central to acquiring feedback, reconciling discomfort and reinforcing behaviour change. In chapters four, five and six, we speculated that feedback conversations about bias may have the potential to promote gradual acceptance of one's biases while working towards managing them. Several studies highlight that relational dynamics are an important influence on the process of implicit bias recognition and management. When confronted with feedback about their biases, participants experienced a discrepancy between their ideal and actual selves, seeking reconciliation of their compartmentalized personal and professional 
identities. Consistent with other theory-oriented models of facilitating performance feedback, relationships between teachers and learners can facilitate safe open discussion on biases while coaching for performance change ${ }^{28}$.

The power and potential of implicit bias related curricula must be anchored on the venerated relationship between a health professional and the patient they are seeking to serve. The shame and blame experienced by individuals with mental illness within healthcare settings is a destructive force with tragic consequences. Seeking feedback from patients and moving away from disconnection and distrust requires refocusing our efforts to understand the lived experience of our patients. Gonzalez et al found that patient perceptions of bias can deteriorate clinical relationships, but that acknowledging the patient's perception and the physician's role in perpetuating bias could restore such relationships ${ }^{42}$. Our studies are consistent with this view. We agree that implicit bias recognition and management curricula should include instruction on developing skills for health professionals to authentically engage with patients as partners.

Implicit biases are something that all of us share. When discussing bias there is no us versus them. Learners who belong to traditionally privileged groups are just as susceptible to the influence of their hidden biases as those who experience oppression and marginalization. Implicit bias recognition and management therefore advances health professions education research beyond dichotomous thinking and towards an emphasis on a universal human experience.

\section{Lessons Learned on Methodology}

Several studies within this thesis utilize the IAT as a prompt to trigger reflection. Our use of the IAT provides an example of a novel elicitation method that affords a unique opportunity for qualitative researchers. Elicitation provides a stimulus for researchers to gain the desired data from the participant ${ }^{43}$. Individual in-depth interviews provide an opportunity for health care researchers to co-create meaning through re-enacting perceptions of events and experiences ${ }^{44}$. While interviews are most commonly used as elicitation tools, we began our research with the hypothesis that asking a participant to verbalize their implicit biases through interviewing alone may prove challenging. While we utilized in-person, semi-structured, indepth interviews, we augmented our methods to employ the IAT. This decision originated from our desire to stimulate rich and meaningful reflection related to our area of study.

The IAT is an online exercise that took our participants roughly 10-15 minutes to complete. The online IAT starts with a disclaimer then instructs users to match 
word-pairs with keyboard strokes to measure the user's association between different concepts. Our participants took the mental-illness IAT, which measured the associations between mental illness, physical illness and dangerousness. Response latencies comprised a numeric score which was aggregated to establish the results. After matching word-pairs, the user completes a demographic survey and answers questions related to their attitudes about mental illness. At the end of the test, the participants received a result on the screen. For example, the result could read "you demonstrated a moderate association between mental illness and dangerousness." Alternatively, results could indicate a mild association between physical illness and dangerousness or no-difference.

While elicitation techniques described in the literature may be visual or verbal, the completion of an online exercise and provision of feedback in the form of text on a computer screen is unique. In general, non-linguistic dimensions of research may provide an opportunity to access complex areas of expertise and experience and generate innovative ways of exploring social processes ${ }^{45}$. For example, visual elicitation may use photos, drawings or diagrams to stimulate discussion for participants on topics or ideas that are difficult to generate through verbal interviewing alone 46,47 . Case-based elicitation may involve describing a scenario or a brief case for participants to read and trigger reflection. Other elicitation techniques include object elicitation ${ }^{48}$, video-elicitation ${ }^{49}$, card sorting, demonstration or simulations 50. While it contains visual components, the IAT is neither exclusively visual nor verbal. It is not an object of an individual's choosing, nor does it provide a description or scenario to explore. The completion of the IAT and delivery of results includes variables that have yet to be described as tools to enhance qualitative research. Therefore, our experience suggests that tools such as the IAT provide an innovative elicitation mechanism that may be useful for researchers seeking to generate deeply reflective responses.

Our findings also suggest that the very nature of implicit bias is too complex, dynamic and multilayered to be reduced and constrained by activities and methodologies related to the IAT. The knowledge generated by my research warns against exclusive coupling of implicit bias education with the IAT. While the test itself is a useful prompt, this thesis emphasizes that the IAT is only one small piece of a larger, complex and interconnected set of components related to the process of recognizing and managing biases.

In addition to the IAT, we also utilized rich pictures in chapter six. Rich pictures are a form of visual elicitation arising from systems engineering ${ }^{51-53}$. Rich pictures have been used by health professions education researchers to understand complex situations ${ }^{51,52}$. We found that some participants struggled with the exercise of visual elicitation, while others seized the opportunity to generate visual depictions of their thoughts, perceptions and experiences. Our experience using rich pictures 
within the specialty context of psychiatrists who practice almost exclusively in a verbal context, contrasts from the use of rich pictures with procedural specialties such as surgery. We suggest that rich pictures hold promise for complex or emotionally challenging topics, however, more exploration and analysis of this particular technique related to specialty context is needed to actualize their potential.

The therapeutic nature of the research interview itself is another methodological tool that improved understanding about facilitating reflective feedback conversations. Our research may well have shaped how participants thought about implicit bias and how they subsequently responded. Others have described how qualitative research interviews may contain therapeutic dimensions, and require sensitivity, arguing that the qualitative research interview should be explicitly acknowledged as a therapeutic process ${ }^{54}$. For example, research interviews require trust, and may involve a redistribution of power ${ }^{55}$. Therefore, researchers are encouraged to build rapport and allow participants to feel safe and comfortable ${ }^{56}$. When investigating potentially sensitive issues, intense emotions may arise, necessitating an opportunity for feedback and debriefing for participants, along with contacts for support and mental health. Safety measures to address risk of confidentiality breaches are also important 57 . While there are existing frameworks to guide qualitative researchers regarding sensitive interviewing ${ }^{58,59}$, we encourage future research on how qualitative interviewing may relate to therapeutic qualities such as enhancing an individual's sense of self-worth and reconciling tensions.

Lastly, the longitudinal qualitative interviewing strategy in chapter seven also represented a different approach to exploring the influence of bias related curricular interventions. Longitudinal qualitative research provides an opportunity to explore change over a period of time with the same group of participants ${ }^{60}$. Our longitudinal interviews were conducted with reflexivity in mind as we asked a nurse researcher to conduct nursing interviews and a physician to conduct physician interviews. This was due to our attention to the relational awareness necessary to explore the experiences of participants over time ${ }^{61}$. Upon reflection, the choice was useful yet could be expanded for future research. We propose that longitudinal interviewing is a useful strategy to explore the influence of bias awareness on individuals and learning environments.

\section{Strengths and Limitations}

Existing research on implicit bias comes from a variety of sources, traditions and epistemological orientations. While the social psychology research that brought implicit bias into mainstream discussion traditionally adheres to positivist and 
post-positivist positions, the topic has been taken up by diverse research traditions, disciplines and individuals from several professional backgrounds. The fragmented literature on how implicit bias relates to health care and education is also varied. Most authors describe the issue, many seek to measure implicit bias and others to understand how it influences and perpetuates inequity. Teaching and learning about bias is therefore a relatively new and uncharted territory.

At the outset of this work, I made a deliberate decision to contain my research within the context of implicit biases towards individuals with mental illness within acute healthcare environments. This setting is unique compared to most research on implicit bias and health professions. Most of the theory and discourse relating to implicit bias is described in the literature in relation to racism or gender. These visible and easily identified categorizations are distinct from mental illness stigma which can be less evident through visual cues. Nonetheless, my research began with the exploratory study described in chapter three that established initial theory that informed the work of the following chapters. The tone and tenor of these chapters shifted from "stigma" to "bias" to emphasize how my research has implications for how health professions educators could advance pedagogy related to all types of inequities, biases or discrimination within health care. This decision may be perceived as both a strength and limitation. In this discussion, we argue that the scope of implicit bias recognition and management curricula should be broadened, but would also caution that more context-specific variation should be considered through future research. Not only would research on different types of bias be important, but also within different health service settings such as ambulatory or long-term care.

Research methods relied almost exclusively on semi-structured interview data, augmented in chapter six with visual methods. While interviews alone may be insufficient to draw hidden and deeply held biases into conscious awareness, the use of the IAT as an elicitation tool was an important component of our approach. The IAT has been subject to robust critique from several epistemological perspectives. Indeed, peer reviewers for chapter seven engaged in vigorous debate on the topic. Some reviewers of the published chapters challenged the idea that verbal reports of cognitive processes or implicit biases could be utilized as data. This perspective, we believe, was rooted in positivist and post-positivist stances that emphasized the need for psychometrics and other tools to sufficiently measure concepts such as implicit bias. Other reviewers agreed with us that our efforts to promote bias awareness were related to fostering critical reflection. This group emphasized that research questions have evolved within health professions education research, leading to tensions and turbulence.

We explained in our response to reviewers that our work was framed within constructivist grounded theory, in relation to workplace learning theories and con- 
sistent with transformative learning paradigms. We wrote in our response to reviewers,

"We did not intend to infer the implicit biases of our participants... We agree with your assertion that verbal probing will not sufficiently foster awareness of implicit biases, however... We were indeed engaging with the promotion of critical reflexivity with implicit bias recognition as an educational strategy. Our study was conducted as an open exploration of the workplace environment over the longitudinal course of 12 months with these influences in mind."

The ensuing discussion suggested that the IAT itself may represent an artefact that provoked contested ownership. Most research involving the IAT has fallen within positivist and post-positivist approaches. This body of work pushes against the boundaries of IAT use and the resulting disruption may represent an opportunity to extend thinking about the nature of implicit bias and its implications for education and health.

It is therefore important to declare that my epistemological stance is consistent with interpretive and constructivist paradigms. We argue for the use of the IAT as a prompt to facilitate discussion and reflection and not as a metric of an individual's bias. In accordance with constructivist grounded theory, my research questions reflected a desire to explore, understand and build theory, not to measure, define or evaluate. The integrated theory depicted in Figure 1 above, represents the synthesis of the knowledge produced through an iterative process of constant comparison, analysis, interpretation and re-exploration.

\section{Future Research and Implications}

The observation that led to this research was one related to the stigma of mental illness. I was struck that despite decades of research on public and educational interventions to reduce stigma, misconceptions about mental illness and people with mental illness continue to persist ${ }^{62}$. Due to being stereotyped, labeled and discriminated against, individuals suffering with mental illness are less likely to seek help and often internalize negative attitudes towards themselves, leading to negative outcomes 63,64 . Implicit stigma is increasingly studied, yet poorly understood. Therefore, the implications of this thesis include a model for stigmareduction education that is unique, innovative and merits further research and evaluation. 
While the stigma of mental illness is a form of invisible bias, I propose that the lessons from this thesis may be transferred and applied to the process of implicit bias recognition and management. As I sought to understand teaching and learning about implicit bias to inform curricular interventions for health professionals, the products of this work inform an integrated theory of implicit bias recognition and management that may be replicated or adapted across contexts and settings to mitigate the negative impact of bias and promote equity for a variety of underserved and marginalized patient groups.

At the time of writing, popular media was fascinated with a story about two young Black men who were arrested and forcibly removed from a Starbucks Coffee store in Philadelphia, U.S.A. The men were waiting quietly for an acquaintance and a viral video of their arrest was shared widely, highlighting racial biases at work. In response, Starbucks Coffee Company announced it would close stores in North America for an afternoon of implicit bias training. I wrote a piece in the popular media that achieved wide reach and led to media interviews and coverage across Canada. As a developing researcher, it suddenly became clear that my nascent program of research would have implications beyond what I had expected.

Research on implicit bias also advances our understanding regarding the conditions when disruption can prove useful for health professionals. Therefore, this research opens a window to better understand how individuals and learning environments respond to disruptions and adapt their role. Whether in the realm of feedback or in relation to curriculum development, existing educational paradigms and instructional strategies often limit the potential for continuous and adaptive learning for individuals necessary to respond to complex, rapid and unpredictable change ${ }^{65}$. As result, health professions education research that pushes boundaries and challenges tradition is often difficult to pursue. It is my sincere hope that my research encourages researchers and educators to dance with their discomfort. 


\section{References}

(1) Blair IV, Steiner JF, Havranek EP. Unconscious (implicit) bias and health disparities: where do we go from here. Perm J. 2011;15(2):71-8.

(2) Burgess D, van Ryn M, Dovidio J, Saha S. Reducing racial bias among health care providers: lessons from social-cognitive psychology. J Gen Intern Med. 2007;22(6):882-7.

(3) Gonzalez CM, Kim MY, Marantz PR. Implicit bias and its relation to health disparities: a teaching program and survey of medical students. Teach Learn Med. 2014;26(1):64-71.

(4) Hernandez RA, Haidet P, Gill AC, Teal CR. Fostering students' reflection about bias in healthcare: Cognitive dissonance and the role of personal and normative standards. Medical teacher. 2013;35(4):e1082-e9.

(5) Teal CR, Gill AC, Green AR, Crandall S. Helping medical learners recognise and manage unconscious bias toward certain patient groups. Medical education. 2012;46(1):80-8.

(6) Teal CR, Shada RE, Gill AC, Thompson BM, Frugé E, Villarreal GB, et al. When best intentions aren't enough: helping medical students develop strategies for managing bias about patients. Journal of general internal medicine. 2010;25(2):115-8.

(7) Chapman EN, Kaatz A, Carnes M. Physicians and implicit bias: how doctors may unwittingly perpetuate health care disparities. J Gen Intern Med. 2013;28(11):1504-10.

(8) Zestcott CA, Blair IV, Stone J. Examining the Presence, Consequences, and Reduction of Implicit Bias in Health Care: A Narrative Review. Group Process Intergroup Relat. 2016;19(4):528-42.

(9) Burgess DJ, Beach MC, Saha S. Mindfulness practice: A promising approach to reducing the effects of clinician implicit bias on patients. Patient Educ Couns. 2016.

(10) Stone J, Moskowitz GB. Non-conscious bias in medical decision making: what can be done to reduce it? Med Educ. 2011;45(8):768-76.

(11) Carnes M, Devine PG, Baier Manwell L, Byars-Winston A, Fine E, Ford CE, et al. The effect of an intervention to break the gender bias habit for faculty at one institution: a cluster randomized, controlled trial. Acad Med. 2015;90(2):22130.

(12) Byrne A, Tanesini A. Instilling new habits: addressing implicit bias in healthcare professionals. Adv Health Sci Educ Theory Pract. 2015;20(5):125562.

(13) Gaertner SL, Dovidio JF, Banker BS, Houlette M, Johnson KM, McGlynn EA. Reducing intergroup conflict: From superordinate goals to decategorization, recategorization, and mutual differentiation. Group Dynamics: Theory, Research, and Practice. 2000;4(1):98.

(14) Gaertner SL, Dovidio JF. The aversive form of racism: San Diego, CA, US: Academic Press; 1986. 
(15) Gaertner SL, Dovidio JF. Understanding and addressing contemporary racism: From aversive racism to the common ingroup identity model. Journal of Social issues. 2005;61(3):615-39.

(16) Gaertner SL, Dovidio JF. Reducing intergroup bias: The common ingroup identity model: Psychology Press; 2014.

(17) Ng SL, Kinsella EA, Friesen F, Hodges B. Reclaiming a theoretical orientation to reflection in medical education research: a critical narrative review. Med Educ. 2015;49(5):461-75.

(18) Boud DJ, Walker D. Promoting reflection in professional courses: the challenge of context. Studies in Higher Education. 1998;23:191-206.

(19) Schon DA. The Reflective Practitioner: How Professionals Think in Action. New York, NY: Basic Books; 1983.

(20) Kinsella EA. Constructivist Underpinnings in Schon's theory of reflective practice. Reflective Practice. 2006;7:277-86.

(21) Kolb D. Experiential Learning as the Science of Learning and Development. Englewood Cliffs, NJ: Prentice Hall; 1984.

(22) Raelin JA. Toward an epistemology of practice. Academy of Management Learning and Practice. 2007(6):495-519.

(23) Kumagai AK, Lypson ML. Beyond cultural competence: critical consciousness, social justice, and multicultural education. Academic Medicine. 2009;84(6):782-7.

(24) Telio S, Ajjawi R, Regehr G. The "educational alliance" as a framework for reconceptualizing feedback in medical education. Acad Med. 2015;90(5):60914.

(25) Boerboom TB, Jaarsma D, Dolmans DH, Scherpbier AJ, Mastenbroek NJ, Van Beukelen P. Peer group reflection helps clinical teachers to critically reflect on their teaching. Medical Teacher. 2011;33(11):e615-23.

(26) Branch WT, Jr., Paranjape A. Feedback and reflection: teaching methods for clinical settings. Acad Med. 2002;77(12 Pt 1):1185-8.

(27) Sargeant J. Reflecting upon multisource feedback as 'assessment for learning'. Perspect Med Educ. 2015;4(2):55-6.

(28) Sargeant J, Lockyer J, Mann K, Holmboe E, Silver I, Armson H, et al. Facilitated Reflective Performance Feedback: Developing an Evidence- and Theory-Based Model That Builds Relationship, Explores Reactions and Content, and Coaches for Performance Change (R2C2). Academic Medicine. 2015;90(12):1698-706.

(29) Eva KW, Armson H, Holmboe E, Lockyer J, Loney E, Mann K, et al. Factors influencing responsiveness to feedback: on the interplay between fear, confidence, and reasoning processes. Advances in Health Sciences Education. 2012;17(1):15-26.

(30) Sargeant J, McNaughton E, Mercer S, Murphy D, Sullivan P, Bruce DA. Providing feedback: exploring a model (emotion, content, outcomes) for facilitating multisource feedback. Medical Teacher. 2011;33(9):744-9.

(31) Sargeant JM, Mann KV, van der Vleuten CP, Metsemakers JF. Reflection: a link between receiving and using assessment feedback. Advances in Health Sciences Education. 2009;14(3):399-410. 
(32) Watling C, Driessen E, van der Vleuten CP, Lingard L. Learning from clinical work: the roles of learning cues and credibility judgements. Med Educ. 2012;46(2):192-200.

(33) Rollnick S, Miller WR. What is motivational interviewing? Behavioural and cognitive Psychotherapy. 1995;23(4):325-34.

(34) Miller WR, Rollnick S. Motivational interviewing: Helping people change: Guilford press; 2012.

(35) Mezirow J. Transformative dimensions of adult learning: ERIC; 1991.

(36) Mezirow J. Understanding transformation theory. Adult education quarterly. 1994;44(4):222-44.

(37) Mezirow J. Perspective transformation. Adult Education Quarterly. 1978;28(2):100-10.

(38) Yen J, Durrheim K, Tafarodi RW. 'I'm happy to own my implicit biases': Public encounters with the implicit association test. The British journal of social psychology. 2018.

(39) Hannah SD, Carpenter-Song E. Patrolling your blind spots: introspection and public catharsis in a medical school faculty development course to reduce unconscious bias in medicine. Culture, Medicine, and Psychiatry. 2013;37(2):314-39.

(40) Ansell DA, McDonald EK. Bias, black lives, and academic medicine. New England Journal of Medicine. 2015;372(12):1087-9.

(41) Maina IW, Belton TD, Ginzberg S, Singh A, Johnson TJ. A decade of studying implicit racial/ethnic bias in healthcare providers using the implicit association test. Social science \& medicine (1982). 2018;199:219-29.

(42) Gonzalez CM, Deno ML, Kintzer E, Marantz PR, Lypson ML, McKee MD. Patient perspectives on racial and ethnic implicit bias in clinical encounters: Implications for curriculum development. Patient education and counseling. 2018.

(43) Gubrium JF, Holstein JA. Handbook of interview research: Context and method: Sage Publications; 2001.

(44) DiCicco-Bloom B, Crabtree BF. The qualitative research interview. Medical education. 2006;40(4):314-21.

(45) Bagnoli A. Beyond the standard interview: The use of graphic elicitation and arts-based methods. Qualitative research. 2009;9(5):547-70.

(46) Clark-Ibáñez M. Framing the social world with photo-elicitation interviews. American behavioral scientist. 2004;47(12):1507-27.

(47) Dempsey JV, Tucker SA. Using photo-interviewing as a tool for research and evaluation. Educational Technology. 1994:55-62.

(48) Willig C. Reflections on the use of object elicitation. 2016.

(49) Henry SG, Fetters MD. Video elicitation interviews: a qualitative research method for investigating physician-patient interactions. The Annals of Family Medicine. 2012;10(2):118-25.

(50) Pratt JM, Yezierski EJ. A novel qualitative method to improve access, elicitation, and sample diversification for enhanced transferability applied to studying chemistry outreach. Chemistry Education Research and Practice. 2018;19(2):410-30. 
(51) Cristancho S. Eye opener: exploring complexity using rich pictures. Perspect Med Educ. 2015;4:138-41.

(52) Cristancho S, Bidinosti S, Lingard L, Novick R, Ott M, Forbes T. Seeing in different ways: introducing "rich pictures" in the study of expert judgment. Qual Health Res. 2015;25(5):713-25.

(53) Monk A, Howard S. Methods \& tools: the rich picture: a tool for reasoning about work context. interactions. 1998;5(2):21-30.

(54) Rossetto KR. Qualitative research interviews. Journal of Social and Personal Relationships. 2014;31(4):482-9.

(55) Anyan F. The Influence of Power Shifts in Data Collection and Analysis Stages: A Focus on Qualitative Research Interview. Qualitative Report. 2013;18:36.

(56) Knox S, Burkard AW. Qualitative research interviews. Psychotherapy Research. 2009;19(4-5):566-75.

(57) Mealer M, Jones J. Methodological and ethical issues related to qualitative telephone interviews on sensitive topics. Nurse Researcher. 2014;21(4).

(58) Dempsey L, Dowling M, Larkin P, Murphy K. Sensitive Interviewing in Qualitative Research. Research in Nursing \& Health. 2016;39(6):480-90.

(59) Brayda WC, Boyce TD. So you really want to interview me?:Navigating "sensitive" qualitative research interviewing. International Journal of Qualitative Methods. 2014 Feb;13(1):318-34.

(60) Balmer DF, Richards BF. Longitudinal qualitative research in medical education. Perspect Med Educ. 2017;6(5):306-10.

(61) Warin J. Ethical mindfulness and reflexivity: Managing a research relationship with children and young people in a 14-year qualitative longitudinal research (QLR) study. Qualitative Inquiry. 2011;17(9):805-14.

(62) Corrigan PW, Miller FE. Shame, blame, and contamination: A review of the impact of mental illness stigma on family members. Journal of Mental Health. 2004;13(6):537-48.

(63) Corrigan PW, Watson AC. The paradox of self-stigma and mental illness. Clinical Psychology: Science and Practice. 2002;9(1):35-53.

(64) Corrigan PW, Watson AC, Barr L. The self-stigma of mental illness: Implications for self-esteem and self-efficacy. Journal of social and clinical psychology. 2006;25(8):875-84.

(65) Hodges BD. Learning from Dorothy Vaughan: artificial intelligence and the health professions. Medical education. 2018;52(1):11-3. 
SUMMARY 
Implicit bias refers to unconscious assumptions, attitudes, beliefs that influence health professionals without their conscious awareness and despite their best intentions. Educating health professionals to recognize and manage their biases may provide a strategy to improve equity for underserved and marginalized populations; however, research into implicit bias recognition and management for health professionals is a nascent area of inquiry. This thesis seeks to develop a deeper understanding of the process of implicit bias recognition and management.

Chapter 1 introduces the concept of implicit bias, highlighting the complexity of implicit compared to explicit biases. For example, implicit biases may be useful, yet they may also be harmful when they perpetuate disparities between different populations. Existing educational strategies to recognize and manage bias involve processes of promoting awareness, reflection and fostering behavioural change. Despite their potential, such strategies are theoretically underdeveloped and underexplored within health professions educational literature. This chapter introduces the studies within this thesis, including key research questions: (1) How do patients and health professions perceive the influence of implicit bias? (2) How do health professionals perceive the influence of an intervention that promotes awareness of their implicit biases, and (3) How do individuals and learning environments influence each other over time in dealing with this awareness? Implicit biases towards individual with mental illness are the setting in which the studies of this thesis are conducted. This chapter also describes how the implicit association test, an online metric of response latency, is utilized as a methodological tool to elicit reflection on implicit biases related to mental illness.

Chapter 2 outlines a potential framework for integrating implicit bias recognition and management into health professions education. The framework distills current research and experience into a six key features: creating a safe and nonthreatening learning context, increasing knowledge about the science of implicit bias, emphasizing how implicit bias influences behaviors and patient outcomes, increasing self-awareness of existing implicit biases, improving conscious efforts to overcome implicit bias, and enhancing awareness of how implicit bias influences others. The chapter offers actionable steps for curriculum designers, including potential approaches to evaluation and assessment. The chapter concludes by suggesting that any educational interventions to promote implicit bias awareness should consider power dynamics and the sociocultural context in which such dynamics occur.

Chapter 3 describes an exploratory study within the context of a paediatric emergency department. Using constructivist grounded theory, semi-structured interviews with physician, nurse, patient, caregiver and administrative staff participants were conducted to better understand the process of implicit bias towards individuals with mental illness. The study found that several forces contribute to 
implicit labeling of patients with mental illness as time-consuming, unpredictable and/or unfixable, leading to unintentional avoidance behaviour from staff, which in turn is are perceived as judgmental and prejudicial by patients and caregivers. Participants also suggested that education that promotes empathy and engagement may be useful to reduce the influence of implicit bias. These findings emphasize how educational interventions to reduce the adverse impact of implicit bias should consider socio-cultural contexts and facilitate positive emotions in health professionals.

Chapter 4 sought to understand how health professionals respond to feedback about their biases. This chapter explores the experience of health professionals who take the implicit association test, an online metric of response time that provides them with a metric of the degree of implicit bias they hold towards patients with mental or physical illness. There was a range of emotional reactions among participants who completed the implicit association test, prompting the need to seek a better understanding of how health professionals perceive the experience of taking the test and receiving their results. This study involved semistructured interviews with pediatric physicians and nurses. Participants described tensions between how having implicit biases reflected or contradicted their idealized and actual personal and professional identities. They accepted their biases while justifying them, and acknowledged a desire to change their biases while accepting that such change is difficult. These findings suggest that once implicit biases are brought into conscious awareness for learners, the resulting tension may be managed through reflection informed by actual and aspirational aspects of an individual's identity.

Chapter 5 delves further into how feedback about one's implicit biases towards individuals with mental illness (revealed through the implicit association test) may influence a group who were particularly susceptible to identity-threat. Through semi-structured interviews with psychiatric residents, physicians and nurses, this study found that participants described the experience of receiving feedback about their implicit biases as positive or neutral, despite critiquing the feedback source and questioning the credibility of the implicit association test. These findings highlight a feedback paradox, suggesting that feedback about the self may be more useful than previously considered. Therefore, a better understanding of how identity influences the process of implicit bias recognition and management is needed.

Chapter 6 examines the relationship between identity and the process of implicit bias recognition and management. Utilizing constructivist grounded theory, 10 faculty and 11 psychiatric residents completed the implicit association test and were asked to draw a rich picture to describe their experiences. Similar to chapter 4, participants acknowledged vulnerabilities which provoked tension between their 
personal and professional identities. They suggested that recognizing and managing biases involves a process described as striving for the ideal while accepting the actual. Relational dynamics were described as influencing the process, however, residents and faculty viewed the role of relationships differently. While faculty identify their struggles, and see themselves as role models, learners saw unrealized potential in their faculty mentors to provide guidance on managing biases.

Chapter 7 returns to the setting of the emergency department, originally explored in chapter 3 . This chapter shifts inquiry through a longitudinal qualitative case study of the learning environment after an intervention was conducted to bring implicit biases into conscious awareness. Results suggest that implicit bias recognition provokes dissonance and disruption among both individuals and learning environments, leading to critical reflection and perceived behavioral changes which further influenced the perception of structural changes within the learning environment itself. Discussion, dialogue and role-modeling within teams appeared to facilitate the process. These findings suggest a model for understanding how individual learners adaptively reinvent their role through the process of recognizing and managing implicit biases.

Chapter 8 integrates the line of inquiry in the preceding chapters by proposing an integrated theory of implicit bias recognition and management. The findings within this thesis culminate with the question, how do we break bias without breaking ourselves? This concluding chapter suggests that recognizing and managing implicit biases involves an iterative process of feedback seeking, role reflection, goal setting and role modeling behavior change. The process balances striving for ideals while accepting shortcomings and cannot be achieved by individuals alone. Implicit bias recognition and management is positioned as a unique form of learning that struggles to fit within existing paradigms of cultural competence education. This chapter also describes the limitations and affordances of chosen methodology, including insights about the use of the implicit association test as an elicitation prompt. Future research that explores how individuals and learning environments respond to complex, rapid and unpredictable change may facilitate a better understanding of how to recognize, address and respond to the influence of implicit biases on the health of underserved and marginalized populations. 
SAMENVATTING 


\section{SAMENVATTING}

Impliciete vooroordelen zijn onbewuste aannames, attitudes en overtuigingen die invloed uitoefenen op zorgprofessionals zonder dat zij zich daarvan bewust zijn en ondanks de beste bedoelingen. Het trainen van zorgprofessionals in het herkennen en beheersen van hun vooroordelen kan een strategie zijn om de gelijkheid te bevorderen van gemarginaliseerde bevolkingsgroepen die onvoldoende zorg ontvangen. Het onderzoek naar herkenning en beheersing van impliciete vooroordelen door zorgprofessionals staat echter nog in de kinderschoenen. Dit proefschrift beoogt een beter begrip te krijgen van het proces van herkennen en beheersen van impliciete vooroordelen.

Hoofdstuk 1 introduceert het begrip 'impliciete vooroordelen' ('implicit bias') en laat zien hoeveel complexer impliciete vooroordelen zijn dan expliciete vooroordelen. Impliciete vooroordelen kunnen bijvoorbeeld nuttig zijn, maar ze kunnen ook schadelijk zijn wanneer ze de ongelijkheid tussen bevolkingsgroepen bestendigen. Bestaande opleidingsstrategieën voor het herkennen en beheersen van vooroordelen maken gebruik van processen om bewustwording, reflectie en gedragsverandering te bevorderen. Ondanks hun potentieel, is de theoretische onderbouwing van dergelijke strategieën zwak, en krijgen ze onvoldoende aandacht in handboeken gebruikt in medische opleidingen. Dit hoofdstuk introduceert de onderzoeken die in dit proefschrift beschreven worden en hun onderzoeksvragen: (1) Wat vinden patiënten en zorgprofessionals van de invloed van impliciete vooroordelen? (2) Wat vinden zorgprofessionals van de invloed van een interventie die het bewustzijn van hun impliciete vooroordelen stimuleert? (3) Hoe beïnvloeden individuen en leeromgevingen elkaar in het omgaan met dit bewustzijn? Impliciete vooroordelen over individuen met een psychische stoornis zijn het onderwerp van de in dit proefschrift beschreven onderzoeken. Verder beschrijft dit hoofdstuk hoe de impliciete associatietest - een online instrument dat de tijd meet die een proefpersoon nodig heeft om een vraag te beantwoorden - gebruikt wordt om reflectie over impliciete vooroordelen met betrekking tot geestesziekten te stimuleren.

Hoofdstuk 2 beschrijft een mogelijk raamwerk voor het integreren van herkenning en beheersing van impliciete vooroordelen in het onderwijs aan zorgprofessionals. Het raamwerk vat de bestaande kennis uit 
onderzoek en praktijk samen in zes belangrijke kenmerken: creëren van een veilige en niet-bedreigende leeromgeving, vergroten van wetenschappelijke kennis over impliciete vooroordelen, benadrukken hoe impliciete vooroordelen gedrag en behandelresultaten beïnvloeden, overdragen van kennis over impliciete vooroordelen, verbeteren van bewuste pogingen om impliciete vooroordelen te ondervangen, en stimuleren van bewustzijn van de manier waarop impliciete vooroordelen anderen beïnvloeden. Dit hoofdstuk biedt concrete stappen voor curriculumontwerpers, bijvoorbeeld een aanpak voor evaluatie en beoordeling, en eindigt met de suggestie dat iedere onderwijsinterventie gericht op het bevorderen van het bewustzijn van impliciete vooroordelen rekening moet houden met machtsverhoudingen en de socioculturele context waarin deze machtsverhoudingen zich voordoen.

Hoofdstuk 3 beschrijft een exploratief onderzoek uitgevoerd in een kinderspoedpoli. Op basis van de Constructivist Grounded Theory werden halfgestructureerde interviews geconstrueerd en daarna afgenomen bij artsen, verpleegkundigen, patiënten, verzorgers en administratief medewerkers om een beter begrip te krijgen van de manier waarop impliciete vooroordelen over mensen met een psychische stoornis werken. Uit de resultaten blijkt dat diverse factoren ertoe bijdragen dat patiënten met een psychische stoornis impliciet gelabeld worden als tijdrovend, onvoorspelbaar en/of ongeneeslijk. Dit leidt tot onbedoeld vermijdingsgedrag van stafleden, dat op zijn beurt weer gezien wordt als aanmatigend en bevooroordeeld door patiënten en hun verzorgers. De deelnemers gaven ook aan dat onderwijs dat empathie en engagement stimuleert, nuttig kan zijn om de invloed van impliciete vooroordelen terug te dringen. Deze resultaten geven aan hoe belangrijk het is dat onderwijsinterventies die bedoeld zijn om de negatieve invloed van impliciete vooroordelen te verminderen, rekening houden met de socioculturele context en positieve gevoelens moeten stimuleren in zorgprofessionals.

In hoofdstuk 4 wordt onderzocht hoe zorgprofessionals reageren op feedback over hun vooroordelen, en beschrijft de ervaring van zorgprofessionals die de impliciete associatietest - een online instrument voor het meten van iemands reactietijd - gedaan hebben. De test laat zien in welke mate zij impliciete vooroordelen hebben over patiënten met psychische of lichamelijke ziekten. De deelnemers bleken een scala aan 
emotionele reacties te vertonen, wat erop duidt dat er behoefte is aan een beter begrip van de manier waarop zorgprofessionals de test en hun resultaten ervaren. Dit onderzoek omvatte halfgestructureerde interviews met kinderartsen en verpleegkundigen. De deelnemers beschreven de spanning die zij voelden tussen de manier waarop hun impliciete vooroordelen hun ideale en feitelijke persoonlijke en professionele identiteit weerspiegelden of daarmee in tegenspraak waren. Ze accepteerden hun vooroordelen en tegelijk rechtvaardigden ze deze, en spraken de wens uit om hun vooroordelen te veranderen. Ze zagen ook in dat een dergelijke verandering moeilijk is. Deze resultaten geven aan dat wanneer leerders zich bewust worden van hun impliciete vooroordelen, de spanning die dit oplevert in de hand kan worden gehouden door reflectie op basis van feitelijke en gewenste aspecten van hun identiteit.

Hoofdstuk 5 gaat nader in op de manier waarop feedback over iemands impliciete vooroordelen over geesteszieke mensen (zoals geïdentificeerd door de impliciete associatietest) een groep kunnen beïnvloeden die bijzonder vatbaar is voor identiteitsbedreiging. Uit halfgestructureerde interviews met psychiatrische arts-assistenten, artsen en verpleegkundigen bleek dat de deelnemers het krijgen van feedback over hun impliciete vooroordelen beoordelen als positief of neutraal, ook al hadden ze kritiek op de bron van de feedback en zetten ze vraagtekens bij de geloofwaardigheid van de impliciete associatietest. Deze resultaten wijzen op een feedbackparadox en suggereren dat feedback over het zelf nuttiger kan zijn dan voorheen gedacht werd. Een beter begrip van de manier waarop iemands identiteit het herkennen en beheersen van impliciete vooroordelen beïnvloedt is daarom noodzakelijk.

Hoofdstuk 6 gaat in op de relatie tussen identiteit en de manier waarop men impliciete vooroordelen kan herkennen en beheersen. Op basis van de Constructivist Grounded Theory werd de impliciete associatietest afgenomen bij tien artsen en elf arts-assistenten psychiatrie, die tevens een gedetailleerd beeld schetsten van hun ervaringen. Net als bij de studie beschreven in hoofdstuk 4, gaven de deelnemers aan dat ze zich kwetsbaar voelden en daardoor een spanning ondervonden tussen hun persoonlijke en hun professionele identiteit. Ze stelden dat het herkennen en beheersen van vooroordelen een proces is waarin ze streven naar een ideaal en tegelijkertijd de realiteit accepteren. Hoewel ze beschreven dat relatiedynamieken dit proces beïnvloeden, hadden stafleden en arts- 
assistenten een andere opvatting over de rol van relaties. Terwijl de stafleden hun worsteling onderkenden en zichzelf zagen als rolmodellen, meenden de studenten dat hun opleiders hen beter zouden kunnen begeleiden bij het beheersen van hun vooroordelen.

Hoofdstuk 7 gaat opnieuw over de spoedpoli die al eerder aan bod kwam in hoofdstuk 3, en bespreekt een longitudinale kwalitatieve casestudy van de leeromgeving nadat een interventie was ondernomen om de deelnemers bewust te maken van hun impliciete vooroordelen. De resultaten geven aan dat het herkennen van impliciete vooroordelen leidt tot dissonantie en ontregeling in zowel individuen als leeromgevingen. Dit leidde tot kritische reflectie en waargenomen gedragsverandering die de perceptie van structurele veranderingen binnen de leeromgeving verder beïnvloeden. Discussie, dialoog en rolmodellen binnen teams bleken dit proces te versnellen. Deze resultaten duiden op een model voor het begrijpen van de manier waarop leerders op adaptieve wijze hun rol opnieuw definiëren door het herkennen en beheersen van impliciete vooroordelen.

In hoofdstuk 8 worden de resultaten uit de voorgaande hoofdstukken samengevat en wordt een integrale theorie geformuleerd voor het herkennen en beheersen van impliciete vooroordelen. Uiteindelijk mondt dit uit in de vraag "Hoe kunnen we vooroordelen tenietdoen zonder onszelf te kort te doen?" Dit afsluitende hoofdstuk maakt duidelijk dat het herkennen en beheersen van impliciete vooroordelen een iteratief proces is van feedback vragen, rolreflectie, doelbepaling en gedragsverandering binnen rolmodellen. In dit proces tracht men idealen te verwezenlijken en tegelijk zijn tekortkomingen te accepteren. Dit kan niet alleen door individuen verwezenlijkt worden. Herkennen en beheersen van impliciete vooroordelen wordt neergezet als een unieke manier van leren die zich een plaats tracht te verwerven in de bestaande paradigma's van studieprogramma's die opleiden tot culturele competentie. Dit hoofdstuk beschrijft ook de beperkingen en mogelijkheden van de gekozen methodologie en inzichten in het gebruik van de impliciete associatietest om reacties uit te lokken. Nader onderzoek naar de manier waarop individuen en leeromgevingen reageren op complexe, snelle en onvoorspelbare veranderingen kan een beter begrip opleveren van manieren om de invloed te herkennen van impliciete vooroordelen op de 
gezondheid van gemarginaliseerde bevolkingsgroepen die onvoldoende zorg ontvangen en hierop in te spelen. 


\section{VALORISATION}




\section{Social and Economic Relevance}

Accreditation standards and legal, regulatory and policy requirements in countries such as the United States and Canada now require organizations and groups to address inequalities related to gender, race, sexual minorities and immigrant/newcomers in the workplace. Over the past several decades, diversity training has become increasingly commonplace ${ }^{1}$, as paradigms shift and traditional cultural competence programs lose their relevance ${ }^{2}$.

In recent years, an increasing number of organizations are seeking to address the issue of implicit bias. In the Spring of 2018, Starbucks Coffee Company announced it would be closing its stores for mandatory implicit bias training for its employees. During this time, the topic of implicit bias had entered mainstream dialogue including the popular media. During the heightened period of coverage, I wrote a newspaper article entitled, "Starbucks and the Impact of Implicit Bias Training," that was shared widely through several popular media outlets including the Canadian National Newspaper, The National Post. I was also interviewed by radio stations across Canada including a national radio show called, "The Current," as well as Canadian Broadcasting Corporation Radio programs in London Ontario, Toronto Ontario, Cape Breton Nova Scotia, Thunder Bay Ontario, Winnipeg Manitoba, Saskatoon, Saskatchewan Edmonton Alberta, Calgary Alberta, and Kamloops British Columbia.

Earlier this year, I was sought for my expertise in implicit bias education to participate in the governance board of the local police service in London, Ontario, Canada. This opportunity emphasizes the importance of implicit bias training in the police services sector, and provides an example of the broad social and economic relevance of my research.

Overall, the findings from this thesis may be used to improve diversity training programs across sectors and contexts. The integrated theory of implicit bias recognition and management described in chapter 8 provides guidance to curriculum developers and consulting companies on important components of implicit bias training.

\section{Target Groups}

While this thesis is relevant in several different settings outside of health professions educators, there are several target groups that may be interested in the products of this work such as diversity professionals and mental illness stigma researchers. Diversity professionals include consulting agencies and corporate training companies which seek to address issues related to diversity and inclusion, while 
mental illness stigma researchers focus on promoting and evaluating initiative to reduce stigmatizing attitudes towards individuals with mental illness.

\section{Innovation}

Previous research on implicit bias recognition and management describes how to facilitate a process of recognizing and managing implicit biases that may perpetuate disparities. The findings of this thesis are innovative because they introduce the dilemma: how do we break bias without breaking ourselves? We suggest that merely teaching and learning about the topic of implicit bias is not enough to address the issue of implicit biases and how they adversely influence equity. Our research emphasizes that when teaching and learning about implicit bias, personal and professional intertwine. We propose that addressing implicit bias involves deeply emotional, personal and vulnerable processes for learners. These findings are important to faculty developers as well as educators across the health professions education continuum.

Our work suggests that within a health professions context, integrating implicit bias recognition and management curricula into existing diversity curricula must address the unintended consequences of learner wellness. As we argue in chapter 4, health professionals often view exhibiting bias and demonstrating stereotyping as antithetical to the values that comprise the "idealized" health professional ${ }^{3-4}$. If educational programs encourage health professionals to become aware of their biases, chapter 7 emphasizes that frustration and confusion accompany such newfound awareness. The resulting self-doubt and emotional reactions described by our participants underscores the importance of role-modeling vulnerability and ensuring a safe learning environment.

\section{Activities and Products}

The work of this thesis has been applied and translated into an implicit bias recognition and management curriculum. The learning materials in the curriculum include brief lectures as well as a 4-hour-workshop. Various aspects of the curriculum have been delivered locally throughout London Health Sciences Centre, in London, Ontario Canada, as well as National and Internationally. There have been requests from the Mental Health Commission of Canada to consider the applicability of this work towards national initiatives on reducing mental illness stigma. Additionally, London Health Sciences Centre has embedded training materials into corporate nursing orientation, demonstrating a sustainable impact of this work on organizational learning. Requests have come in from other settings including adult medicine and addictions services to adapt this curriculum for use in relation to addictions stigma. 
In June 2018, funding was secured from Associated Medical Services Foundation to adapt the curriculum into the digital realm. In collaboration with a local organization (mindyourmind.ca) with expertise in digital initiatives to improve youth mental health, the findings from my research is informing the design of online modules for youth with lived experience of mental illness and for health professions students to reduce the adverse impact of mental illness stigma, and improve patient outcomes.

\section{Additional Knowledge Dissemination Activities}

\section{Invited Lectures}

I have been invited to lecture on the products of this thesis at Central Michigan University in Michigan, U.S.A. I have also spoken at Ben-Gurion University in Beersheva Israel, at the Health Equity Forum at Georgetown University in Washington, D.C., and was an invited speaker on the topic of implicit bias and wellness at the National Academy of Medicine.

\section{National and International Presentations}

Workshops and oral presentations have included the Research Symposium of the Arnold P. Gold Foundation, Canadian Conference on Medical Education, and Canadian Academy of Child and Adolescent Psychiatry, Rogano Meeting and Association for Medical Education in Europe Conference. Several presentations have also taken place through the Association of American Medical Conferences including several at Annual Meetings $(2015,2016)$ and at Professional Development Conferences $(2016,2017,2018)$.

\section{Local Presentations}

Locally, I have presented several times at scientific meetings within London, Ontario. For example, at the Centre for Education Research and Innovation Annual Symposium at Western University in 2016 and 2017. Also at the Schulich School of Medicine and Dentistry annual Distributed Education Conference, and Department of Psychiatry Division of Child and Adolescent Psychiatry Research Conference, where our poster won the prize for "Best Poster" in 2017.

\section{$\underline{\text { References }}$}

(1) Anand R, Winters MF. A retrospective view of corporate diversity training from 1964 to the present. Academy of Management Learning \& Education. 2008 Sep;7(3):356-72.

(2) Nivet MA, Castillo-Page L, Conrad SS. A diversity and inclusion framework for medical education. Academic Medicine. 2016 Jul 1;91(7):1031.

(3) Notzer N, Soffer S, Aronson M. Traits of the "ideal physician" as perceived by medical students and faculty. Med Teach. 1988;10:181-189.

(4) Arkes HR, Tetlock PE. Attributions of implicit prejudice, or "would Jesse Jackson 'fail' the Implicit Association Test?” Psychol Inq. 2004;15:257-278. 


\section{ACKNOWLEDGEMENTS}


I am so incredibly fortunate for a dream team of supervisors. Lorelei, you have always been an advocate and sponsor for my work. Thank you for believing in me and for making me imagine all this was even possible. Pim, you have been consistently kind and supportive. The momentum of this work would not have been possible without your gentle nudging and deep, reflective feedback.

Chris, you have defined for me what a mentor and supervisor can be. Your generosity of time and attention is what allowed my work to advance and provided sunlight to nourish my growth as a writer, and a scientist. Every supervision meeting left me feeling optimistic about my progress while motivated to improve. I appreciate your support more than mere words can express. Thank you! I also wish to acknowledge my colleagues and friends at Western University's Centre for Education Research and Innovation (CERI), who provided me with a home away from home.

Within my Department of Psychiatry and London Health Sciences Centre, I would like to thank Paul Links who provided support and inspiration to get me started down the path of this research. Thank you to colleagues in the Division of Child and Adolescent Psychiatry and to Rod Lim and Rob Sibbald for being there for advice and guidance along the way. I would also like to thank my research teams and research assistants. Ally Milne, you have been incredible. Michael Wodzinski, you are gifted and have been a natural with constructivist grounded theory. Thank you for your dedication to this research.

The studies within this thesis would not have been possible without the grant support of Associated Medical Services and the AMS-Phoenix Family. Additional funding from the Children's Health Foundation at London Health Sciences Centre and the Academic Medical Organization of Southwestern Ontario was essential to bringing this research to fruition. I would also like to thank my many research participants who had the courage and candour to share their vulnerabilities with us.

My deepest gratitude goes to my wife Sarah for being my rock and stalwart support throughout the endless hours and time away from her and my family that this thesis commanded of me. Sarah, your love and support is what gives me life and energy. You made this possible. Thank you also to my parents for supporting me and for instilling the value of lifelong learning and critical questioning so early in my life. To my daughter Anaya, I call you my gift and my inspiration. Your curious and inquisitive mind and perpetual growth mindset reminds me why I love working with children and why the transformative power of education is at the heart of everything I do. Nyle, thank you for lending your Baba to this thesis for the past few years. I promise endless games of uno and monopoly lie ahead 


\section{CURRICULUM VITAE}


Javeed Sukhera is an Assistant Professor of Psychiatry and Paediatrics at the Schulich School of Medicine and Dentistry at Western University in London, Ontario, Canada where he is also the Senior Designate Physician Lead for Child and Adolescent Psychiatry at London Health Sciences Centre (LHSC). He provides clinical consultation to the Child and Adolescent Mental Healthcare Program, Paediatric Chronic Pain Program and Transcultural Mental Health Program. He holds certification from the Royal College of Physicians and Surgeons of Canada in both Psychiatry and Child and Adolescent Psychiatry. He is also double-board certified in Psychiatry and Child and Adolescent Psychiatry from the American Board of Psychiatry and Neurology.

He completed his honours bachelor of science degree at Trinity College at the University of Toronto and his medical degree at the Medical School for International Health (MSIH), an innovative collaboration between Columbia University and BenGurion University in Israel that provides a four-year MD program with an emphasis on global health. He completed his residency in psychiatry and fellowship in child and adolescent psychiatry at the University of Rochester in New York.

He sits on several committees and councils at the local, provincial, national and international levels. He is President-Elect of the Ontario Psychiatric Association. He sits on the Governance Committee of the Academic Medical Organization of Southwestern Ontario and Board of the Clinical Teachers Association at Western University. He was recently appointed to the London Police Services Board.

His work has been recognized by the Schulich School of Medicine and Dentistry's 2018 Award of Excellence, Western University Department of Psychiatry Clinical Innovation Award, Arnold Gold Foundation, and the Associated Medical Services Phoenix Fellowship.

He is a proud father to daughter Anaya, son Nyle and married to Sarah. He resides in London, Ontario, Canada. His hobbies include traveling and quiet time with his family. 


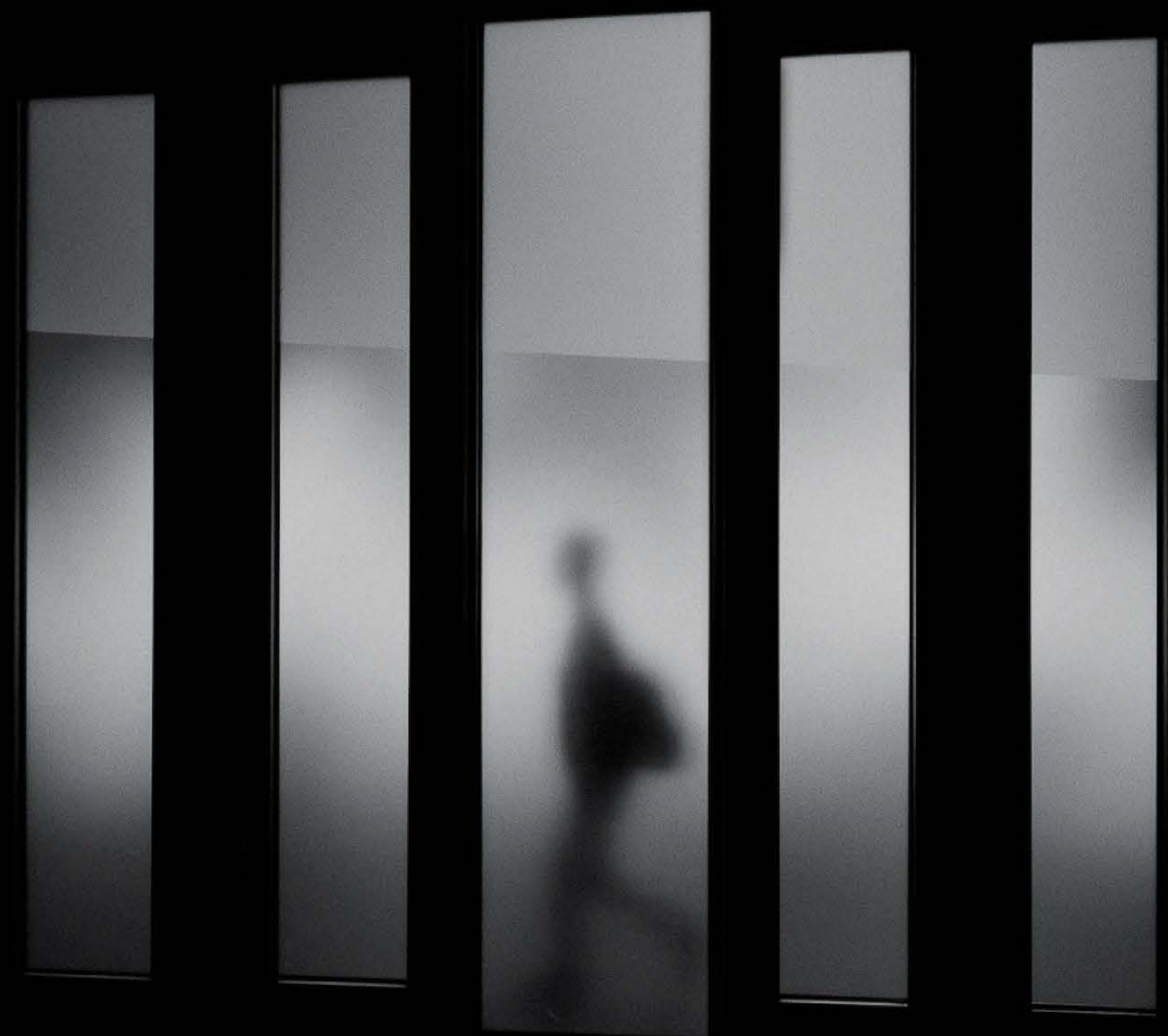

